Aus der Klinik für Psychiatrie und Psychotherapie

(Prof. Dr. med. J. Wiltfang)

der Medizinischen Fakultät der Universität Göttingen

\title{
Analyse neurodegenerativer Prozesse im Gyrus Dentatus im Tg4-42-Mausmodell der Alzheimerdemenz
}

\author{
INAUGURAL-DISSERTATION \\ zur Erlangung des Doktorgrades \\ der Medizinischen Fakultät der \\ Georg-August-Universität zu Göttingen
}

vorgelegt von

Nils Schubert

aus

Moers

Göttingen 2017 
Dekan:

Referent/in

Ko-Referent/in:

Datum der mündlichen Prüfung: 05.04.2018
Prof. Dr. rer. nat. H. K. Kroemer

Prof. Dr. rer. nat. O. Wirths

Prof. Dr. med. C. Stadelmann-Nessler 
Hiermit erkläre ich, die Dissertation mit dem Titel "Analyse neurodegenerativer Prozesse im Gyrus Dentatus im Tg4-42Mausmodell der Alzheimerdemenz" eigenständig angefertigt und keine anderen als die von mir angegebenen Quellen und Hilfsmittel verwendet zu haben.

Göttingen, März 2018

Nils Schubert 


\section{Inhaltsverzeichnis}

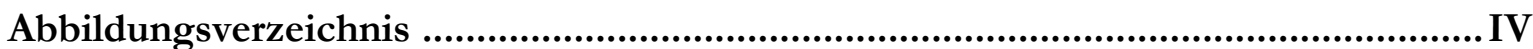

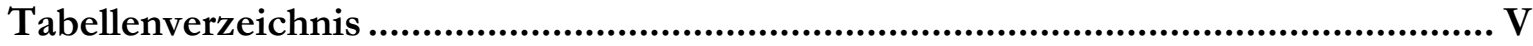

Abkürzungsverzeichnis....................................................................................... VII

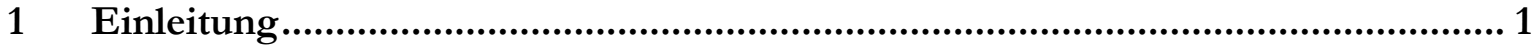

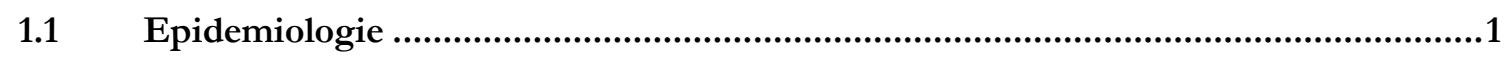

1.1.1 Prävalenz der Alzheimerdemenz...................................................................................

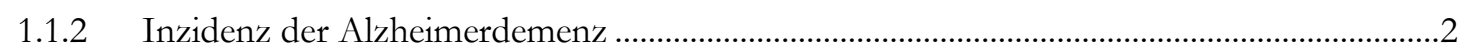

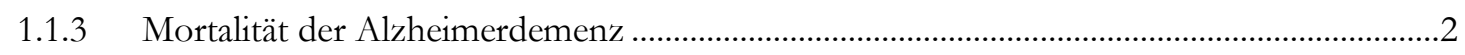

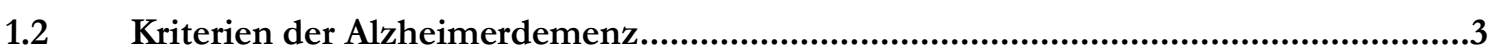

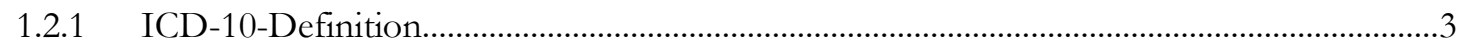

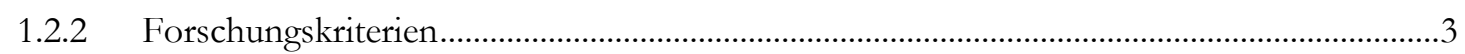

1.2.3 Milde kognitive Beeinträchtigung …………….................................................................

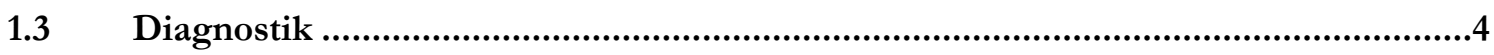

1.3.1 Kognitive Kurztests und neuropsychologische Testung.........................................................

1.3.2 Laborchemische Diagnostik …………………............................................................6

1.3.3 Apparative Diagnostik .....................................................................................................

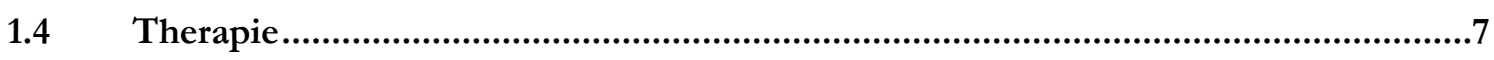

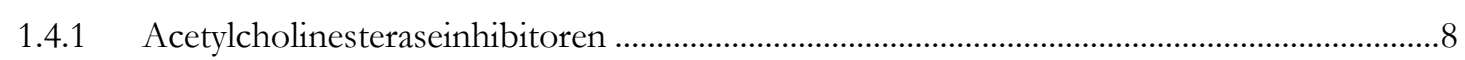

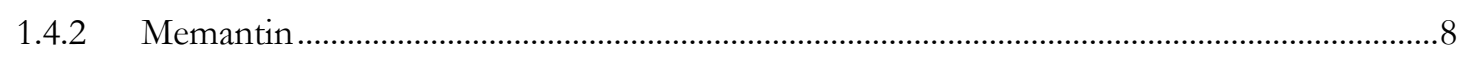

1.4.3 Experimentelle therapeutische Verfahren ..........................................................................

1.5 Makroskopische pathologische Auffälligkeiten ............................................................ 10

1.6 Mikroskopische pathologische Auffälligkeiten .......................................................... 10

1.6.1 Plaques................................................................................................................ 10

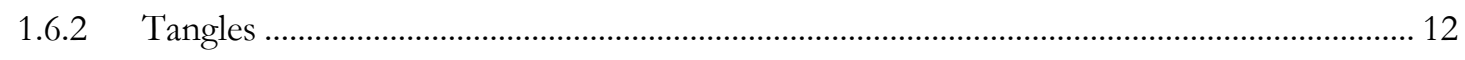

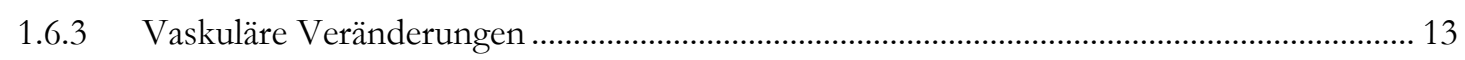

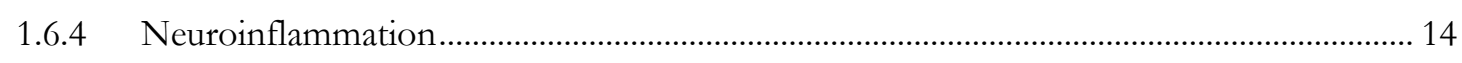

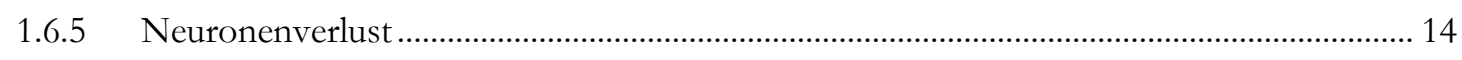

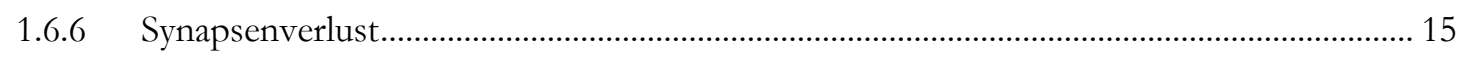

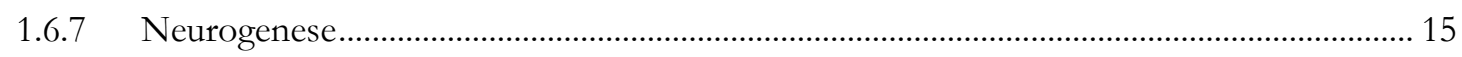

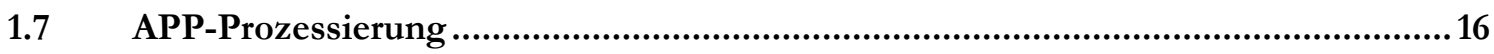

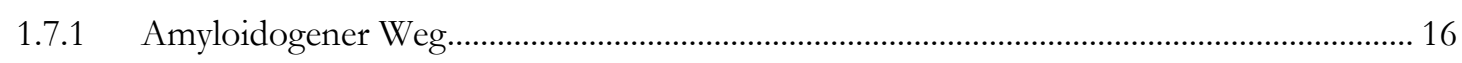

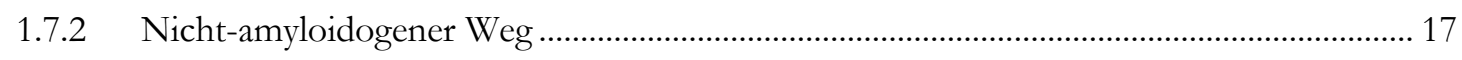

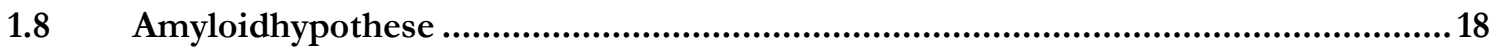

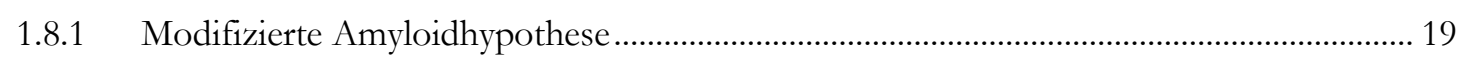

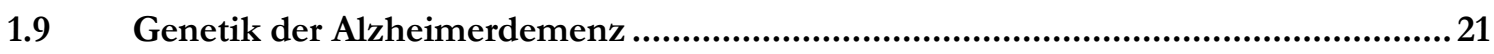

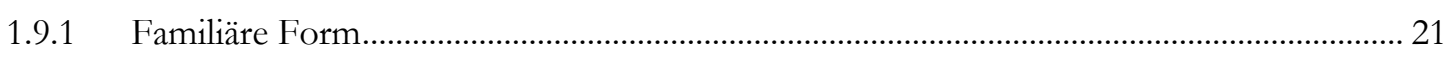

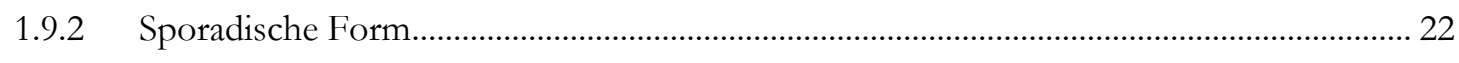

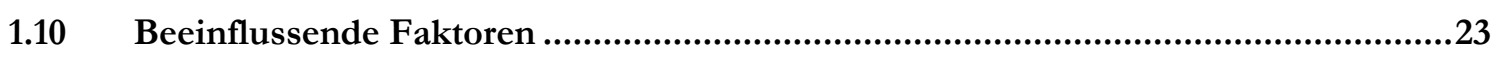




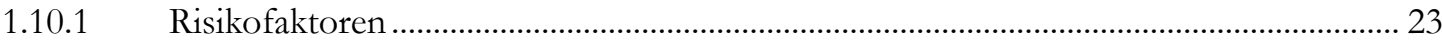

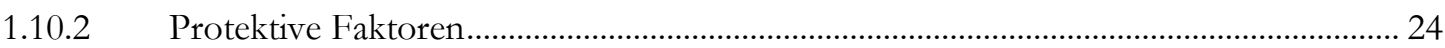

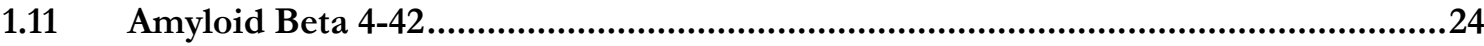

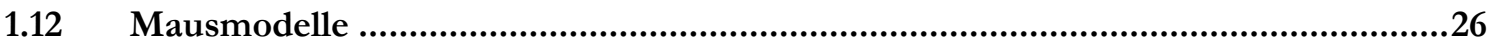

1.13 Das Tg4-42-Mausmodell ....................................................................27

Zielsetzung und Fragestellung der Arbeit ....................................................28

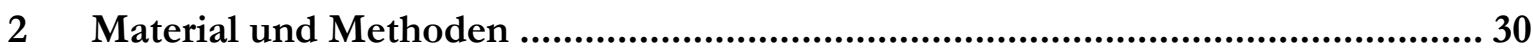

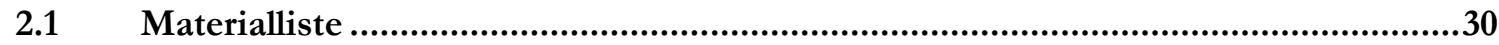

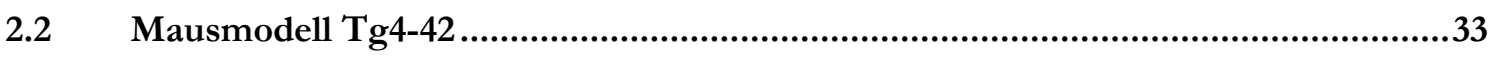

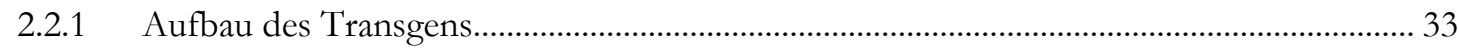

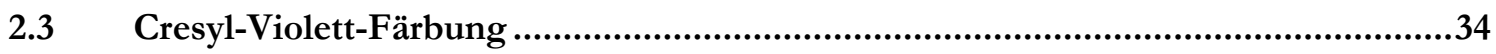

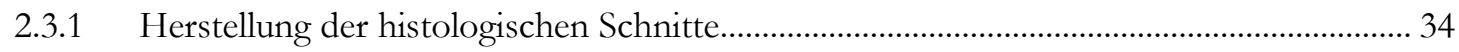

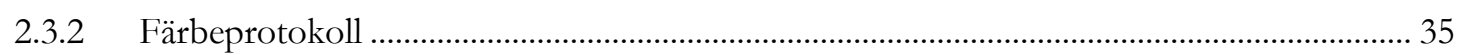

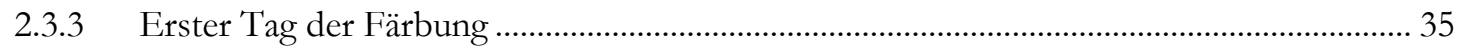

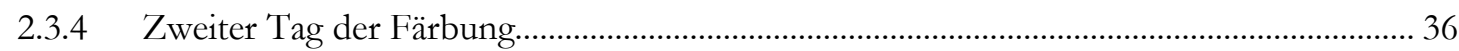

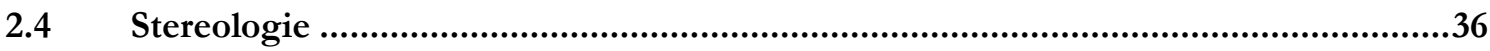

2.4.1 Ablauf und Methodik.................................................................................................... 36

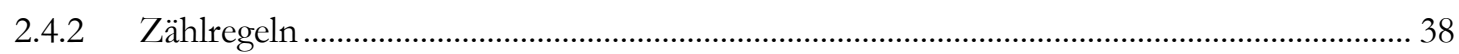

2.4.3 Berechnung der Gesamtzahl der Neuronen im Gyrus Dentatus ...................................... 39

2.4.4 Berechnung des Volumens des Gyrus Dentatus ................................................................. 41

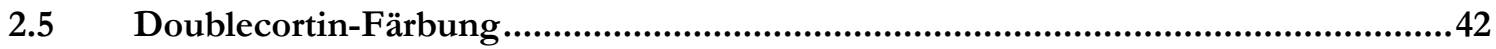

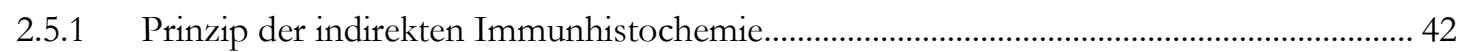

2.5.2 Herstellung der histologischen Schnitte zur indirekten „Free-floating DAB-

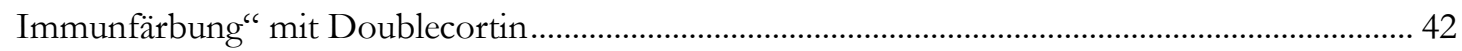

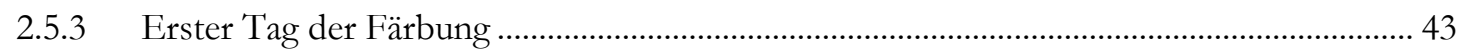

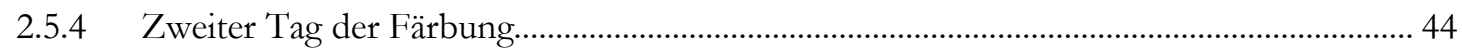

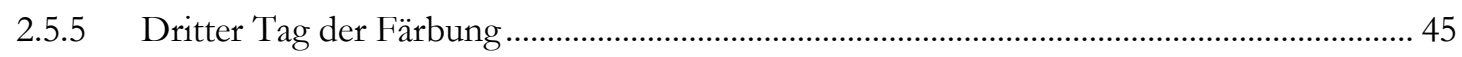

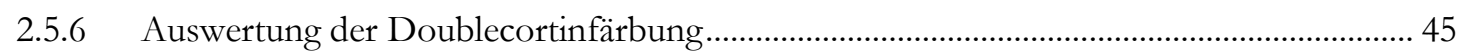

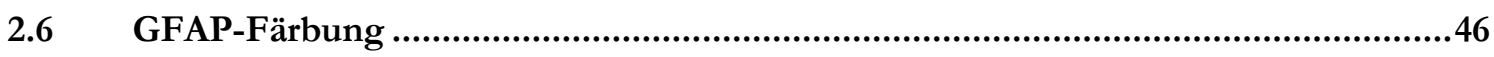

2.6.1 Präparatherstellung zur immunhistochemischen Färbung mit GFAP und

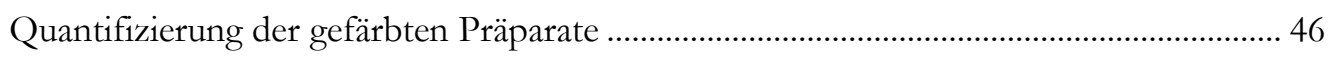

2.6.2 Indirekte immunhistochemische Färbung der Paraffinschnitte zur nachfolgenden

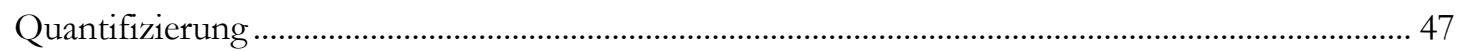

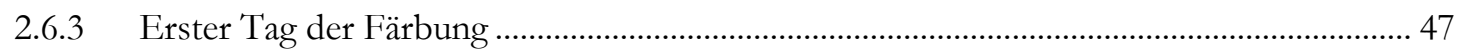

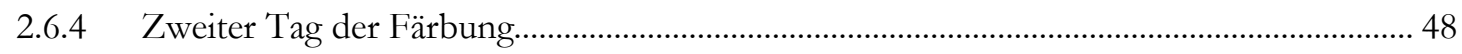

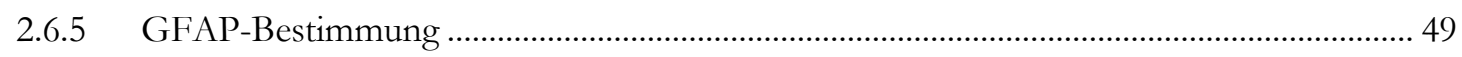

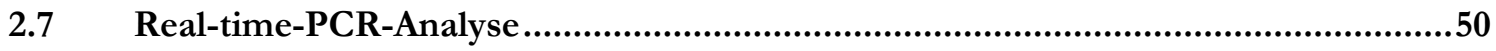

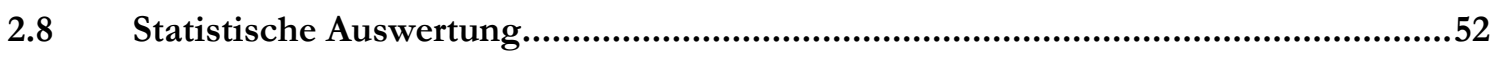

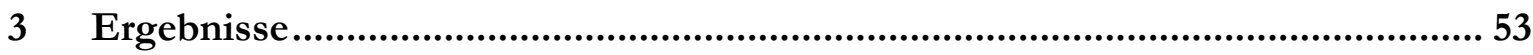

3.1 Quantifizierung der Neuronenzahl im Gyrus Dentatus im Tg4-42-Mausmodell.....53

3.2 Quantifizierung des Volumens des Gyrus Dentatus im Tg4-42-Mausmodell ...........59

3.3 Quantifizierung der Neurogenese im Gyrus Dentatus im Tg4-42-Mausmodell ......62

3.4 Quantifizierung der Astrogliose im Gyrus Dentatus im Tg4-42-Mausmodell..........69 
3.5 Bestimmung der GFAP-Expression im Tg4-42-Mausmodell ....................................71

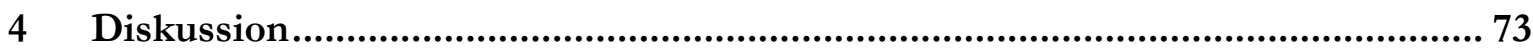

4.1 Neuronenverlust im Gyrus Dentatus im Tg4-42-Modell ...........................................73

4.2 Unverändertes Volumen des Gyrus Dentatus im Tg4-42-Modell ..............................76

4.3 Verminderte Neurogenese im Gyrus Dentatus im Tg4-42-Modell ............................77

4.4 Gesteigerte Astrogliose im Gyrus Dentatus im Tg4-42-Modell ................................. 81

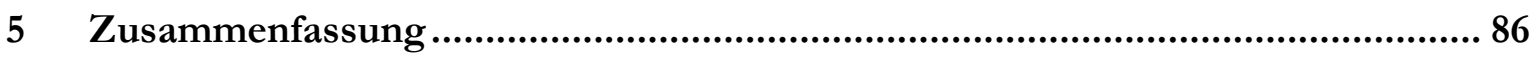

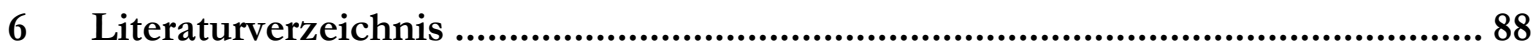




\section{Abbildungsverzeichnis}

Abbildung 1: Mini-Mental-Status-Test

Abbildung 2: Makroskopische Veränderungen bei der Alzheimerdemenz 10

Abbildung 3: Darstellung humaner A $\beta$-Plaques ................................................................................ 12

Abbildung 4: Darstellung humaner Tangles ............................................................................... 13

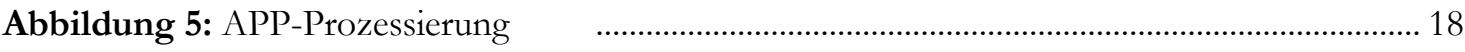

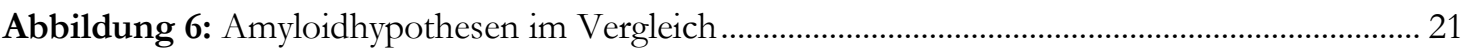

Abbildung 7: Schematische Darstellung des Tg4-42-Transgens .................................................... 34

Abbildung 8: Darstellung des stereologischen Zählbereichs ........................................................... 39

Abbildung 9: Darstellung der Doublecortinfärbung .......................................................................... 46

Abbildung 10: Quantifizierung GFAP-positiver Astrozyten ........................................................ 50

Abbildung 11: Vergleichende Darstellung der quantifizierten Neuronen im Gyrus Dentatus

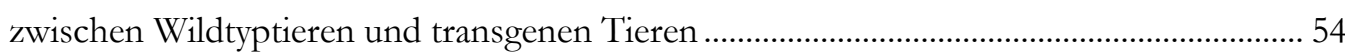

Abbildung 12: Gegenüberstellung der Neuronenzahl im direkten Altersvergleich der beiden Genotypen

Abbildung 13: Vergleichende Übersichtsaufnahme der Cresyl-Violett-Färbung der Neurone des Gyrus Dentatus

Abbildung 14: Vergleichende Detailaufnahme der Cresyl-Violettfärbung der Neurone des Gyrus Dentatus

Abbildung 15: Überblick über die Volumina des Gyrus Dentatus der transgenen Tiere und der Wildtyptiere

Abbildung 16: Vergleichende Darstellung der Quantifizierung der Neurogenese bei transgenen Tieren und Wildtyptieren

Abbildung 17: Gegenüberstellung der Neurogenese im direkten Altersvergleich der beiden Genotypen

Abbildung 18: Vergleichende Übersichtsaufnahme der neugebildeten Neurone im Gyrus Dentatus

Abbildung 19: Vergleichende Detailaufnahme der neugebildeten Neurone im Gyrus Dentatus .. 66 Abbildung 20: Vergleichende Darstellung der relativen Neuroinflammation im Gyrus Dentatus 70

Abbildung 21: Exemplarische Darstellung der Neuroinflammation im Gyrus Dentatus eines sechs Monate alten transgenen Tieres. 71

Abbildung 22: Vergleichende Darstellung der GFAP-Expression bei transgenen Tieren und Wildtyptieren 


\section{Tabellenverzeichnis}

Tabelle 1: Eigenschaften von $A \beta_{4-42}$

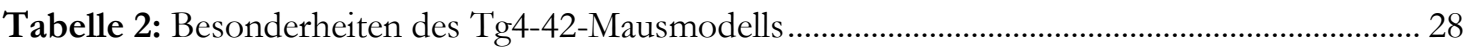

Tabelle 3: Zielsetzung und Fragestellung der Arbeit........................................................................... 29

Tabelle 4: Primäre Antikörper zur immunhistochemischen Färbung ................................................ 30

Tabelle 5: Sekundäre biotinylierte Antikörper zur immunhistochemischen Färbung...................... 30

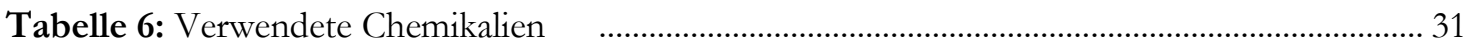

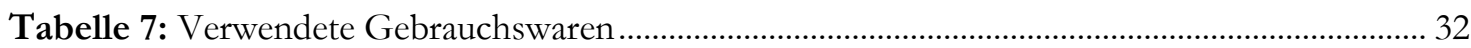

Tabelle 8: Verwendete Geräte und Ausstattung...................................................................................... 32

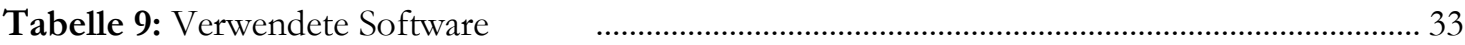

Tabelle 10: Verwendete Tiere zur stereologischen Auswertung....................................................... 34

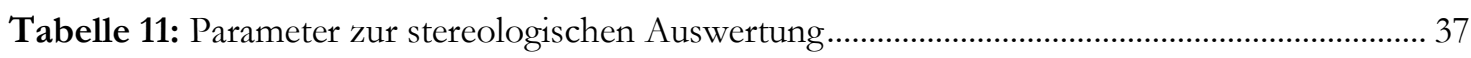

Tabelle 12: Verwendete Tiere zur Doublecortinfärbung ..................................................................... 42

Tabelle 13: Verwendete Tiere zur GFAP-Quantifizierung.................................................................. 47

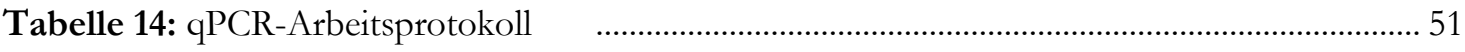

Tabelle 15: Reagenzien und Volumen der qPCR-Reagenzien............................................................. 52

Tabelle 16: Verwendete Tiere zur qPCR-Analyse ………………………………………………..... 52

Tabelle 17: Auflistung der in Abbildung 11 dargestellten und mittels one-way-ANOVA berechneten signifikanten $\mathrm{p}-$ Werte 54

Tabelle 18: Auflistung der in Abbildung 12 dargestellten und mittels t-Test berechneten p-Werte zwischen beiden Genotypen im direkten Altersvergleich.

Tabelle 19: Übersicht über die quantifizierten Neurone und Mittelwerte der transgenen Tiere aller Altersstufen 57

Tabelle 20: Übersicht über die quantifizierten Neurone und Mittelwerte der Wildtyptiere beider Altersstufen .58

Tabelle 21: Übersicht über Volumina und Mittelwerte der transgenen Tiere ..................................... 61

Tabelle 22: Übersicht über Volumina und Mittelwerte der Wildtyptiere.

Tabelle 23: Auflistung der in Abbildung 16 dargestellten und mittels one-way-ANOVA bestimmten signifikanten Unterschiede

Tabelle 24: Auflistung der in Abbildung 17 dargestellten und mittels t-Test bestimmten p-Werte, die sich zwischen den Genotypen im direkten Altersvergleich ergeben.....

Tabelle 25: Detaillierte Auflistung und Gegenüberstellung der quantifizierten Neurone der Tg4-

42 Mäuse aller Altersstufen sowie Auflistung und Gegenüberstellung der Mittelwerte..... 68

Tabelle 26: Detaillierte Auflistung und Gegenüberstellung der quantifizierten Neurone der Wildtyptiere beider Altersstufen sowie Auflistung und Gegenüberstellung der Mittelwerte. 
Tabelle 27: Auflistung des in Abbildung 20 dargestellten und mittels t-Test bestimmten p-Wertes, der sich zwischen den Genotypen bei sechs Monate alten Tieren ergibt 70

Tabelle 28: Auflistung der in Abbildung 22 dargestellten und mittels t-Test bestimmten p-Werte, die sich zwischen den Genotypen im direkten Altersvergleich ergeben 72 


\section{Abkürzungsverzeichnis}

$\mathrm{A} \beta$

$\mathrm{A} \beta_{\mathrm{pE} 3-42}$

$\mathrm{ABC}$

Ach

AChE

$\mathrm{AD}$

ADAM a disintegrin and metalloproteinase

ANOVA analysis of variance

ApoE Apolipoprotein E

APP Amyloid-Vorläuferprotein

asf

BACE1 $\quad \beta$-site cleaving ensyme 1

CA

CT

$\mathrm{DAB}$

DC

EK

fAD

FCS

GFAP

GD

MCI

MMST

MRT
Cornu Ammonis

Computertomografie

Diaminobenzidin

Doublecortin

entorhinaler Kortex

familiäre Alzheimerdemenz

fetales Kälberserum

saures Gliafaserprotein

Gyrus Dentatus

mild cognitive impairment

Mini-Mental-Status-Test

Magnetresonanztomographie 
NFT neurofibrilläre Tangles

NMDA N-Methyl-D-Aspartat

PBS phosphatgepufferte Salzlösung

PCR Polymerase-Kettenreaktion

PET Positronenemissionstomographie

PSEN Presenilin

qPCR quantitative Echtzeit PCR

ssf section sampling fraction

TBS Tris-gepufferte Salzlösung

TRH Thyrotropin Releasing Hormone

tsf thickness sampling fraction

WHO Weltgesundheitsorganisation

WT Wildtyp

ZNS zentrales Nervensystem 


\section{$1 \quad$ Einleitung}

\section{$1.1 \quad$ Epidemiologie}

Demenzerkrankungen gehören neben anderen Erkrankungen, wie Chorea Huntington, Morbus Parkinson und progressive supranukleäre Blickparese zu den neurodegenerativen Hirnerkrankungen. Zu den Demenzerkrankungen im Speziellen werden neben der Alzheimerdemenz (AD) die frontotemporale sowie die vaskuläre Demenz gezählt (Masuhr et al. 2013). In einer Studie in der bei 1000 Individuen post mortem eine Autopsie durchgeführt wurden, ergaben sich in 86\% der Fälle AD-assoziierte Veränderungen von denen jedoch nur 43\% der „reinen“ Form der Alzheimererkrankung entsprachen. 26\% zeigten pathologische Veränderungen einer zerebrovaskulären Demenz und 10\% konnten der Lewykörperchendemenz zugeschrieben werden (Jellinger 2006; WHO | Dementia: a public health priority 2012). Damit stellt die AD mit über 43\% den größten Anteil an allen Demenzerkrankungen.

\subsubsection{Prävalenz der Alzheimerdemenz}

Im Jahr 2015 waren weltweit 46,8 Millionen Menschen an einer Demenz erkrankt. Mit 9,8 Millionen lebte davon in Ostasien der Großteil gefolgt von Westeuropa mit 7,4 Millionen. In Deutschland litten im Jahr 2015 1,6 Millionen an einer Demenz. Bis zum Jahr 2030 wird von einer Zunahme der Demenzerkrankungen auf eine Gesamtzahl von 74,4 Millionen ausgegangen, die sich bis zum Jahr 2050 auf 131,5 Millionen vervielfachen soll (World Alzheimer Report 2015). Die Prävalenz der Demenzen und damit auch der AD steigt ab einem Alter von 65 Jahren exponentiell an (Mayeux und Stern 2012). Verschiedene Studien geben für Westeuropa bei den über 60-Jährigen eine Prävalenz der Demenzerkrankung von 6,92\% an (World Alzheimer Report 2015). Betrachtet man den Verlauf der Prävalenz von Demenzerkrankungen in Fünfjahresabständen so besteht in der Gruppe der 60- bis 64-Jährigen eine Prävalenz von circa 1,6\% (WHO | Dementia: a public health priority 2012; World Alzheimer Report 2015). In der Spanne der 60- bis 85-Jährigen kommt es zu einem 12- bis 15-fachen Anstieg der Prävalenz der Demenzerkrankungen (WHO | Dementia: a public health priority 2012; World Alzheimer Report 2015), der zum Großteil durch die AD bedingt ist (Mayeux und Stern 2012). Weiterhin ergibt sich laut Bericht der World Health Organization (WHO) aus dem Jahr 2012 und des „World Alzheimer Report 2015“ ein Anstieg der Prävalenz in der Gruppe der 85- bis 89 -Jährigen auf 20\% und in der Gruppe der über 90-Jährigen auf bis zu 40\%. 


\subsubsection{Inzidenz der Alzheimerdemenz}

Eine genaue Inzidenzrate demenzieller Erkrankungen, speziell der AD, zu ermitteln, ist schwieriger als die Feststellung der Prävalenz. Zum einen lässt sich das Alter in dem eine AD beginnt, nicht genau festlegen, da diese Erkrankung eine gewisse Zeit asymptomatisch verläuft und zum anderen ist es aus demselben Grund schwierig, eine gesunde Vergleichsgruppe zu definieren (Mayeux und Stern 2012). Dennoch lässt sich beobachten, dass die Inzidenz der Demenzerkrankungen weltweit exponentiell mit zunehmendem Alter ansteigt und sich im Schnitt alle sechs Jahre verdoppelt. Für die Gruppe der 60- bis 64-Jährigen besteht weltweit eine Inzidenz von drei bis vier auf 1000 Personenjahre. In der Gruppe der 85- bis 89-jährigen ergibt sich eine mittlere Inzidenz von 53,1 auf 1000 Personenjahren und in der Gruppe der über 90-Jährigen wird eine mittlere Inzidenz von bis zu 104 auf 1000 Personenjahre vermutet (WHO | Dementia: a public health priority 2012; World Alzheimer Report 2015). In absoluten Zahlen geht der „World Alzheimer Report 2015“ davon aus, dass pro Jahr weltweit 9,9 Millionen Menschen an Demenz erkranken; 2,5 Millionen davon alleine in Europa (World Alzheimer Report 2015). Für Deutschland wird eine Inzidenz von etwa 300.000 vermutet (Bickel 2016).

\subsubsection{Mortalität der Alzheimerdemenz}

Eine exakte durch Demenzerkrankungen bedingte Mortalitätsrate festzulegen, ist nicht möglich, da die meisten AD-Patienten an zusätzlichen Erkrankungen leiden, die zum Tod führen können. Diese Erkrankungen können zum einen durch die Demenz bedingt, zum anderen vollkommen unabhängig von dieser entstanden sein (WHO | Dementia: a public health priority 2012). Dennoch lässt sich beobachten, dass an einer AD erkrankte Menschen im Schnitt 7,1 Jahre nach Diagnose versterben. Die Vergleichsgruppe der nicht an einer AD erkrankten lebt im Schnitt elf Jahre und somit knapp vier Jahre länger (Fitzpatrick et al. 2005). 


\subsection{Kriterien der Alzheimerdemenz}

\subsubsection{ICD-10-Definition}

Im ICD-10, anhand dessen im deutschen Gesundheitssystem Erkrankungen kodiert werden, wird die AD wie folgt definiert (ICD-10-GM-2017 F00.-* 2017):

„Die Alzheimer-Krankheit ist eine primär degenerative zerebrale Krankheit mit unbekannter Ätiologie und charakteristischen neuropathologischen und neurochemischen Merkmalen. Sie beginnt meist schleichend und entwickelt sich langsam aber stetig über einen Zeitraum von mehreren Jahren. "

\subsubsection{Forschungskriterien}

Neben der Definition des ICD-10 bestehen Forschungskriterien für die AD, die unter anderem vom „National Institute on Aging“ in Zusammenarbeit mit der „Alzheimer’s Association“ (NIA-AA) 2011 entwickelt wurden. Diese sind detaillierter als die Definition des ICD-10 und werden im Folgenden genauer erläutert. In den von McKhann (2011) verfassten Forschungskriterien werden zunächst allgemeine Kriterien für die Diagnose einer Demenz zusammengetragen. Eine Demenz kann demnach diagnostiziert werden, wenn kognitive Symptome oder Störungen vorliegen, die

1. eine Störung der Alltagsfunktion bedingen,

2. zu einer Verschlechterung der Symptome im Vergleich zu früheren Zeiten darstellen,

3. nicht durch ein Delir oder eine andere psychische Erkrankung bedingt sind,

4. durch eine Kombination aus Eigen- und Fremdanamnese sowie objektivierbarer kognitiver Tests bewertet und gegebenenfalls durch eine neuropsychologische Testung erweitert wurden, falls die vorangegangenen Tests keine klare Diagnose ergeben haben.

5. Es müssen zusätzlich mindestens zwei der folgenden Kriterien vorliegen:
a. Beeinträchtigung des Gedächtnisses
b. Beeinträchtigung beim Verstehen und Durchführen komplexer Aufgaben
c. Beeinträchtigung räumlich-visueller Fähigkeiten
d. Beeinträchtigung der Sprachfunktion
e. Veränderung der Persönlichkeit beziehungsweise des Verhaltens

Die Kriterien für die Diagnosestellung einer wahrscheinlichen AD werden von McKhann (2011) wie folgt definiert:

1. die allgemeinen Kriterien für eine Demenz müssen erfüllt sein

2. die Symptome entwickeln sich schleichend innerhalb von Monaten bis Jahren und nicht plötzlich innerhalb von Stunden bis Tagen

3. klare selbstständige oder fremdanamnestisch beobachtete Verschlechterung der Kognition 
4. initiale und prominente kognitive Defizite in

a. amnestischer Ausprägung (häufigste Ausprägung): Diese Form zeigt Defizite im Erlernen neuer Informationen und der Wiedergabe kürzlich gelernter Informationen.

b. nicht amnestischer Ausprägung: Diese Form zeigt Defizite im sprachlichen Bereich, wie zum Beispiel Wortfindungsstörungen, im räumlich-visuellen Bereich, wie zum Beispiel räumliche Orientierungsstörungen und im exekutiven Bereich.

Zudem werden Ausschlusskriterien für eine AD definiert. Zu diesen zählen erhebliche begleitende zerebrovaskuläre Erkrankungen, Kernmerkmalen der Lewykörperchendemenz, starke Merkmale einer frontotemporalen Demenz oder Hinweise für eine andere Ursache der kognitiven Defizite (McKhann et al. 2011).

\subsubsection{Milde kognitive Beeinträchtigung}

Neurodegenerative Prozesse beginnen meist schon viele Jahre vor Auftreten der klassischen AD-Symptome und der Diagnosestellung einer AD. Bevor die Diagnosekriterien für eine AD erreicht sind, können leichte Gedächtnisstörungen als Frühsymptome auftreten, die das erwartete $\mathrm{Ma}$ für das jeweilige Alter und den jeweiligen Bildungsstand übersteigen. Die Patienten weisen jedoch noch nicht die komplette Ausprägung einer Demenz auf. Kognitive Einschränkungen treten hingegen noch nicht auf. Diese Phase wird als milde kognitive Beeinträchtigung (mild cognitive impairment (MCI)) bezeichnet (Petersen et al. 1999).

\subsection{Diagnostik}

In der S3-Leitlinie zur Diagnostik und Therapie von Demenzen, die 2016 von der Deutschen Gesellschaft für Neurologie (DGN) und der Deutschen Gesellschaft für Psychiatrie und Psychotherapie, Psychosomatik und Nervenheilkunde (DGPPN) aktualisiert wurde, wird empfohlen mit der Eigen- und Fremdanamnese zu beginnen sowie eine körperliche und psychopathologische Untersuchung folgen zu lassen, um die Ursache der Symptome zu eruieren und somit Erkrankungen oder Medikamente, die demenzähnliche Symptome auslösen oder imitieren können, auszuschließen (Leitlinie Demenzen 2016). Im Anschluss können weitere Untersuchungen wie kognitive Kurztests folgen.

\subsubsection{Kognitive Kurztests und neuropsychologische Testung}

Kognitive Kurztests bieten die Möglichkeit einer orientierenden Einschätzung des Schweregrades einer möglicherweise bestehenden Demenz. Hierzu können der Mini-Mental-StatusTest (MMST), der DemTect oder der Montreal Cognitive Assessment Test genutzt werden 
(Leitlinie Demenzen 2016). Von Folstein et al. (1975) wurde der MMST entwickelt, um innerhalb weniger Minuten eine grobe Übersicht über die Schwere der kognitive Beeinträchtigung von Patienten zu bekommen (Folstein et al. 1975). Der Test besteht aus elf Fragen und ist in zwei Teile untergliedert. Es können maximal 30 Punkte erreicht werden. Im ersten Teil werden sprachliche Reaktion, zeitliche sowie räumliche Orientierung, Merkfähigkeit und Aufmerksamkeit getestet. In diesem Abschnitt können maximal 21 Punkte erreicht werden. Der zweite Teil testet die Fähigkeit, mündliche und schriftliche Anweisungen zu befolgen, gezeigte Objekte korrekt zu benennen, einen Satz spontan schriftlich zu formulieren sowie eine vorgegebene Figur nachzuzeichnen. In diesem Teil können maximal neun Punkte erreicht werden (Folstein et al. 1975). Anhand des erreichten Zahlenwertes kann eine Schweregradeinteilung der AD vorgenommen werden. Eine Punktzahl $<10$ entspricht einer
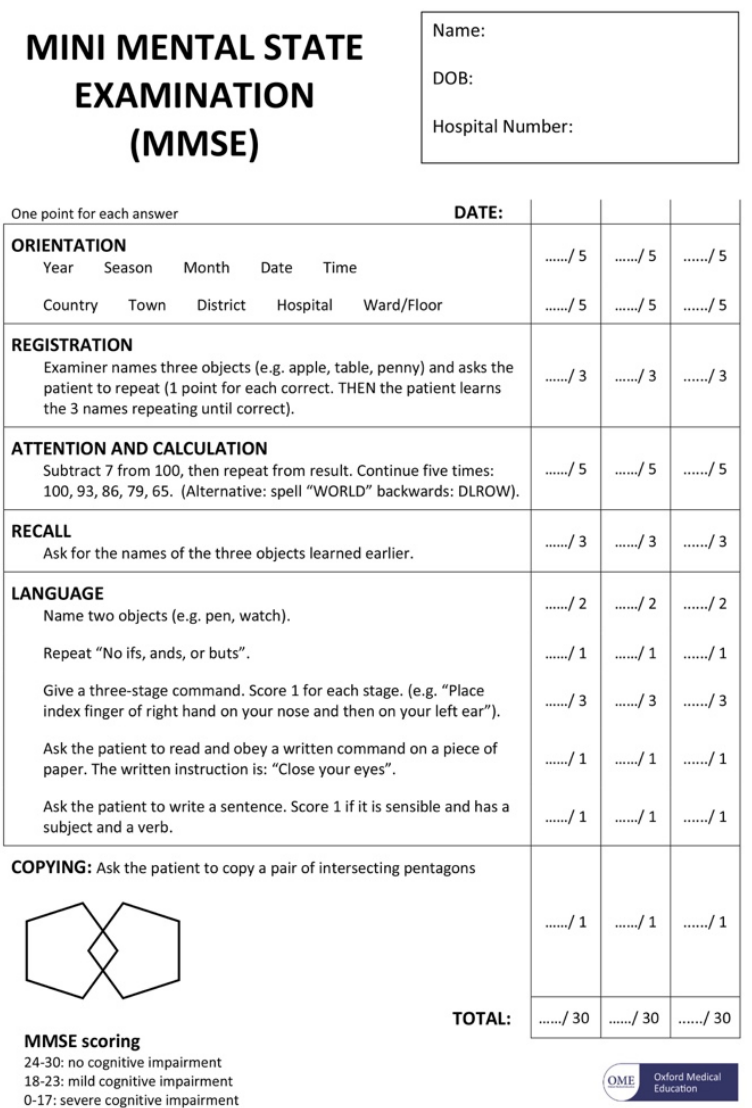

\section{Abbildung 1: Mini-Mental-Status-Test.}

Quelle:

ttp://www.oxfordmedicaleducation.com/wpcontent/uploads/2015/08/MMSE-printable-minimental-state-examination.pdf.

Besucht am 15.02.2017 schweren Demenz. Zwischen zehn und 19 wird von einer moderaten und zwischen 20 und 26 von einer leichten Form gesprochen (Leitlinie Demenzen 2016). Abbildung 1 zeigt das Aufgabenblatt des Mini-Mental-StatusTests.

Durch den MMST ist eine schnelle orientierende Einschätzung der kognitiven Beschaffenheit des Patienten möglich. Jedoch muss beachtet werden, dass die positive Erkennung einer Demenz mithilfe dieses Tests von der Demenzprävalenz der betrachteten Bevölkerung abhängt. In Populationen mit hoher Demenzprävalenz ist dieser Test zur Erkennung, jedoch nicht zum Ausschluss einer Demenz geeignet. In Populationen mit einer niedrigen Demenzprävalenz ergeben sich gegenteilige Effekte (Mitchell 2009). Bei Unsicherheit über die Genau- 
igkeit des Ergebnisses eines kognitiven Kurztests sollte dieser durch eine neuropsychologische Diagnostik ergänzt werden (Leitlinie Demenzen 2016). Zusätzlich zu den Auffälligkeiten in Anamnese, körperlicher Untersuchung, kognitiven Kurztests und der neuropsychologischen Testung können Auffälligkeiten in der klinisch chemischen Diagnostik bestehen.

\subsubsection{Laborchemische Diagnostik}

Die laborchemische Diagnostik bezieht sowohl Blutwerte als auch Liquorparameter ein. Besondere Bedeutung kommt ihr in der Untersuchung von Blutparametern zur Findung reversibler Demenzen, die circa neun Prozent aller dementiellen Symptome ausmachen können, zu (Clarfield 2003). Hierzu zählt die Erstellung eines Blutbildes, Bestimmung der Elektrolyte, des Blutzuckers, des TSH sowie der Vitamin-B12-Konzentration (Blennow et al. 2006; Leitlinie Demenzen 2016). Neben dem Ausschluss reversibler dementieller Symptome, wie sie beispielsweise bei entzündlichen Erkrankungen des zentralen Nervensystems (ZNS) auftreten können, eignet sich die Liquordiagnostik zur Detektion von Neurodegenerationsmarkern. Zu

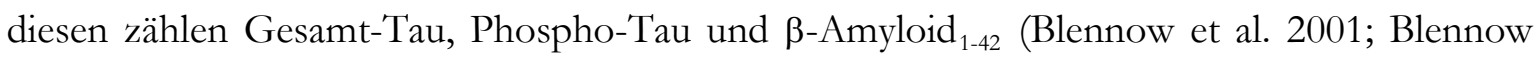
und Hampel 2003; Blennow 2004; Blennow et al. 2006; Scheltens et al. 2016).

Tau ist ein Mikrotubuli-assoziiertes Protein, welches sich in neuronalen Axonen findet. Bei einer AD steigt das Gesamt-Tau im Liquor um circa 300\% im Vergleich zu gesunden Menschen an (Blennow 2004). Es wird davon ausgegangen, dass die Konzentration des GesamtTaus im Liquor die Stärke der neuronalen Degeneration beziehungsweise des neuronalen Schadens widerspiegelt, da es auch nach akuten Hirninfarkten zu einem signifikanten Anstieg des Gesamt-Taus im Liquor kommt (Hesse et al. 2000; Blennow et al. 2001). Die mittlere Sensitivität des Gesamt-Taus an einer AD leidende Individuen von gesunden Menschen zu unterscheiden liegt bei 81\%. Die Spezifität beträgt 91\% (Blennow 2004). Zusätzlich zum GesamtTau steigt das Phospho-Tau im Liquor bei einer AD an (Blennow et al. 2001). Zum Anstieg von Phospho-Tau kommt es jedoch im Gegensatz zum Gesamt-Tau nicht nach einem akuten Hirninfarkt (Hesse et al. 2001). Dies bedeutet möglicherweise, dass Phospho-Tau weniger ein Marker für die Degeneration von Neuronen ist, als vielmehr die Bildung von Tangles bei Alzheimer anzeigt. Die Sensitivität liegt bei $80 \%$ und die Spezifität bei $92 \%$ (Blennow und Hampel 2003). Die $A \beta_{1-42}$-Konzentration fällt bei einer AD im Liquor im Vergleich zur Kontrollgruppe um 50\% ab. Als Ursache hierfür gilt, dass bei einer $\mathrm{AD} A \beta_{1-42}$ im Gehirn Plaques bildet und somit in geringerer Konzentrationen im Liquor gelöst ist. Die Sensitivität liegt bei 86\%, wohingegen die Spezifität 90\% erreicht (Blennow und Hampel 2003; Blennow et al. 2006). $A \beta_{1-42}$ und Gesamt-Tau eignen sich gut um eine AD von Differentialdiagnosen, wie Morbus Parkinson abzugrenzen, jedoch sorgen die Marker für keinen diagnostischen Vorteil 
bei der Differenzierung zu anderen Demenzerkrankungen (Blennow und Hampel 2003). Phospho-Tau kann jedoch die Unterscheidung zwischen einer AD und anderen Demenzerkrankungen erleichtern (Hampel et al. 2004).

\subsubsection{Apparative Diagnostik}

Magnetresonanztomographie (MRT) und Computertomographie (CT) haben eine große Bedeutung bei der Diagnostik alternativer und teilweise reversibler Ursachen einer Demenz, wie beispielsweise Hirntumoren oder Normaldruckhydrozephalus (Hejl et al. 2002; Blennow et al. 2006). Bei der AD zeigt sich in der Bildgebung eine Atrophie des gesamten Gehirns, insbesondere des medialen Temporallappens mit Hippocampus und entorhinalem Kortex (EK) (Zakzanis et al. 2003). Anhand von Messungen der Atrophie des Hippocampus mittels MRT ist es möglich, Patienten mit einer AD von kognitiv unauffälligen älteren Menschen zu unterscheiden (Blennow et al. 2006; Jagust 2006), jedoch ist eine Abgrenzung zu anderen Demenzerkrankungen mittels MRT schwierig (Frisoni et al. 1999) und eignet sich nur als zusätzliches diagnostisches Mittel neben Anamnese, kognitiven Tests oder neuropsychologischer Testung (Leitlinie Demenzen 2016). In longitudinalen MRT-Studien konnte zudem gezeigt werden, dass es bei Demenzpatienten zu einer Progredienz der Hirnatrophie kommt und bei symptomfreien älteren Individuen die Stärke der Atrophie des Gehirns auf die Entstehung einer Demenz hindeuten kann (Jack et al. 2005; Whitwell 2008). Dennoch wird von der DGN und DGPPN in ihrer Leitlinie zur Demenz aus dem Jahr 2016 der kraniellen Bildgebung keine primäre Bedeutung in Therapieentscheidung oder Demenzdifferenzierung zugeschrieben. Neben MRT und CT zeigen sich in der Positronenemissionstomographie (PET) Auffälligkeiten, wie Hypometabolisierungen von ${ }^{18} \mathrm{~F}$-fluorodeoxyglukose in parietotemporalen Regionen des Gehirns, die auf eine beginnende Konversion von MCI zur vollen AD hindeuten können (Chételat et al. 2003). Mittels PET kann zudem zwischen an AD-leidenden Patienten und gesunden älteren Menschen unterschieden (Herholz et al. 2002), sowie zwischen einer AD und anderen Demenzerkrankungen wie der Lewy-Körperchen-Demenz differenzieren werden (Minoshima et al. 2001).

\subsection{Therapie}

Eine kurative Therapie der AD existiert nicht. Lediglich symptomatische Therapien sind möglich. Zum einen können Acetylcholinesteraseinhibitoren (AChE-Inhibitoren) zum anderen NMDA-Antagonisten eingesetzt werden. 


\subsubsection{Acetylcholinesteraseinhibitoren}

Die cholinerge Hypothese geht davon aus, dass es bei der AD zum Verlust cholinerger Neurone im basalen Vorderhirn im Nucleus basalis Meynert und dadurch zu einem verminderten Angebot an Acetylcholin (ACh) kommt. Dies führt zu Störungen im Neokortex und Hippocampus und in der Folge zu Gedächtnisstörungen und kognitiven Symptomen (Terry und Buccafusco 2003). Um dem verminderten Angebot an ACh entgegenzuwirken, kann versucht werden durch AChE-Inhibitoren den Abbau des Neurotransmitters zu verlangsamen und dadurch die Konzentration im synaptischen Spalt zu erhöhen. Zu den bei der AD angewandten Medikamenten, die zu dieser Arzneimittelgruppe zählen, gehören Donepezil, Galantamin und Rivastigmin. Bei den beiden erstgenannten handelt es sich um selektive Acetylcholinesteraseinhibitoren (Blennow et al. 2006). Alle Medikamente haben leicht positive Effekte auf die durch die AD bedingten kognitiven Einschränkungen und Verhaltensauffälligkeiten. Sie werden bei leichten und mäßigen Ausprägungsformen der Erkrankung eingesetzt. In mehreren Studien konnte gezeigt werden, dass es unter anderem im MMST nach einer drei bis sechs Monate langen Einnahmezeit eines der Medikamente zu einer leichten Verbesserung des Testergebnisses um bis zu vier Punkte kommt. Kein Medikament ist den anderen hinsichtlich seiner Effizienz überlegen (Birks 2006).

\subsubsection{Memantin}

Neben Acetylcholin ist Glutamat bei der Genese der AD von Bedeutung. Da Glutamat der wichtigste exzitatorische Neurotransmitter im ZNS ist, spielen er und der NMDA-Rezeptor unter physiologischen Bedingungen eine entscheidende Rolle bei der Gedächtnisbildung, der neuronalen Plastizität und unterstützen den Lernprozess (Sucher et al. 1996). Bei der AD kommt es zu einem Anstieg der glutamatergen Aktivität. Dies führt reflektorisch zu einer niedrigen Aktivität des NMDA-Rezeptors, wodurch es zu Beeinträchtigungen der neuronalen Funktion kommen kann (Areosa et al. 2005). Um diesem Prozess entgegenzuwirken, kann Memantin, ein nicht-kompetitiver NMDA-Rezeptorantagonist, eingesetzt werden. Memantin beeinflusst dabei nicht die physiologische Funktion des Rezeptors (Wilcock 2003; Parsons et al. 2007). Bei leichten Ausprägungsformen der Erkrankung konnte kein Effekt von Memantin beobachtet werden (Areosa et al. 2005). Den besten Wirkungseffekt scheint die Substanz bei moderaten bis schweren Ausprägungsformen zu haben (Wilcock 2003). In Kombination mit Donepezil und anderen AChE-Inhibitoren kann es zur weiteren Verbesserung der Symptome kommen (Tariot et al. 2004; Parsons et al. 2013). 


\subsubsection{Experimentelle therapeutische Verfahren}

Zusätzlich zu den genannten Medikamenten ist die Erforschung kurativer therapeutischer Verfahren von Bedeutung. Als mögliche Ansätze werden Verhinderung der A $\beta$-Produktion, A $\beta$-Aggregation, sowie gesteigerte $A \beta$-Ausscheidung in Betracht gezogen (Blennow et al. 2006). $\beta$-Sekretaseinhibitoren führten bei transgenen AD-Mäusen zu einer Reduktion der A $\beta$ Konzentration (Chang et al. 2004). In einem Mausmodell konnte zudem gezeigt werden, dass durch aktive Immunisierung der Mäuse mit humanem A $\beta$-Peptid ein Rückgang der Plaquebelastung und der assoziierten Pathologien erreicht werden konnte (Bard et al. 2000). Studien zur aktiven Immunisierung beim Menschen mussten jedoch aufgrund korrelierender Menigoenzephalitiden abgebrochen werden (Orgogozo et al. 2003). 


\subsection{Makroskopische pathologische Auffälligkeiten}

Kortikale Atrophie stellt die auffälligste makroskopische Pathologie bei der AD dar. Sie ist hauptsächlich durch Neuronen- und Synapsenverlust bedingt. Von der Atrophie ist vorwiegend der superiore Frontal-, der inferiore Parietal- und der mediale Temporallappen mit Hippocampus, Amygdala und EK betroffen, wodurch es nachfolgend vor allem zur Erweiterung der temporalen Hörner des seitlichen Ventrikels kommt (Bottino et al. 2002; Nestor et al. 2008; Dickerson et al. 2009; Dickerson et al. 2011).

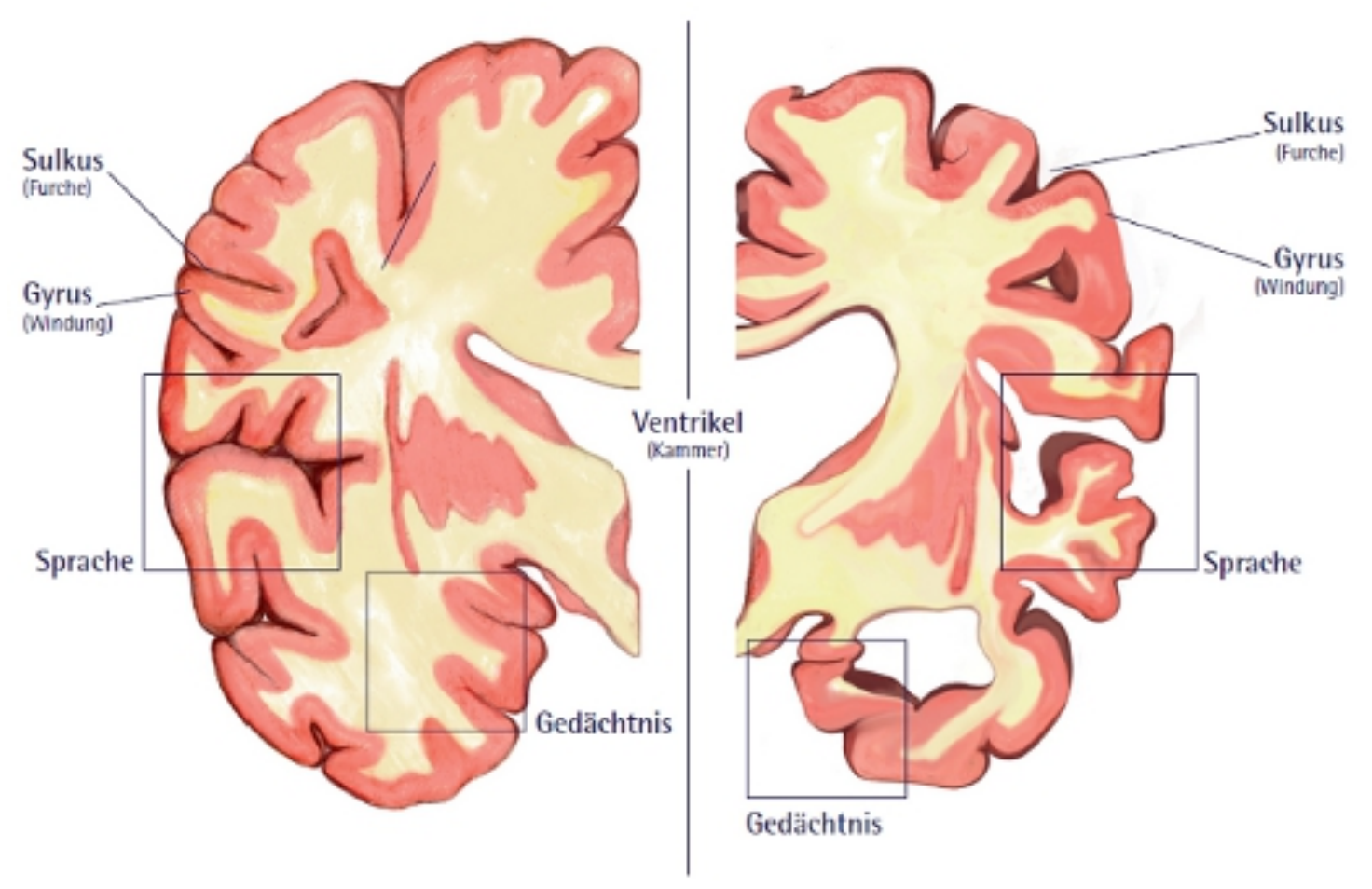

Abbildung 2: Makroskopische Veränderungen bei der Alzheimerdemenz. Gegenüberstellung eines physiologischen Gehirns (linke Darstellung) und eines von AD betroffenen Gehirns (rechte Darstellung). Atrophie von Hippocampus und Kortex mit nachfolgender Erweiterung des Ventrikelsystems. Die Gehirne sind in der Frontalebene dargestellt. Quelle: http://alzheimer-forschung.de/alzheimer-krankheit/illustrationen_gehirnmitalzheimer.htm. Besucht am 15.02.2017

\subsection{Mikroskopische pathologische Auffälligkeiten}

\subsubsection{Plaques}

Eine der Hauptmanifestationen im Gehirn von AD-Patienten sind Plaque-artige A $\beta$-Aggregate im extrazellulären Raum. Erstmals wurden diese Plaques von Alois Alzheimer beschrieben 
(Alzheimer 1907). A $\beta$ wurde 1984 von Glenner und Wong als Bestandteil von Amyloidablagerungen in meningealen Blutgefäßen von AD-Patienten identifiziert. Diese Plaques bestehen aus mehreren Proteinablagerungen, deren größter Bestandteil das 4,2 kDa große A $\beta$ ist. A $\beta$ bildet eine $\beta$-Faltblattstruktur und besteht aus 39-43 Aminosäuren (Masters et al. 1985a; Glenner 2012). Es geht aus dem größeren Amyloid-Vorläufer-Protein (APP) hervor (Hardy und Selkoe 2002; Holtzman et al. 2011). A $\beta$-Plaques können in eine diffuse und eine neuritische Form unterteilt werden (Holtzman et al. 2011).

Diffuse Plaques bilden im Gegensatz zu den neuritischen Plaques keine $\beta$-Faltblattstruktur (Holtzman et al. 2011) und treten im Zerebellum, Putamen, Nucleus caudatus, Thalamus sowie im limbischen und assoziativen Kortex auf (Yamaguchi et al. 1988; Joachim et al. 1989; Selkoe 2001). Sie erreichen einen Durchmesser von bis zu $200 \mu \mathrm{m}$. Diese Plaques besitzen weder ein fibrilläres kompaktes Zentrum noch lassen sich in deren Umgebung dystrophe Neuriten nachweisen (Yamaguchi et al. 1988; Selkoe 2001). Hauptbestandteil der diffusen Form ist $A \beta_{1-42}$, wohingegen $A \beta_{1-40}$ fast gar nicht nachzuweisen ist (Iwatsubo et al. 1994). Es wird angenommen, dass die diffusen Plaques eine Vorläuferform der neuritischen Plaques darstellen, da sie unter anderem in Hirnregionen wie dem limbischen System gesunder älterer Menschen vorkommen, in denen bei AD-Patienten diffuse und neuritische Plaques nachweisbar sind (Serrano-Pozo et al. 2011a). Zum anderen können bei an Trisomie 21 erkrankten jungen Menschen diffuse Plaques in AD-typischen Hirnregionen nachgewiesen werden, in denen sich später neuritische Plaques und neurofibrilläre Tangles zeigen (Lemere et al. 1996). Die Bildung neuritischer Plaques beginnt im Isokortex, breitet sich in allokortikale Bereiche wie EK und Hippocampusformation aus, schließt anschließend Striatum, Thalamus und Hirnstamm mit ein und befällt zum Schluss den Pons und das Kleinhirn (Thal et al. 2002). Sie können eine Größe von zehn bis $>120 \mu \mathrm{m}$ erreichen (Selkoe 2001). Im Gegensatz zu den diffusen Plaques lassen sie sich mit Kongo Rot anfärben (Serrano-Pozo et al. 2011a). In der Umgebung neuritischer Plaques lassen sich dystrophe Neuriten, Synapsen- und Neuronenverluste sowie vermehrt Astrozyten und Mikroglia nachweisen (McGeer und McGeer 1995; Pike et al. 1995b; Knowles et al. 1999; Selkoe 2001; Holtzman et al. 2011). Die Proliferation von Astrozyten und Mikroglia verschlechtert wahrscheinlich den Krankheitsverlauf. Es gibt jedoch auch Hinweise, dass der Proliferation eine protektive Wirkung zukommt (Holtzman et al. 2011). Dystrophe Neuriten sind meist dilatiert und weisen ultrastrukturelle Veränderungen, wie vergrößerte Lysosomen, zahlreiche abnorme Mitochondrien (Hirai et al. 2001) und gepaarte helikale Filamente auf (Selkoe 2001). Hauptbestandteil der neuritischen Plaques ist $A \beta_{1-42}$, welches länger und hydrophober als die häufiger produzierte kürzere Variante $A \beta_{1-40}$ ist und schneller Aggregate bildet (Jarrett et al. 1993). Neben $A \beta_{1-42}$ ist $A \beta_{1-40}$ (Selkoe 2001), Tau (Su et al. 1998), APP 
(Cras et al. 1991) und Ubiquitin (Dickson et al. 1990) in neuritischen Plaques zu finden. Zusätzlich zur Ansammlung im Hirngewebe kann es zu Ablagerungen von amyloiden Plaques im Gefäßsystem kommen. Die Plaques lagern sich vornehmlich in der Gefäßwand zwischen Intima und Media leptomengingealer Arterien und kortikaler Arteriolen in posterior-parietalen und okzipitalen Hirnregionen ab. Etwa 80\% aller AD-Patienten sind von solchen Amyloidangiopathien betroffen (Serrano-Pozo et al. 2011a).

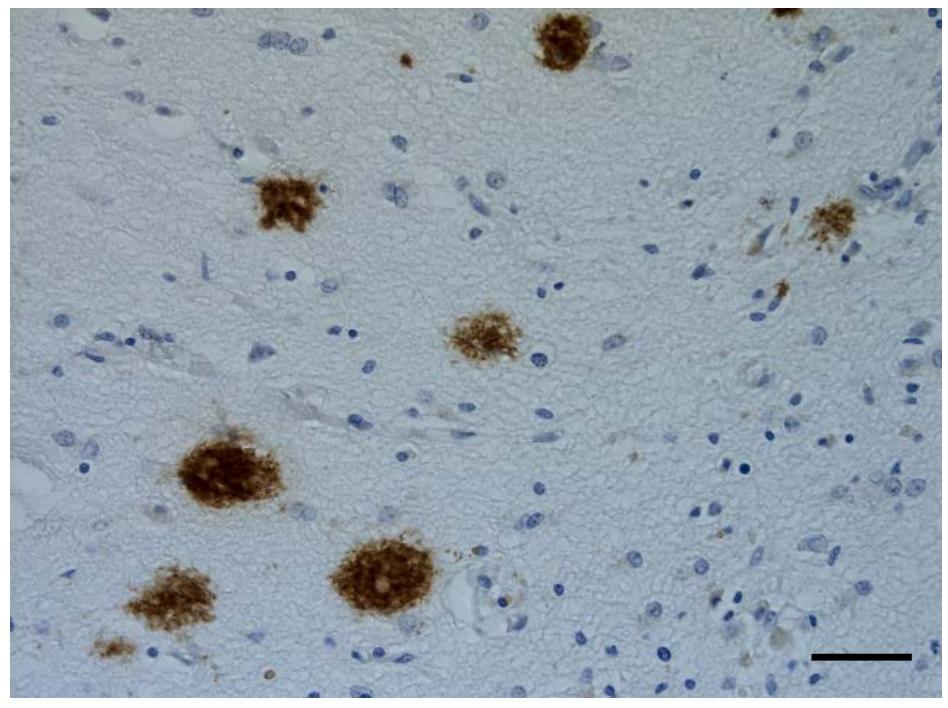

Abbildung 3: Darstellung humaner Aß-Plaques. Maßstab: $250 \mu \mathrm{m}$

\subsubsection{Tangles}

Neben A $\beta$-Plaques stellen neurofibrilläre Tangles (NFT) eine weitere mikroskopische Pathologie der Alzheimererkrankung dar. Tangles bestehen dabei aus abnormal hyperphosphoryliertem Tau-Protein (Grundke-Iqbal et al. 1986). Das Tau-Protein gehört neben MAP1 (Mikrotubuli-assoziiertes Protein 1) und MAP2 (Mikrotubuli-assoziiertes Protein 2) zu den Mikrotubuli-assoziierten Proteinen. Ihre physiologische Funktion besteht in der Förderung, der Bildung und Stabilisierung von Mikrotubuli. Die Aktivität von Tau hängt dabei vom Grad der Phosphorylierung ab, die wiederum durch multiple Kinasen und Phosphatasen reguliert wird. Die Hyperphosphorylierung findet intrazellulär statt. Eine Hyperphosphorylierung von Tau führt dabei zur Ablösung von Tau und anderen Mikrotubuli-assoziierten Proteinen von ihrer mikrotubulären Bindungsstelle. Dies führt zur Auflösung der Mikrotubuli und einer damit einhergehenden Beeinträchtigung des axonalen Transportes. Neben der Auflösung der Mikrotubuli kommt es durch die Hyperphosphorylierung zur Polymerisierung von Tau, die zur Aggregation nicht löslicher Fibrillen und später zu Tangles führt. Durch Verlust der Mikrotubulistabilität und Entstehung der Tangles kommt es zu neuronaler und synaptischer Funktions- 
einschränkung (Iqbal et al. 2005; Blennow et al. 2006). Zurzeit ist jedoch noch nicht bekannt, ob neurofibrilläre Tangles Ursache oder Folge der AD sind (Blennow et al. 2006). Es wird jedoch angenommen, dass die neurofibrillären Tangles bei der AD als Reaktion auf die Akkumulation bestehender A $\beta$-Plaques gebildet werden (Selkoe 2001) und zum anderen die Phosphorylierung von Tau durch intrazelluläre A $\beta$-Oligomere erleichtert wird (LaFerla et al. 2007). Die Bildung von Tau beginnt in transentorhinalen Regionen, breitet sich Richtung Hippocampus und Amygdala aus und erreicht später den neokortikalen Assozationskortex (Braak et al. 1999). Die größten Ansammlungen neurofibrillärer Tangles finden sich im Allokortex und limbischen Kortex (Arnold et al. 1991). Neben der AD gibt es weitere sogenannte Tauopathien, bei denen es zu einer abnormen Hyperphosphorylierung von Tau kommt. Zu ihnen gehören unter anderem die frontotemporale Demenz, die kortikobasale Degeneration oder die progressive supranukleäre Blickparese. Allen ist gemein, dass die Akkumulation von hyperphosphoryliertem Tau mit neurofibrillärer Degeneration und Demenz assoziiert ist (Iqbal et al. 2005).

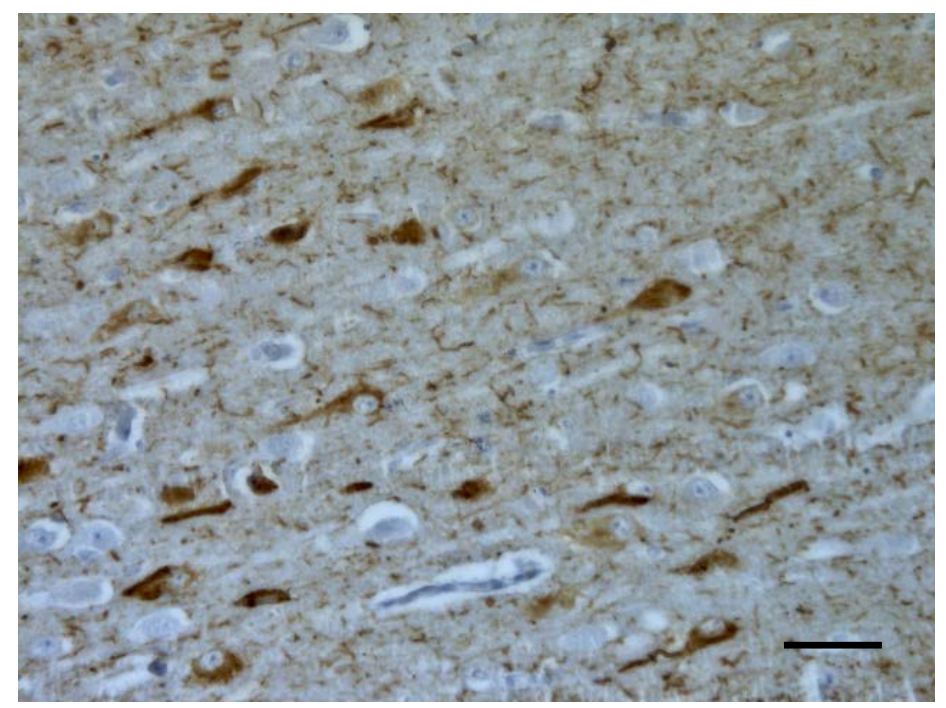

Abbildung 4: Darstellung humaner Tangles. Maßstab: $250 \mu \mathrm{m}$

\subsubsection{Vaskuläre Veränderungen}

Neben den genannten Pathologien lassen sich bei an AD erkrankten Menschen häufig zusätzlich Erkrankungen und Störungen im mikrovaskulären System feststellen (Farkas und Luiten 2001; Mayeux und Stern 2012). Diese Veränderungen sind nicht Folge, sondern vielmehr Ursache der Alzheimererkrankung, da sowohl für die AD als auch für zerebrovaskuläre Erkrankungen dieselben Risikofaktoren bestehen (Royall 2002). Durch dysfunktionale Blutgefäße kommt es zu kognitiven Einschränkungen der Patienten, die zum einen durch eine schlechtere 
metabolische Versorgung der Neurone und zum anderen durch eine verminderte Beseitigung von entstandenem A $\beta$ bedingt ist (Iadecola 2004). In einigen Studien konnte gezeigt werden, dass zerebrovaskuläre Pathologien mit einhergehender Ischämie zu einer Steigerung der APPExpression und damit verbundener vermehrter A $\beta$-Bildung führen (Jendroska et al. 1995; Blennow et al. 2006). Jedoch wird von anderer Seite vermutet, dass zerebrovaskuläre Pathologien und die $\mathrm{AD}$ unabhängig voneinander auftreten und die Gefäßveränderungen die Wahrscheinlichkeit ansteigen lassen, dass asymptomatische AD-typische Veränderungen im Gehirn symptomatisch werden (Riekse et al. 2004, Blennow et al. 2006).

\subsubsection{Neuroinflammation}

Bei der AD kommt es im Gehirn neben den genannten Aspekten auch zu inflammatorischen Prozessen. So sind reaktive Astrozyten und aktivierte Mikrogliazellen häufig mit neuritischen Plaques assoziiert. Dies führt zu der Vermutung, dass A $\beta$ ein bedeutender Auslöser reaktiver inflammatorischer Prozesse ist (Itagaki et al. 1989; Pike et al. 1995). Zudem konnte in weiteren Experimenten beobachtet werden, dass es zu einem linearen Anstieg von Astrozyten und Mikroglia mit fortschreitendem Krankheitsverlauf kommt, obwohl die Plaquebildung nach einiger Zeit ein Plateau erreicht. Es wurde herausgefunden, dass neben der Assoziation zu Plaques eine hochsignifikant positive Korrelation zwischen reaktiven inflammatorischen Prozessen und NFTs besteht (Serrano-Pozo et al. 2011b). Den zeitlichen Verlauf der AD betrachtend, treten reaktive Mikroglia vorwiegend in frühen AD-Stadien auf, wohingegen Astrozyten in späteren Stadien signifikant vermehrt zu finden sind (Vehmas et al. 2003). Nicht eindeutig belegbar ist, ob inflammatorische Prozesse den Krankheitsverlauf verschlechtern oder protektive Effekte aufweisen (Lucin und Wyss-Coray 2009).

\subsubsection{Neuronenverlust}

Eine weitere Auffälligkeit in Gehirnen von AD-Patienten ist der Verlust von Nervenzellen, welcher nach einiger Zeit makroskopisch zu kortikaler Atrophie führen kann (Serrano-Pozo et al. 2011a). Neurodegenerative Prozesse beginnen im transentorhinalen Kortex, breiten sich weiter in EK und Hippocampus aus und erreichen in späteren Stadien Temporal-, Frontalund Parietallappen (Thompson et al. 2003; Thompson et al. 2007). In stereologischen Auswertungen zeigt sich, dass zum Beispiel der EK besonders vom Neuronenverlust betroffen ist. Diesem kommt eine besondere Bedeutung als neuroanatomische Verbindung zwischen Neokortex und Hippocampus-Formation zu. Schicht II des EK gibt afferente Impulse zur Hippocampus-Formation, und Schicht IV erhält Informationen von dieser. Schon bei Patienten in frühen Stadien ihrer Alzheimererkrankung kommt es in Schicht II zu einem Abfall der Neu- 
ronenzahl um 60\% und in Schicht IV um 40\% im Vergleich zu nicht erkrankten Menschen im Alter von 60 bis 90 Jahren. Bei Patienten im Spätstadium liegt der Abfall in Schicht II bei 90\% und in Schicht IV bei 70\%. Bei der gesunden Vergleichsgruppe bleibt die Neuronenzahl im EK konstant (Gómez-Isla et al. 1996). Im Gegensatz zum EK zeigt sich in der Cornu Ammonis (CA)1-Region des Hippocampus in der Frühphase der Alzheimererkrankung kein signifikanter Verlust der Neuronenzahl (West et al. 2004). In Phasen der manifesten Erkrankung kann jedoch ein signifikanter Verlust der Neuronenzahl in der CA1- (West et al. 2004) sowie der CA3-Region des Hippocampus nachgewiesen werden (Padurariu et al. 2012). Die Stärke des Neuronenverlustes korreliert dabei stark mit der Erkrankungsdauer und der Anzahl NFTs, wobei die Zahl des Neuronenverlustes diese deutlich übersteigt (Gómez-Isla et al. 1997). Neben NFTs könnte auch intraneuronales $A \beta$ Ursache des Nervenzellverlustes bei der AD sein (Bayer und Wirths 2011).

\subsubsection{Synapsenverlust}

Eine weitere Ursache für die kortikale Atrophie ist der Verlust von Synapsen (Serrano-Pozo et al. 2011a). In Studien, in denen anhand des präsynaptischen Proteins Synaptophysin die Synapsendichte im Hippocampus und temporalem Kortex bei AD-Patienten mit nicht erkrankten Menschen verglichen wurde, zeigt sich, dass es bei der AD zu einer signifikanten Abnahme von Synapsen in den betrachteten Hirnregionen kommt (Honer et al. 1992; Scheff und Price 1993). Das Ausmaß des Synapsenverlustes überschreitet in einigen Hirnregionen sogar das des Neuronenverlustes und scheint damit nicht vom Neuronenverlust abzuhängen, sondern eher diesem vorranzugehen. Dies führt wiederum zu einer schlechteren Verbindung der übrigen Neurone miteinander. Die synaptische Dichte scheint ein besseres Maß für den Grad der Demenz zu sein als die anderen genannten Parameter (Terry et al. 1991; Ingelsson et al. 2004). Gegenläufig zur Abnahme der Synapsendichte kommt es zur Größenzunahme der übrigen Synapsen. Es wird davon ausgegangen, dass es sich dabei um einen Kompensationsmechanismus handelt (Scheff und Price 1993).

\subsubsection{Neurogenese}

Neurogenese findet postnatal beim Menschen im ZNS zum einen im anterioren Teil der subventrikulären Zone des lateralen Ventrikels und zum anderen in der subgranulären Zone des Gyrus Dentatus (GD) statt (Taupin und Gage 2002; Abrous et al. 2005). Schätzungen zufolge werden im Hippocampus einige tausend neue Zellen pro Tag gebildet, von denen jedoch etwa die Hälfte innerhalb einiger Tage wieder zu Grunde geht (Abrous et al. 2005; Rodríguez und Verkhratsky 2011). Neurogenese ist ein komplexer Prozess aus mehreren Schritten, zu denen 
Proliferation, Migration, Differenzierung und Reifung neuronaler Vorläuferzellen zählen sowie Wachstum und Synapsenbildung reifer Zellen. Defekte in einzelnen oder mehreren Schritten beeinflussen die Neurogenese (Crews und Masliah 2010). Die Neubildung von Neuronen hat als aktiver Prozess im GD eine große Bedeutung beim Lernen, für das Gedächtnis und spielt zudem eine Rolle für die neuronale Plastizität (Gage et al. 1998). In Tierversuchen konnte gezeigt werden, dass eine Umgebung, die vielfältige Reize bietet sowie körperliche Aktivität die Neurogenese im Hippocampus stimulieren können (Brown et al. 2003). Bei AD-Patienten gibt es widersprüchliche Thesen, die zum einen besagen, dass es zu einem Anstieg (Jin et al. 2004b) und zum anderem zu einem Abfall der Neurogenese kommt (Boekhoorn et al. 2006). Eine eingeschränkte Neurogenese könnte für die Progression der Erkrankung von Bedeutung und an der kognitiven Verschlechterung der Patienten beteiligt sein (Rodríguez und Verkhratsky 2011). In Tiermodellen, die eine APP-Überexpression aufweisen, konnte gezeigt werden, dass es zu einem Abfall der Neurogenese im GD und der subventrikulären Zone kommt (Wang et al. 2004; Donovan et al. 2006; Rodríguez und Verkhratsky 2011). In einem anderen Tierexperiment zeigte sich, dass $A \beta_{1-42}$ einen neurogenen Effekt haben kann (Sotthibundhu et al. 2009). Bei der AD konnte in post mortem untersuchtem Hirngewebe beides beobachtet werden. In der subventrikulären Zone kam es zu einer Abnahme und im GD zu einer Zunahme neuronaler Vorläuferzellen (Jin et al. 2004b; Ziabreva et al. 2006).

\subsection{APP-Prozessierung}

Neuritische Plaques bestehen aus $\beta$-Amyloid, welches aus seinem größeren AmyloidVorläufer-Protein (APP) hervorgeht. Das APP-Gen befindet sich auf Chromosom 21, aus dem durch alternatives Spleißen hauptsächlich drei Isoformen entstehen können. Zu diesen gehören APP 695, APP 751 und APP 770. APP 695 wird vorwiegend in Neuronen exprimiert (Kang und Müller-Hill 1990). APP gehört zu den Typ-I-Membranproteinen, bestehend aus einem großen extrazellulären, einem hydrophoben durch die Membran gehenden und einem kurzen C-terminalen intrazellulären Teil (Zhang et al. 2011; Zhang et al. 2012). Nach der Translation kann APP durch verschiedene Proteasen und Sekretasen prozessiert werden. Diese Prozessierung kann in den amyloidogenen oder den nicht-amyloidogenen Weg unterteilt werden.

\subsubsection{Amyloidogener Weg}

Im amyloidogenen Weg wird APP durch die $\beta$ - und $\gamma$-Sekretase gespalten. Zunächst schneidet die $\beta$-Sekretase (BACE1) vor der A $\beta$-Sequenz des APP. Hierdurch entsteht sAPP- $\beta$ und ein 
aus 99 Aminosäuren bestehendes membranassoziiertes C-terminales Fragment (C99). Anschließend wird C99 durch die $\gamma$-Sekretase gespalten. Es entsteht eine intrazelluläre Domäne von APP und $A \beta_{1-40}$ beziehungsweise $A \beta_{1-42}$ (Zhang et al. 2012). Bei BACE1 handelt es sich um eine Typ-I-transmembran-Aspartylprotease (Yan et al. 1999). Ein Anstieg der Expression und Aktivität von BACE1 wurde bei der sporadischen Form der Alzheimererkrankung festgestellt (Yang et al. 2003). Die $\gamma$-Sekretase ist ein Komplex, der aus Presenilin 1 (PSEN1) oder Presenilin 2 (PSEN2), PEN2 (presenilin enhancer 2), APH1 (anterior pharynx defective 1) und Nicastrin besteht (Zhang et al. 2012).

\subsubsection{Nicht-amyloidogener Weg}

Im nicht-amyloidogenen Weg wird APP durch die $\alpha$ - und $\gamma$-Sekretase gespalten. Zunächst schneidet die $\alpha$-Sekretase zwischen der 16. und 17. Aminosäure in der A $\beta$-Sequenz des APP. Hierdurch wird verhindert, dass schädliches $\beta$-Amyloid entsteht (Sisodia 1992). Infolge des Schnittes entsteht das große extrazelluläre lösliche Spaltprodukt sAPP- $\alpha$ und ein kleineres 83 Aminosäuren großes, an die Membran gebundenes C-terminales Stück. Anschließend schneidet die $\gamma$-Sekretase von diesem Stück das p3-Fragment ab und hinterlässt eine 59 Aminosäuren große intrazelluläre Domäne. Das P3-Fragment und die 59 Aminosäuren große intrazelluläre Domäne werden schnell abgebaut (Zhang et al. 2012). Die intrazelluläre Domäne hat mannigfaltige Funktionen, wohingegen über P3 nichts bekannt ist (Chow et al. 2010). Das lösliche sAPP- $\alpha$ ist bei verschiedenen Prozessen von Relevanz. Es wird vermutet, dass es die Bildung von Synapsen und Zelladhäsion fördert (Mattson 1997), neuroprotektiv wirkt (Chow et al. 2010) und als Wachstumsfaktor die Proliferation embryonaler (Ohsawa et al. 1999) und adulter Stammzellen reguliert (Caillé et al. 2004). Die $\alpha$-Sekretase gehört zu den Disintegrin- und Metalloproteinasen (ADAM) (Buxbaum et al. 1998). Jedoch ist nicht bekannt welche Disintegrin- und Metalloproteinase der $\alpha$-Sekretase entspricht (Asai et al. 2003). Möglicherweise handelt es sich um ADAM-10, da diese zum einen im Gehirn vorkommt zum anderen ein Anstieg des sAPP- $\alpha$-Spiegels in Zellen beobachtet werden kann, wenn ADAM-10 überexprimiert ist (Lammich et al. 1999). 


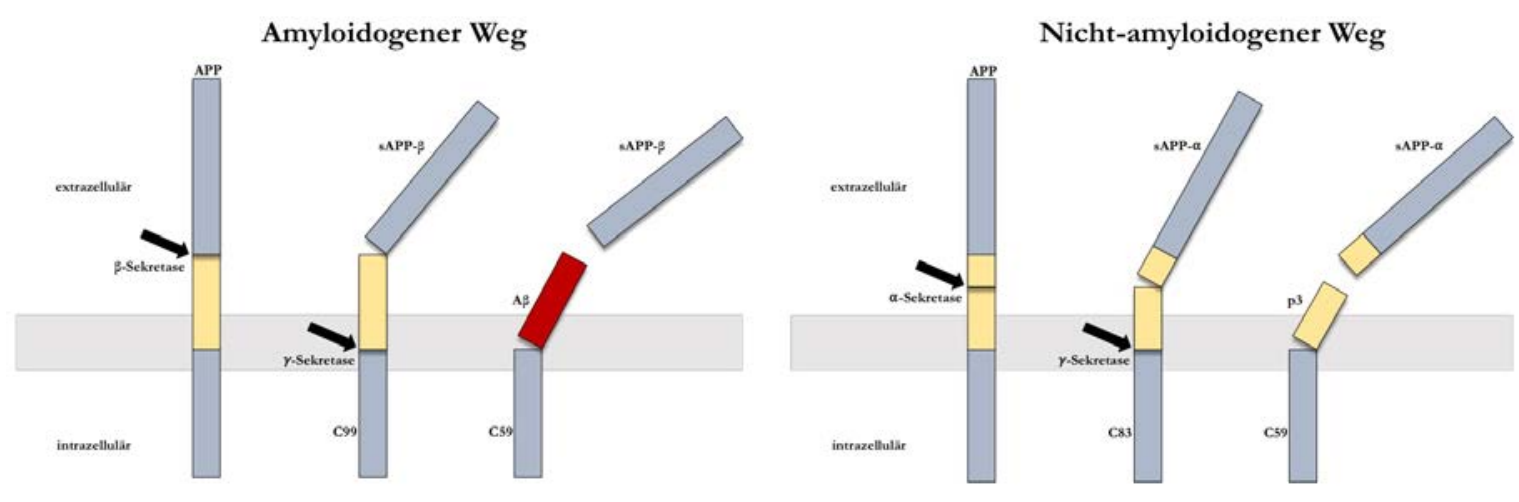

Abbildung 5: APP-Prozessierung: Im amyloidogenen Weg (links) schneidet die $\beta$-Sekretase oberhalb der A $\beta$-Sequenz. Es entstehen sAPP- $\beta$ und das C99-Fragment. Anschließend schneidet die $\gamma$-Sekretase innerhalb des C99-Fragments und unterhalb der A $\beta$-Sequenz, wodurch A $\beta$ und das C59-Fragment entstehen. Im nicht-amyloidogenen Weg (rechts) schneidet die $\alpha$-Sekretase zuerst innerhalb der A $\beta$-Sequenz. Es entstehen sAPP- $\alpha$ und das C83Fragment. Anschließend schneidet die $\gamma$-Sekretase innerhalb des C83-Fragments und unterhalb der A $\beta$-Sequenz, wodurch p3 und das C59-Fragment entstehen. Es entsteht kein A $\beta$. Abbildung modifiziert nach (De Strooper et al. 2010).

\subsection{Amyloidhypothese}

Die Amyloidhypothese geht davon aus, dass die Ablagerung von A $\beta$ im Gehirn den zentralen Schritt zur Entstehung der AD darstellt. Durch die Ablagerung extrazellulärem A $\beta$ s kommt es zu Neuronenverlust, Bildung von Tangles und vaskulären Schäden und infolgedessen zur AD (Hardy und Higgins 1992). Als Unterstützung für diese Hypothese gilt unter anderem, dass es unter Trisomie 21 vermehrt zur AD kommt (Glenner und Wong 1984), da APP auf Chromosom 21 lokalisiert ist (Owen et al. 1990). Dies führt zu einer gesteigerten Gendosis des APP und somit zu einem Anstieg der A $\beta$-Produktion. Als weiteres wichtiges Argument gelten die bei der familiären AD-Form (fAD) durchgeführten genetischen Untersuchungen. Hierbei wurden Mutationen in PSEN1, PSEN2 und APP entdeckt, die zu einem Anstieg der extrazellulären A $\beta$-Konzentration und infolgedessen zu AD-Symptomen führen (Tanzi 2012). Die genetischen Mutationen bei der fAD gelten als das stärkste Argument für die Amyloidhypothese (Selkoe 2011). Unterstützend konnten auch in einigen fAD-Mausmodellen Assoziationen zwischen $\mathrm{A} \beta$-Ansammlungen und $\mathrm{AD}$-ähnlichen Symptomen, wie Gedächtnisverlust, beobachtet werden (Pimplikar 2009). Zudem gilt APOE4, welches mit einem verringerten A $\beta$ Abbau in Zusammenhang gebracht wird, als stärkster Risikofaktor der sporadischen ADForm (Karran et al. 2011). 
Es gibt jedoch auch Gründe an dieser Hypothese zu zweifeln. Zum einen korreliert weniger die Menge der A $\beta$-Ablagerungen als vielmehr die Konzentration neurofibrillärer Tangles mit dem Ausprägungsgrad der demenziellen Erkrankung (Arnold et al. 1991). Zum anderen zeigen einige AD-Patienten mit starken kognitiven Einschränkungen post mortem keine A $\beta$ Ablagerungen. Gegenteilig konnten A $\beta$-Ablagerungen bei kognitiv unauffälligen Menschen nachgewiesen werden (Pimplikar 2009). Zudem kommt es in einigen AD-Mausmodellen zu Gedächtniseinschränkungen, lange bevor erste A $\beta$-Ablagerungen nachweisbar sind (Lesné et al. 2008). Diese Informationen zusammenführend muss davon ausgegangen werden, dass eher andere oder zumindest zusätzliche Ursachen neben den extrazellulären $A \beta$-Ablagerungen, zur Pathologie der Alzheimererkrankung führen. Ein möglicher Erklärungsansatz ist intraneuronales $A \beta$.

\subsubsection{Modifizierte Amyloidhypothese}

Intrazelluläre $A \beta$-Ablagerungen wurden erstmals in der Mitte der 80er Jahre entdeckt (Masters et al. 1985b). Anschließend wurde bei AD-Patienten (Gouras et al. 2000), bei an Trisomie 21erkrankten Menschen (Gyure et al. 2001) und bei transgenen Mäusen (Wirths et al. 2001) post mortem die intrazelluläre Ablagerung bestätigt. Bei intrazellulärem $A \beta$ handelt es sich vorwiegend um $A \beta_{1-42}$ (Gouras et al. 2000; LaFerla et al. 2007). Da es sich zu Beginn in Regionen ablagert, die bei beginnender AD zuerst betroffen sind, scheint es ein frühzeitiges Ereignis in der Pathogenese der Erkrankung zu sein. Zudem scheint es der Ablagerung NFTs und extraneuronaler Plaques vorrauszugehen (Gouras et al. 2000; Gyure et al. 2001; Fernández-Vizarra et al. 2004). Nach Akkumulation extraneuronaler Plaques kommt es zu einer Reduktion der intraneuronalen Ansammlungen (Gyure et al. 2001). Generell bestehen zwei Möglichkeiten, die zur Ansammlung von intrazellulärem A $\beta$ führen können. Zum einen kann ein Teil des produzierten $A \beta$ s direkt intrazellulär verbleiben und dort akkumulieren. Zum anderen besteht die Möglichkeit, dass ein Teil nachdem er von der Zelle sekretiert wurde, wieder von dieser aufgenommen wird (LaFerla et al. 2007). Für die Wiederaufnahme existieren mehrere Mechanismen. A $\beta$ kann unter anderem durch Bindung an den nikotinischen Acetylcholinrezeptor (Nagele et al. 2002) oder den ApolipoproteinE-Rezeptor (Bu et al. 2006) zusammen mit diesen in die Zelle aufgenommen werden.

Intraneuronales $A \beta$ ist zu Beginn als Monomer vorhanden. Aus den Monomeren können sich schnell Oligomere, wie Di- oder Trimere sowie längere Aggregate, wie Protofibrillen und Fibrillen bilden (LaFerla et al. 2007; Benilova et al. 2012). Den oligomeren A $\beta$-Spezies wird der stärkste Einfluss auf die Pathologie der AD zugeschrieben. Dimere stören Lernprozesse und Gedächtnisbildung (Cleary et al. 2005) sowie synaptische Funktionen und Langzeitpoten- 
zierung (Walsh et al. 2002). Längere Oligomere, wie Dodekamere, führen außerdem in transgenen Mausmodellen zu pathologischen Veränderungen der Kognition und des Gedächtnisses (Lesné et al. 2006). In Untersuchungen an humanem Hirngewebe und in Tests mit oligomerspezifischen Antikörpern bei transgenen Mäusen konnte gezeigt werden, dass die für die Pathologie der AD wichtigen Oligomere tatsächlich intra- und nicht extrazellulär gebildet werden (Walsh et al. 2000; Oddo et al. 2006). Das intraneuronal vorhandene A $\beta$ akkumuliert vorwiegend in multivesikulären Körperchen, Lysosomen und Mitochondrien. Dies führt zu funktionellen Störungen der Mitochondrien, Proteasomen und des Kalziumstoffwechsels sowie zur Initiierung synaptischer Dysfunktionen und Erleichterung der Tau-Hyperphosphorylierung (LaFerla et al. 2007). Intraneuronales $A \beta$ führt nicht nur zu zellulären Dysfunktionen, sondern scheint zudem auch mit apoptotischem Zelltod in den Gehirnen von transgenen Mäusen (LaFerla et al. 1995) und AD-Patienten (Chui et al. 2001) zu korrelieren. Interessant ist, dass nur $A \beta_{1-42}$ und nicht das kürzere $A \beta_{1-40}$ nach Injektion in menschliche Neuronen zum Zelltod führt.

Wenn die aufgelisteten Informationen zusammengetragen werden, kann eine modifizierte $\beta$ Amyloid-Hypothese in Betracht gezogen werden, in der nicht das extra- sondern das intrazelluläre $\mathrm{A} \beta$ das Schlüsselelement zur Entstehung der $\mathrm{AD}$ darstellt. Nach der modifizierten Hypothese wird das intrazelluläre genau wie das extrazelluläre $A \beta$ bei der klassischen AmyloidHypothese zunächst durch bestimmte Risikofaktoren, wie zunehmendes Alter, Trisomie 21 oder Mutationen in APP, PSEN1 oder PSEN2 vermehrt produziert. In der modifizierten Hypothese akkumuliert das intrazellulär produzierte $A \beta$ direkt innerhalb der Zelle oder wird nach Sekretion durch verschiedene Mechanismen wieder in die Zelle aufgenommen. Folgend löst das intrazelluläre A $\beta$ AD-typische Prozesse, wie Dysfunktion und Verlust von Neuronen und Synapsen, aus, die bei der klassischen Amyloid-Hypothese durch extrazelluläres A $\beta$ bedingt sind. In Folge der pathologischen Prozesse zeigen sich eine makroskopisch beobachtbare Atrophie des Gehirns und schließlich das Vollbild der Demenz (Wirths et al. 2004). 


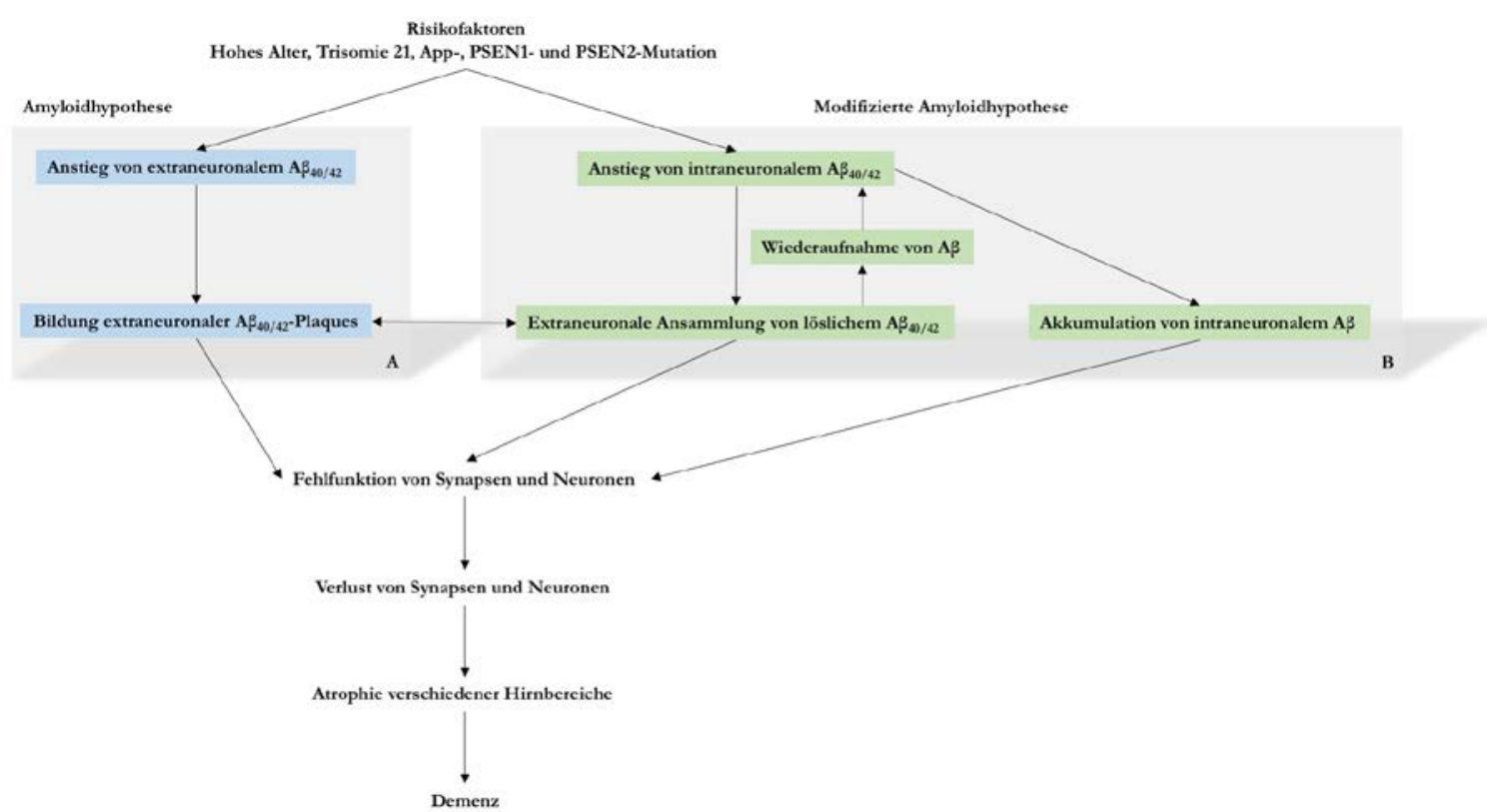

Abbildung 6: Amyloidhypothesen im Vergleich. Vergleichendes Fließdiagramm der klassischen (A) und der modifizierten Amyloidhypothese (B). In den Kästchen sind die Unterschiede der jeweiligen Hypothesen gegenübergestellt. Die Merkmale der klassischen Hypothese sind blau und die Merkmale der modifizierten Hypothese sind grün unterlegt. Aspekte, in denen sich beide Hypothesen gleichen, sind nicht farbig unterlegt. Abbildung modifiziert nach (Wirths et al. 2004).

\subsection{Genetik der Alzheimerdemenz}

Die AD kann sowohl als familiäre (fAD, präsenile Demenz vom Alzheimertyp) als auch als sporadische Form (senile Demenz vom Alzheimertyp) auftreten.

\subsubsection{Familiäre Form}

An der fAD ist mit $<5 \%$ aller AD-Patienten und einer Prävalenz von $0,1 \%$ nur ein kleiner Teil erkrankt. Meist kommt es bei dieser Form zu einem Krankheitsbeginn vor dem 65. Lebensjahr mit rascher Progression der Symptome. Der familiären Form können Mutationen verschiedener Gene zugeordnet werden. Zu ihnen zählen Mutationen im PSEN1 auf Chromosom 14 (Schellenberg et al. 1992), im PSEN2 auf Chromosom 1 (Rogaev et al. 1995) und im APP auf Chromosom 21 (Goate et al. 1991; Williamson et al. 2009; Reitz und Mayeux 2014; Scheltens et al. 2016). Aktuell sind 24 Mutationen für APP, 185 Mutationen für PSEN1 und 13 Mutationen für PSEN2 bekannt (Tanzi 2012), von denen die meisten autosomal-dominant vererbt werden (Reitz und Mayeux 2014) und/oder zu einem Anstieg des Verhältnisses zwischen 
$A \beta_{42} / A \beta_{40}$ führen (Tanzi und Bertram 2005). Der relative Anstieg des $A \beta_{42}$ fördert die Aggregation der Peptide zu Oligomeren und Amyloid-Plaques (Jarrett et al. 1993). APP kann zur Symptomatik der AD auf zwei verschiedenen Wegen führen. Erstens durch ein vermehrtes Vorhandensein des nicht mutierten Wildtypgens auf dem 21. Chromosom bei Trisomie 21 und infolgedessen zu einer bedingten Überexpression von APP. Zweitens durch APPMissens-Mutationen, die in der Schnittstelle der $\beta$-Sekretase, nach der Schnittstelle der $\gamma$ Sekretase oder in der A $\beta$-Region selbst liegen können (Selkoe 2011). Zu einem Anstieg aller A $\beta$-Spezies kommt es bei der schwedischen Mutation. Diese weist eine Doppel-MissensMutationen an Kodon 670 und 671 in der Schnittstelle der $\beta$-Sekretase auf (Mullan et al. 1992; Citron et al. 1992; Selkoe 2011). Bei einer Missens-Mutation nach der Schnittstellte der $\gamma$ Sekretase an Kodon 717 (Chartier-Harlin et al. 1991), der sogenannten London-Mutation (Goate et al. 1991), kommt es zu einer relativen Erhöhung der stärker aggregierenden $\mathrm{A} \beta_{1-42^{-}}$ Peptide, ohne die gesamte A $\beta$-Produktion zu beeinflussen (Suzuki et al. 1994). Mutationen in der A $\beta$-Region, die bei der sogenannten Arctic-Mutation auftreten, fördern Aggregation und Bildung von Protofibrillen (Nilsberth et al. 2001; Selkoe 2011). Von Mutationen in PSEN1 und PSEN2 sind mehrere hundert Familien betroffen. Die Mutationen beeinflussen die $\gamma$ Sekretase-Aktivität und führen darüber zu einem Anstieg des Verhältnisses zwischen $A \beta_{1-42}$ und $A \beta_{1-40}$ (Wolfe et al. 1999; Wolfe 2007).

\subsubsection{Sporadische Form}

Von der sporadischen Form ist mit über 90\% der größere Teil aller AD-Patienten betroffen. Sie beginnt meist nach dem 65. Lebensjahr und zeigt im Vergleich zur fAD ein langsameres Voranschreiten. Auch sie ist stark mit genetischen Variationen assoziiert, jedoch spielen Lebensbelastungsfaktoren (vgl 1.10) eine wichtigere Rolle als bei der familiären Form. Aus diesem Grund ist es bei der sporadischen Form viel schwieriger, neue Gen-Loci zu identifizieren (Bertram et al. 2010; Tanzi 2012; Scheltens et al. 2016). Der wichtigste identifizierte genetische Risikofaktor ist das Apolipoprotein E (ApoE) E4-Allel (Corder et al. 1993), dessen Gen sich auf Chromosom 19q13 befindet (Strittmatter et al. 1993). Insgesamt gibt es drei AllelVarianten des ApoE $(\varepsilon 2, \varepsilon 3, \varepsilon 4)$, deren Genprodukte unter physiologisschen Bedingungen am Transport und Stoffwechsel von Fetten beteiligt sind (Mahley et al. 1984). Heterozygote Träger des $\varepsilon 4$-Allels weisen ein vierfach erhöhtes Risiko auf (Corder et al. 1994), wohingegen homozygote Träger sogar ein mehr als zehnfach erhöhtes Risiko für die Entstehung einer senilen Demenz haben (Tanzi 2012). Zu einem erhöhten Risiko kommt es dadurch, dass das ع4-Allel wahrscheinlich zu einer verminderten Beseitigung und/oder zu einer gesteigerten 
Aggregation von A $\beta$ führt (Ma et al. 1994; Evans et al. 1995; Bertram et al. 2010). Im Gegensatz zum $\varepsilon 4$ - senkt das $\varepsilon 2$-Allel das Risiko für die Entstehung einer AD um den Faktor vier (Corder et al. 1994). Da nicht alle $\varepsilon 4$-Allel-Träger an einer AD erkranken (Selkoe 2011), scheint es weder notwendig noch ausreichend für die Entstehung der Erkrankung zu sein. Stattdessen handelt es sich eher um einen genetischen Risikofaktor, der das Alter des Auftretens dosisabhängig senkt (Tanzi 2012; Reitz und Mayeux 2014).

\subsection{Beeinflussende Faktoren}

\subsubsection{Risikofaktoren}

Neben den genetischen Risikofaktoren sind eine Reihe anderer Einflüsse bekannt, die das Auftreten einer Alzheimerdemenz wahrscheinlicher machen. Der stärkste Risikofaktor für das Entstehen einer AD ist ein hohes Lebensalter. Die Prävalenz steigt, wie in 1.1.1 beschrieben, ab dem 65. Lebensjahr exponentiell an und erreicht bei über 90-Jährigen einen Wert von mehr als 40\%. Neben einem hohen Lebensalter stellen zerebrovaskuläre Erkrankungen einen wichtigen Risikofaktor dar. Häufig ist eine Koexistenz von stattgefundenen Hirninfarkten und bestehender Alzheimerdemenz zu beobachten (Schneider und Bennett 2010). Eine mögliche Erklärung ist, dass es durch Infarkte zu Zerstörung und Atrophie des Hirngewebes kommt. Ein anderer Erklärungsansatz geht davon aus, dass sich $A \beta$ nach einem Hirninfarkt vermehrt bildet, da Hypoxie und Ischämie einen Anstieg der APP-Prozessierung bedingen (Mayeux und Stern 2012). Bluthochdruck im mittleren Lebensalter ist ein weiterer Risikofaktor, im hohen Lebensalter unter einer Demenz zu leiden (Whitmer et al. 2005). Im höheren Lebensalter hingegen wirkt sich ein zu niedriger Blutdruck negativ auf die Entstehung einer Demenz aus (Mayeux und Stern 2012). Neben den genannten Faktoren erhöht Diabetes Typ II das Risiko für die Entstehung einer AD (Profenno et al. 2010). Es wird vermutet, dass es unter anderem durch die mit Diabetes Typ II einhergehende Hyperinsulinämie zur abgeschwächten zerebralen $A \beta$-Beseitigung und dadurch bedingt zu einer gesteigerten $A \beta$-Akkumulation kommt (Farris et al. 2003). Tabakkonsum ist ebenfalls für das Auftreten einer AD prognostisch ungünstig, da es zu oxidativem Stress und dadurch bedingt zu vermehrtem Zellschaden im Gehirn kommen kann (Mayeux und Stern 2012). Zudem zeigt sich in einer Studie, dass vor allem bei Männern anamnestische traumatische Kopfverletzungen das Risiko für die Entwicklung einer AD ansteigen lassen (Fleminger et al. 2003). 


\subsubsection{Protektive Faktoren}

Neben den bekannten Risikofaktoren gibt es auch Faktoren, die das Risiko an einer AD zu erkranken senken können. Zu diesen werden von R. Mayeux and Y. Stern (2012) kognitive Reserven, bestimmte Ernährungsgewohnheiten und körperliche Aktivität gezählt. Die Ernährungsgewohnheiten schließen unter anderem die Reduzierung von Cholesterin mit ein, da hierdurch das Risiko für Gefäßschäden im Gehirn gesenkt werden kann. Ebenfalls kommt es durch den regelmäßigen Konsum von Omega-3-Fettsäuren und einer erhöhten Vitamin-DZufuhr zu einer Reduktion des AD-Risikos. Jedoch bestehen bezüglich der genannten Ernährungsempfehlungen gewisse Inkohärenzen in der aktuellen Literatur, die durch additive, synergistische oder antagonistische Effekte bedingt sein können (Mayeux und Stern 2012). Aus diesem Grund wird im allgemeinen eine mediterrane Ernährung empfohlen. Diese enthält die genannten Ernährungsempfehlungen im Wesentlichen. In verschiedenen Studien konnte gezeigt werden, dass eine solche Ernährung das Risiko für die Entstehung einer AD senkt (Scarmeas et al. 2006; Scarmeas et al. 2009). In Tierversuchen wurde zudem beobachtet, dass durch körperliche Aktivität Mechanismen der neuronalen Plastizität und Neurogenese angeregt werden sowie eine vermehrte Vaskularisation im Gehirn erreicht werden kann. In einigen humanen Studien konnte ebenfalls herausgestellt werden, dass körperliche Aktivität einen protektiven Faktor haben kann. Andere Studien konnten jedoch keine positiven Einflüsse auf die Prävention einer AD beobachten (Mayeux und Stern 2012).

\subsection{Amyloid Beta 4-42}

Amyloid- $\beta$-Peptide, von denen es verschiedene Varianten gibt, bilden die Grundlage der Amyloid- $\beta$-Plaques. Diese Peptide können sowohl N-terminal an Position 1 mit der Aminosäure Aspartat beginnen als auch einen N-terminalen Verlust der ersten Aminosäuren aufweisen. Eine häufige bei der $\mathrm{AD}$ zu finde $\mathrm{A} \beta$-Variante ist das um drei Aminosäuren verkürzte mit Phenylalanin beginnende $A \beta_{4-42}$. (Masters et al. 1985b). Durch Quantifizierungen der $A \beta-$ Spezies wurde festgestellt, dass $A \beta_{42}$ im Vergleich zu $A \beta_{40}$ in Plaques häufiger vorkommt. $A \beta_{4}$ ${ }_{42}$ ist zudem bei der AD und vaskulärer Demenz eine relativ häufige Variante der $\mathrm{A} \beta_{42}$-Spezies (Lewis et al. 2006). AD-Patienten weisen im Schnitt etwa viermal mehr A $\beta_{4-42}$ im Gehirn auf, als gesunde ältere Menschen (Portelius et al. 2015). Außerdem konnte mittels Massenspektrometrie und Immunpräzipitation gezeigt werden, dass $A \beta_{4-42}$ neben $A \beta_{1-42}$ im Hippocampus und Kortex bei $\mathrm{AD}$ die größte $A \beta$-Fraktion ist. Im Kortex machen $A \beta_{1-42}$ und $A \beta_{4-42}$ mehr als 60\% aller A $\beta$-Isoformen aus (Portelius et al. 2010). Stärker N-terminal-verkürzte Peptide, wie $A \beta_{4-42}$ aggregieren zudem schneller und stärker als Peptide mit einem längeren $\mathrm{N}$-Terminus 
(Pike et al. 1995; Bouter et al. 2013). Gleiches gilt auch für Peptide, deren c-terminale Aminosäuren an Position 42 enden. Sie zeigen höhere Sedimentationswerte als diejenigen, die an Position 40 enden (Pike et al. 1995). Außerdem beeinflusst der N-Terminus das Fibrillisationsverhalten (Haupt et al. 2012). N-terminal verkürzte Peptide weisen zudem stärkere neurotoxische Effekte als mit Position 1 beginnende Peptide auf (Pike et al. 1995; Russo et al. 2002).

Speziell die Eigenschaften des $A \beta_{4-42}$ wurden von Bouter et al (2013) in Experimenten ermittelt und mit anderen $A \beta$-Varianten $\left(A \beta_{1-42}, A \beta_{\mathrm{pE} 3-42}, A \beta_{4-40}\right.$ und $\left.A \beta_{4-43}\right)$ verglichen. Es konnte gezeigt werden, dass $A \beta_{4-42}$ nach $A \beta_{\mathrm{PE} 3-42}$ und vor den genannten anderen Varianten die stärkste Neigung hat stabile Aggregate zu bilden. Weiterhin konnten die von Haupt (2012) gemachten Beobachtungen, dass N-terminal-verkürzte Peptide schneller aggregieren und Fibrillen bilden als nicht N-terminal-verkürzte Peptide wie $A \beta_{1-42}$, wiederholt werden. Dies weist auf die besondere Bedeutung des N-terminalen Restes für das Aggregationsverhalten hin. In Untersuchungen mit SDS-Page zeigen $A \beta_{1-42}, A \beta_{\mathrm{pE} 3-42}$ und $A \beta_{4-42}$ Monomere und Aggregate, wie Trimere und Tetramere, während andere Peptid-Varianten lediglich Monomere und Dimere bilden. Nach wenigen Tagen zeigen sich für $A \beta_{1-42}, A \beta_{\mathrm{PE3-42}}$ und $A \beta_{4-42}$ zusätzlich Oligomere mit höherem Molekulargewicht. Zur Analyse der akuten Effekte in vitro auf neuronale Funktion und Lebensfähigkeit wurden zunächst Nervenzellen den erwähnten A $\beta$-Varianten ausgesetzt. Alle Varianten zeigen einen dosisabhängigen Einfluss auf die Abnahme der Lebensfähigkeit der Neurone. Die stärksten toxischen Effekte bestehen in vitro für $\mathrm{A} \beta_{4-42}, \mathrm{~A} \beta_{\mathrm{PE} 3-42}$ und $\mathrm{A} \beta_{1-42}$. Zur Beurteilung akuter neurotoxischer Effekte der genannten Peptide in vivo wurden diese Mäusen intraventrikulär injiziert. Alle N-terminal-verkürzten Varianten führen zu Defiziten im Arbeitsgedächtnis. Die stärksten Effekte ergeben sich für $\mathrm{A} \beta_{4-40}$ und $A \beta_{4-42}$ (Bouter et al. 2013). Tabelle 1 gibt einen Überblick über die Eigenschaften des $A \beta_{4-}$ 42 .

Tabelle 1: Eigenschaften von $A \beta_{4-42}$

\begin{tabular}{|l|}
\hline \multicolumn{1}{|c|}{ Eigenschaften von $\mathbf{A} \boldsymbol{\beta}_{4-42}$} \\
\hline Starke Neigung stabile Aggregate zu bilden \\
\hline Aggregiert schnell und bildet Fibrillen \\
\hline Toxische Wirkung auf Nervenzelle \\
\hline Beeinflussung des Arbeitsgedächtnisses nach intraventrikulärer Injektion in Wildtypmäuse \\
\hline
\end{tabular}


Führt man die genannten Eigenschaften von $\mathrm{A} \beta_{4-42}$ zusammen, kann davon ausgegangen werden, dass dieses Peptid ein relevantes Element in der Pathogenese der AD ist (Bayer und Wirths 2014).

\subsection{Mausmodelle}

Durch die Entdeckung der für fAD-typischen Mutationen im APP- und PSEN-Gen wurde der Weg für die Entwicklung transgener Mausmodelle geebnet. Die Mehrzahl der transgenen Mausmodelle exprimierte zunächst mutiertes humanes APP.

Als erste transgene Mauslinie wurde hierzu das PDAPP-Mausmodell entwickelt. Dieses exprimiert durch den PDGF-Promotor humanes APP mit der Indiana Mutation (V717F). Infolgedessen kommt es zunächst zu sichtbaren extrazellulären $A \beta$-Ablagerungen im Hippocampus und später auch im Isokortex (Games et al. 1995). Außerdem zeigen sich dystrophe Neurite, vermehrt Astrozyten und eine Zunahme der Mikroglia sowie altersabhängige Gedächtnisdefizite. Zu einem Verlust von Neuronen kommt es hingegen nicht (Irizarry et al. 1997). Die Tg2576-Mauslinie stellt ein weiteres Mausmodell dar. Dieses führt zur Überexpression von humanem APP mit der Schwedischen Mutation (K670N/M671L) unter der Kontrolle eines Hamster-Prionen-Promotors. Auch bei diesem Mausmodell kommt es wie bei der PDAPP-Mauslinie zu extrazellulären A $\beta$-Ablagerungen, Bildung dystropher Neuriten und vermehrter Gliose sowie altersabhängigen Gedächtnisdefiziten (Hsiao et al. 1996). Neben den genannten gibt es eine Vielzahl weiterer Mausmodelle, die versuchen Mutationen im APP-Gen abzubilden. Allen ist gemein, dass sie zu einem extrazellulären Anstieg von A $\beta$ führen, eine gesteigerte Neuroinflammation bedingen und Verhaltensauffälligkeiten aufweisen (Duyckaerts et al. 2008). Zusätzlich zu den APP-Mausmodellen gibt es transgene Mauslinien, die mutiertes humanes PSEN exprimieren. Einige PSEN-Mausmodelle führen im Gehirn zu einem Anstieg von $A \beta_{42}$, stören den Kalziumstoffwechsel im endoplasmatischem Retikulum oder führen zu einer vermehrten Phosphorylierung von Tau (Oyama et al. 1998; Duyckaerts et al. 2008). AuBer den genannten wurden Mausmodelle entwickelt, die mehrere kombinierte Mutationen im APP-Gen aufweisen oder Kombinationen in APP und PSEN zeigen. Solche Mausmodelle zeigen deutlich schwerere AD-ähnliche Verläufe. Es kommt früher zu Plaque-Formationen, stärkerer Neuroinflammation und Verhaltensdefiziten (Casas et al. 2004; Oakley et al. 2006; Cavanaugh et al. 2014).

Obwohl es bei AD-Patienten zu starkem Neuronenverlust kommt, zeigen die meisten AD-Mausmodelle keinen oder nur einen geringen Neuronenverlust (Duyckaerts et al. 2008). $\mathrm{Zu}$ einem deutlichen Neuronenverlust kommt es hingegen bei einigen doppelt-transgegen 
Tiermodellen, wie 5xFAD (Oakley et al. 2006) oder APP/PS1K1 (Casas et al. 2004). Beide weisen eine Kombination von Mutationen in APP und PSEN auf. Zudem konnte bei diesen Mausmodellen intraneuronales $A \beta$ nachgewiesen werden, sodass ein Zusammenhang zwischen intraneuronalem A $\beta$ und Neuronenverlust vermutet wird (Wirths und Bayer 2012). Transgene AD-Mausmodelle haben zu einem besseren Verständnis der AD beigetragen. Jedoch können sie nie komplett die Erkrankungen abbilden, sondern immer nur einen kleinen Ausschnitt wiederspiegeln.

\subsection{Das Tg4-42-Mausmodell}

Amyloid- $\beta_{4-42}$ ist eine in den Gehirnen von AD-Patienten häufig vorkommende, am NTerminus-verkürzte A $\beta$-Spezies (Portelius et al. 2010). Bis zur Entwicklung des Tg4-42Mausmodells war jedoch wenig über die Auswirkungen dieses Peptides auf Entstehung und Progression der AD bekannt. Die meisten AD-Mausmodelle bilden durch Überexpression von APP und/oder PSEN1 Mutationen und Ursachen der familiären, jedoch nicht der häufigeren sporadischen Form ab (Duyckaerts et al. 2008). Um chronische Einflüsse von $A \beta_{4-42}$ auf Mäusegehirne zu analysieren ohne dabei Mutationen in APP und/oder PSEN1 als Störfaktoren zu haben, wurde das Tg4-42-Mausmodell entwickelt (Wittnam 2012). Die Mäuse sekretieren an das murin thyrotropin releasing hormone gebundenes $A \beta_{4-42}$ neuronal. Das Fusionspeptid erleichtert dabei die extrazelluläre Freisetzung (Alexandru et al. 2011). Da $A \beta_{4-42}$ direkt exprimiert wird, ist eine enzymatische Modifikation nicht notwendig (Wittnam 2012). Die Generierung des Modells wird in 2.2 genauer erläutert.

Tg4-42-Mäuse zeigen ab einem Alter von zwei Monaten starke intraneuronale A $\beta$ Ablagerungen in der CA1-Region des Hippocampus. Mit zunehmendem Alter kommt es jedoch zur Abnahme der A $\beta$-Expression, aufgrund des Verlustes von Neuronen in der CA1Region (Bouter et al. 2013). Zudem zeigen sich bei zwei Monate alten Tieren reaktive Mikroglia in derselben Region und Astroglia in der Umgebung des Hippocampus. Beides weist auf eine hippocampale Neurodegeneration hin (Wittnam 2012; Bouter et al. 2013; Bouter 2015). In der CA1-Region kommt es bereits bei vier Monate alten homozygten Tieren zu einem signifikanten Neuronenverlust von $\sim 45 \%$ im Vergleich zu gleichalten Wildtyptieren (WT-Tiere). Mit zunehmendem Alter steigt der der Verlust exponentiell an und erreicht ein Plateau bei sechs Monate alten Tieren mit einem Verlust von $\sim 65 \%$. Hemizygote Tiere zeigen in derselben Region erst ab einem Alter von acht Monaten einen Neuronenverlust von $\sim 38 \%$ im Vergleich zum WT-Tier. Mit zunehmendem Alter kommt es auch bei hemizygoten Tieren zu einem Fortschreiten des Nervenzellverlustes. Sie zeigen bei einem Alter von zwölf Monaten 
einen Anstieg des Neuronenverlustes auf 49\% im Vergleich zur gleichalten WT-Tieren. Im Alter von drei Monaten zeigt sich kein Unterschied in der Neuronenzahl zwischen hemizygoten, homozygoten und WT-Tieren (Bouter et al. 2013; Bouter 2015). Neben den genannten neuropathologischen Veränderungen bestehen Beeinträchtigungen des räumlichen Gedächtnisses. Einschränkungen des räumlichen Lernens und des räumlichen Referenzgedächtnisses bestehen bei acht Monate alten homozygten und bei zwölf Monate alten hemizygoten Tieren im Vergleich zu gleichalten WT-Tieren. Bei drei Monate alten Tieren besteht wie beim Neuronenverlust kein Unterschied zwischen den verschiedenen Genotypen (Bouter et al. 2013). Angstverhalten und Arbeitsgedächtnis zeigen keine Auffälligkeiten und unterscheiden sich nicht von WT-Tieren (Wittnam 2012; Bouter 2015). Tabelle 2 gibt einen Überblick über die beschriebenen Besonderheiten.

Tabelle 2: Besonderheiten des Tg4-42-Mausmodells

\begin{tabular}{|ll|}
\hline & Besonderheiten des Tg4-42-Mausmodells \\
\hline Ab zwei Monate: & intraneuronale A $\beta$-Ablagerungen in der CA1-Region \\
\hline Ab zwei Monate: & reaktive Mikroglia in der CA1-Region \\
\hline Ab zwei Monate: & reaktive Astroglia in hippocampaler Umgebung \\
\hline Ab vier Monate: & $\begin{array}{l}\text { signifikanter Neuronenverlust in der CA1-Region homozygoter } \\
\text { Tiere }\end{array}$ \\
\hline Ab acht Monate: & signifikanter Neuronenverlust in der CA1-Region hemizygoter Tiere \\
\hline Ab acht Monate: & Beeinträchtigung des räumlichen Gedächtnisses homozygoter Tiere \\
\hline Ab zwölf Monate: & Beeinträchtigung des räumlichen Gedächtnisses hemizygoter Tiere \\
\hline
\end{tabular}

\subsection{Zielsetzung und Fragestellung der Arbeit}

Amyloid- $\beta_{4-42}$ ist eine sehr häufige in den Gehirnen von $\mathrm{AD}$-Patienten vorkommende $\mathrm{A} \beta$ Spezies (Portelius et al. 2010). Der chronische Einfluss von $A \beta_{4-42}$ wurde jedoch bisher nur von Bouter et. al. (2013) genauer untersucht. Bouter et. al. (2013) bezogen sich dabei vor allem auf durch den chronischen Einfluss von $A \beta_{4-42}$ bedingte Verhaltensveränderungen der Tiere und histologische Auffälligkeiten in der CA1-Region des Hippocampus. Ziel der vorliegenden Arbeit ist es, neue und weiterführende Erkenntnisse über das Tg4-42-Mausmodell und den damit verbundenen Einfluss von $A \beta_{4-42}$ auf die $A D$ zu gewinnen und somit zu einem besseren Verständnis der Pathogenese und Symptomatik der AD beizutragen. Um dieses Ziel zu erreichen, wurde der bei diesem Tiermodell zuvor noch nicht betrachtete GD des Hippocampus 
einigen quantitativen Untersuchungen unterzogen.

Zunächst sollte mittels Stereologie eine Quantifizierung der Neurone im GD durchgeführt werden. Hierzu wurden Tiere im Alter von zwei bis sechs Monate verwendet, um einen altersabhängigen Verlauf der Neuronenzahl zu ermitteln. Anschließend sollte bei Tieren derselben Altersstufen im GD ebenfalls ein altersabhängiger Verlauf der Neurogeneserate mittels eines Antikörpers für Doublecortin bestimmt und die Ergebnisse mit den stereologischen Daten verglichen werden. Ziel war es herauszufinden, ob zwischen Verlust und neugebildeten Neuronen eine gegenseitige Beeinflussung im Sinne eines gleichgerichteten Abfalls oder eines gegenläufigen Anstiegs besteht. Bei denselben Altersstufen sollte außerdem untersucht werden, ob das Volumen des GD von der Neuronenzahl beeinflusst wird. Weiterhin sollte bei sechs Monate alten transgenen Tieren der GD auf inflammatorische Prozesse mittels eines Antikörpers für GFAP (saures Gliafaserprotein) untersucht werden. Als abschließende Frage wurde mittels qPCR die Genexpression von GFAP bei zwei, vier und acht Monate alten transgenen Tieren bestimmt und zur gemessenen Neuroinflammation in Relation gesetzt. Alle ermittelten Daten wurden mit drei und sechs Monate alten WT-Tieren verglichen. Tabelle 3 listet die Fragestellungen stichwortartig auf.

Tabelle 3: Zielsetzung und Fragestellung der Arbeit

\begin{tabular}{|l|}
\hline \multicolumn{1}{|c|}{ Zielsetzung und Fragestellungen der Arbeit } \\
\hline Quantifizierung der Neuronenzahl im Gyrus Dentatus im Tg4-42-Mausmodell \\
\hline Quantifizierung der Neurogenese im Gyrus Dentatus im Tg4-42-Mausmodell \\
\hline $\begin{array}{l}\text { Bestimmung des Einflusses von Neuronenzahl und Neurogenese auf das Volumen des } \\
\text { Gyrus Dentatus im Tg4-42-Mausmodell }\end{array}$ \\
\hline Quantifizierung der Neuroinflammation im Gyrus Dentatus im Tg4-42-Mausmodell \\
\hline Bestimmung der Genexpression von GFAP in Relation zur Neuroinflammation \\
\hline
\end{tabular}




\section{Material und Methoden}

\subsection{Materialliste}

Tabelle 4: Primäre Antikörper zur immunhistochemischen Färbung

\begin{tabular}{|l|l|l|l|l|}
\hline Antikörper & Herkunft & Epitop & Verdünnung & Firma \\
\hline Doublecortin & Ziege & $\begin{array}{l}\text { Exprimiertes } \\
\text { Doublecortin } \\
\text { migrierender } \\
\text { Neurone }\end{array}$ & $1: 500$ & Santa Cruz \\
\hline GFAP & Maus & $\begin{array}{l}\text { Saures Gliafa- } \\
\text { serprotein }\end{array}$ & $1: 500$ & $\begin{array}{l}\text { Synaptic Sys- } \\
\text { tems }\end{array}$ \\
\hline
\end{tabular}

Tabelle 5: Sekundäre biotinylierte Antikörper zur immunhistochemischen Färbung

\begin{tabular}{|l|l|l|l|}
\hline Antikörper & Herkunft & Verdünnung & Firma \\
\hline anti-Ziege & Kaninchen & $1: 250$ & Dako \\
\hline anti-Maus & Kaninchen & $1: 250$ & Dako \\
\hline
\end{tabular}


Tabelle 6: Verwendete Chemikalien

\begin{tabular}{|c|c|}
\hline Chemikalie & Firma \\
\hline 2-Propanol & Carl Roth GmbH + Co. KG, Karlsruhe, Deutschland \\
\hline ABC-Kit & Vector Laboratories, Burlingame, Kalifornien, USA \\
\hline Cresyl Violet Acetat & Fluka Chemie GmbH, Steinheim, Deutschland \\
\hline Essigsäure & Merck Schuchardt OHG, Hohenbrunn, Deutschland \\
\hline Ethanol 99\% & Walter CMP GmbH \& Co.KG, Kiel, Deutschland \\
\hline FCS & Biochrom GmbH, Berlin, Deutschland \\
\hline Gewebekleber & $\begin{array}{l}\text { Tissue-Tek }{ }^{\circledR} \text { O.C.T.TM Compound, SAKURA } \\
\text { Finetek Europe B.V. }\end{array}$ \\
\hline Hämalaunlösung & $\begin{array}{l}\text { Carl Roth GMBH + CO. KG, Karlsruhe, Deutsch- } \\
\text { land }\end{array}$ \\
\hline Milchpulver & $\begin{array}{l}\text { Carl Roth GMBH + CO. KG, Karlsruhe, Deutsch- } \\
\text { land }\end{array}$ \\
\hline Natriumacetat-Trihydrat & $\begin{array}{l}\text { Carl Roth GMBH + CO. KG, Karlsruhe, Deutsch- } \\
\text { land }\end{array}$ \\
\hline PBS & Biochrom GmbH, Berlin, Deutschland \\
\hline Roti-Histokitt & $\begin{array}{l}\text { Carl Roth GMBH }+ \text { CO. KG, Karlsruhe, Deutsch- } \\
\text { land }\end{array}$ \\
\hline Tris & $\begin{array}{l}\text { Carl Roth GMBH + CO. KG, Karlsruhe, Deutsch- } \\
\text { land }\end{array}$ \\
\hline Triton X 100 & $\begin{array}{l}\text { Carl Roth GMBH + CO. KG, Karlsruhe, Deutsch- } \\
\text { land }\end{array}$ \\
\hline Wasserstoffperoxid $30 \%$ & $\begin{array}{l}\text { Carl Roth GMBH + CO. KG, Karlsruhe, Deutsch- } \\
\text { land }\end{array}$ \\
\hline Xylol & $\begin{array}{l}\text { Carl Roth GMBH + CO. KG, Karlsruhe, Deutsch- } \\
\text { land }\end{array}$ \\
\hline Zitronensäure-Monohydrat & $\begin{array}{l}\text { Carl Roth GMBH + CO. KG, Karlsruhe, Deutsch- } \\
\text { land }\end{array}$ \\
\hline
\end{tabular}


Tabelle 7: Verwendete Gebrauchswaren

\begin{tabular}{|l|l|}
\hline Material & Firma \\
\hline Deckglas 24x60mm & $\begin{array}{l}\text { Menzel-Gläser, Gerhard Menzel GmbH, Braun- } \\
\text { schweig, Deutschland }\end{array}$ \\
\hline Eppendorfgefäße & $\begin{array}{l}\text { Greiner Bio-One International AG, Krems- } \\
\text { münster, Österreich }\end{array}$ \\
\hline Falconß-Röhrchen 15ml / 50ml & $\begin{array}{l}\text { Greiner Bio-One International AG, Krems- } \\
\text { münster, Österreich }\end{array}$ \\
\hline Kryoröhrchen & Biochrom GmbH, Berlin, Deutschland \\
\hline Objektträger Superfrost $囚 P l u s$ & $\begin{array}{l}\text { Thermo Scientific, Gerhard Menzel GmbH, } \\
\text { Braunschweig, Deutschland }\end{array}$ \\
\hline Pasteur-Kapillarpipetten & Wilhelm Ulbrich GdbR, Bamberg, Deutschland \\
\hline Pipetten 0,5-1 $\mu$ l; 10-100 $\mu \mathrm{l} ; 100-1000 \mu l$ & $\begin{array}{l}\text { Greiner Bio-One International AG, Krems- } \\
\text { münster, Österreich }\end{array}$ \\
\hline Pipettenspitzen & Sarstedt, Nümbrecht, Deutschland \\
\hline Stereologiegefäße & $\begin{array}{l}\text { Straight-Side Wide-Mouth Jar PC, Size 15ml, } \\
\text { Nalge Nunc International }\end{array}$ \\
\hline
\end{tabular}

Tabelle 8: Verwendete Geräte und Ausstattung

\begin{tabular}{|l|l|}
\hline Gerät & Firma \\
\hline Kühlplatte Leica EG 1140 C & Leica Vertrieb GmbH, Wetzlar \\
\hline Mikrotom Cool Cut, HM 335 E & MICROM International GmbH, Walldorf \\
\hline Mikroskop, BX51 DP 50 & Olympus Cooperation, Tokyo, Japan \\
\hline Wasserbad & $\begin{array}{l}\text { Gesellschaft für Labortechnik GmbH, Burgwe- } \\
\text { del }\end{array}$ \\
\hline
\end{tabular}


Tabelle 9: Verwendete Software

\begin{tabular}{|l|l|}
\hline Software & Firma \\
\hline GraphPad Prism Version 6.0 & GraphPad Software Inc., Kalifornien, USA \\
\hline ImageJ Software & $\begin{array}{l}\text { National Institute of Health (NIH), Maryland, } \\
\text { USA }\end{array}$ \\
\hline Microsoft Office 2016 & Microsoft, Redmond, Washington, USA \\
\hline
\end{tabular}

\subsection{Mausmodell Tg4-42}

Das N-verkürzte $A \beta_{4-42}$ ist für die Erforschung der $A D$ von großer Bedeutung, da es eine in den Gehirnen von AD-Patienten häufig vorkommende A $\beta$-Spezies ist. Um die Effekte dieser A $\beta$-Spezies besser untersuchen zu können, wurde das transgene Mausmodell Tg4-42 entwickelt (Bouter et al. 2013). Für die nachfolgend beschriebenen Methoden, wie Cresyl-Violett-, Doublecortin- und GFAP-Färbung sowie stereologische Auswertung und qPCR-Analyse wurde dieses Mausmodell verwendet.

\subsubsection{Aufbau des Transgens}

Das Tg4-42 Mausmodell exprimiert humanes $A \beta_{4-42}$, welches zunächst an das Signalpeptid des murinen thyrotropin releasing hormone (TRH) gekoppelt ist und durch den neuronalen Promotor Thy-1 kontrolliert wird (Bouter et al. 2013). Der murine Thy-1 Promotor steuert die neuronale Expression des pre-pro-TRH A $\beta_{4-42}$ fusionierten Peptides. $A \beta_{4-42}$ ist zur sekretorischen Freisetzung an pre-pro-TRH gekoppelt. Im endoplasmatische Retikulum (ER) setzt eine SignalPeptidase das pro-TRH-A $\beta_{4-42}$ frei. Im trans-Golgi und sekretorischen Vesikeln wird der Rest des Signalpeptides durch Prohormonkonvertasen abgespalten. A $\beta_{4-42}$ kann nun freigesetzt und von der Zelle sekretiert werden. Abbildung 7 gibt eine genaue Übersicht über den Aufbau des Transgens (Wittnam 2012). 


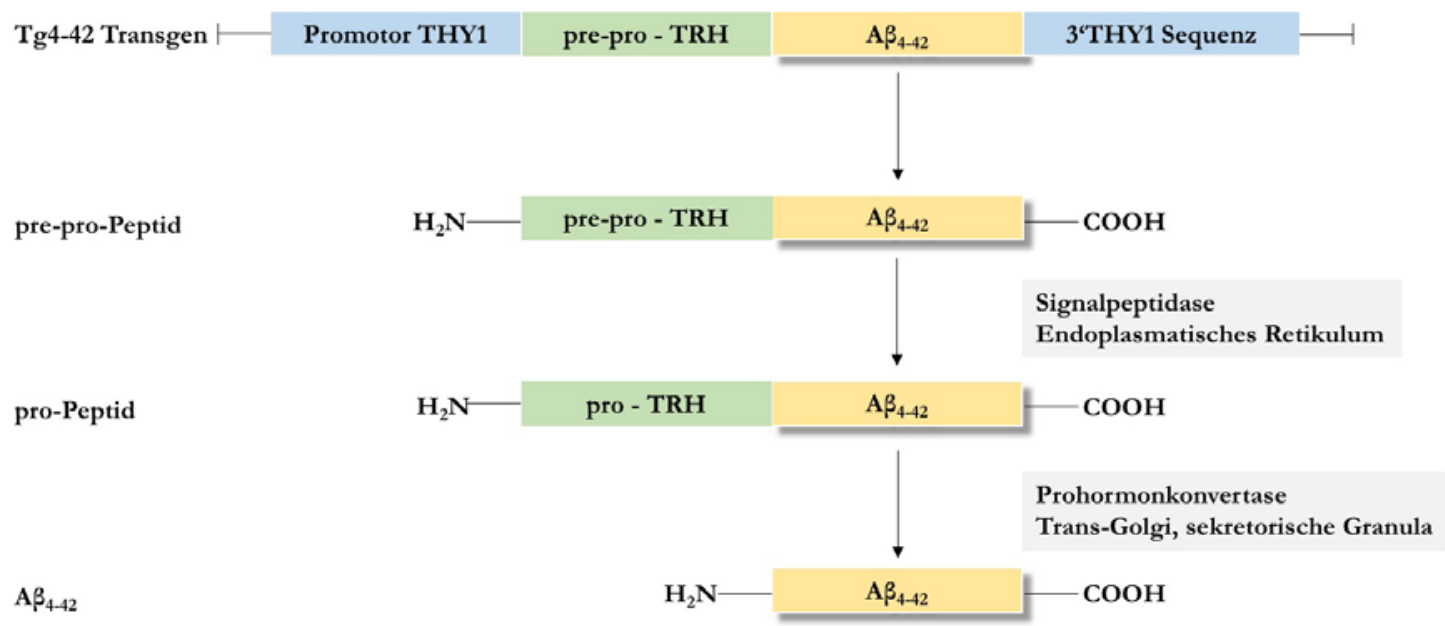

Abbildung 7: Schematische Darstellung des Tg4-42-Transgens. Abbildung modifiziert nach (Wittnam 2012).

\subsection{Cresyl-Violett-Färbung}

\subsubsection{Herstellung der histologischen Schnitte}

Für die Stereologie wurden $30 \mu \mathrm{m}$ dicke Schnitte verschiedener Altersstufen verwendet. Hierbei handelte es sich um Tiere im Alter von zwei bis sechs Monaten des Tg4-42-Mausmodells. Zusätzlich wurden zum Vergleich W'T-Tiere im Alter von drei und sechs Monaten ausgewertet. Die Anzahl der ausgewerteten Mäuse je Altersgruppe und Genotyp ist Tabelle 10 zu entnehmen. Die Herstellung der Schnitte fand mittels eines Kryostaten statt, welcher zuvor auf $-20{ }^{\circ} \mathrm{C}$ heruntergekühlt wurde. Die Hemisphären wurden zunächst mittels Gewebekleber auf dem Schneideblock des Kryostaten fixiert. Zur Aufbewahrung der Schnitte wurden zehn Gefäße verwendet. Die Schnitte wurden alternierend in die Gefäße verteilt, sodass zwischen den Schnitten innerhalb eines Gefäßes ein Abstand von zehn Schnitten bestand. Anschließend wurden die Schnitte bei $-80{ }^{\circ} \mathrm{C}$ bis zur weiteren Verwendung gelagert.

Tabelle 10: Verwendete Tiere zur stereologischen Auswertung

\begin{tabular}{|l|l|l|l|l|l|}
\hline & 2 Monate & 3 Monate & 4 Monate & 5 Monate & 6 Monate \\
\hline Tg4-42 & 4 & 4 & 4 & 4 & 4 \\
\hline WT & & 3 & & & 3 \\
\hline
\end{tabular}




\subsubsection{Färbeprotokoll}

Um nachfolgend die wie in 2.3.1 hergestellten Schnitte auf elektrostatischen Objektträgern zu sortieren und anschließend mit der Cresyl-Violett-Färbung fortzufahren, wurden die Schnitte eines Gefäßes zunächst mit eiskalter 0,01 M phosphatgepufferter Salzlösung (PBS) für circa fünf Minuten gespült. Anschließend wurden die Schnitte über Nacht bei Raumtemperatur getrocknet, um sie am nächsten Tag mit Cresyl-Violett färben zu können. Die benötigten Materialien sind Abschnitt 2.3.2.1 und 2.3.2.2 zu entnehmen.

\subsubsection{Chemikalien}

- Cresyl-Violett (Fluka Chemie GmbH, Steinheim, Deutschland)

- Corbit-Balsam

- Essigsäure (Merck Schuchardt OHG, Hohenbrunn, Deutschland)

- Ethanol (100\%) (Walter CMP GmbH \& Co.KG, Kiel, Deutschland)

- Isopropanol (=2-Propanol) (Carl Roth GMBH + CO. KG, Karlsruhe, Deutschland)

- Natriumacetat-Trihydrat (Carl Roth GMBH + CO. KG, Karlsruhe, Deutschland)

- Rotiß-Histokitt-Einschlussmittel

- Triton X-100 (Carl Roth GMBH + CO. KG, Karlsruhe, Deutschland)

- Wasser, destilliert

- Xylol (Carl Roth GMBH + CO. KG, Karlsruhe, Deutschland)

\subsubsection{Weitere Hilfsmittel}

- Färbeküvetten

- Filter

\subsubsection{Erster Tag der Färbung}

Zu Beginn wurde die für den Puffer notwendige Stammlösung (im Folgenden 1A genannt) angesetzt. Hierzu wurde 13,61 g Natriumacetat-Trihydrat in $100 \mathrm{ml}$ destilliertes Wasser gegeben. Es entstand eine $1 \mathrm{M}$ Natriumacetatlösung. Von dieser Lösung wurden $40 \mathrm{ml}$ entnommen und mit 9,6 ml Essigsäure vermischt. Dieses Gemisch wurde auf ein Gesamtvolumen von $1000 \mathrm{ml}$ mittels destilliertem Wassers aufgefüllt, wodurch die Arbeitslösung (im Folgenden 1B genannt) entstand. Danach wurde die Färbelösung vorbereitet. Hierbei war zu beachten, dass diese einen Tag vor Anwendung hergestellt werden musste. Für die Färbelösung wurden $0,1 \mathrm{~g}$ Cresyl-Violett in $1 \mathrm{~L}$ der Arbeitslösung gelöst. Das Gemisch wurde für 30 Minuten geschüttelt. Bevor die Färbelösung am nächsten Tag genutzt werden konnte, musste sie zuvor gefiltert werden. Für die Delipidation mussten ergänzend Stammlösung (im 
Folgenden 3A genannt), bestehend aus $20 \mathrm{ml}$ Triton X-100 und $980 \mathrm{ml}$ destilliertem Wasser sowie Arbeitslösung (im Folgenden 3B genannt) angesetzt werden.

\subsubsection{Zweiter Tag der Färbung}

Am nächsten Tag wurde mit der Delipidation der Schnitte begonnen. Zuerst wurden die Schnitte in eine Färbeküvette gegeben und zehn Minuten 1B ausgesetzt. Danach wurde 1B durch neue Arbeitslösung 1B ausgetauscht und wieder zehn Minuten gewartet. Anschließend wurde $1 \mathrm{~B}$ entfernt und durch $3 \mathrm{~B}$ ersetzt. Es folgte eine 20-minütige Inkubation mit 3B. Nach Entfernung von 3B wurde nochmals zehn Minuten mit 1B inkubiert. Nach diesem Schritt war die Delipidation abgeschlossen. Es folgte die Färbung.

Als erster Schritt wurde dafür die am Vortag hergestellte Färbelösung gefiltert. Die Schnitte wurden für jeweils acht Minuten in die Färbelösung gegeben. Danach wurde die Färbelösung gewechselt, indem die Schnitte in eine neue Küvette mit frischer gefilterter Färbelösung kamen. Auf die Färbung folgte die Dehydaration. Die Schnitte wurden zu Beginn dreimal für jeweils eine Minute in 1B gegeben. Die Lösung wurde nach jeder Minute gewechselt. Es folgten drei Minuten in 100\%igem Ethanol. Anschließend verblieben die Schnitte für zehn Minuten in Isopropanol. Die Dehydaration wurde mit jeweils zweimal fünf Minuten in Xylol abgeschlossen. Zum Schluss wurden die Schnitte auf den Objektträgern mit Roti®-HistokittEinschlussmittel eingebettet.

\subsection{Stereologie}

\subsubsection{Ablauf und Methodik}

Nach der Färbung konnte mit der stereologischen Auswertung des GD begonnen werden. Anhand des Mausebildatlanten von Paxinos und Franklin wurde die Region des GD auf Bregma -1.34 - -3.64 festgelegt. Die Design-basierte stereologische (Design based stereology) Quantifizierung der Neurone des GD wurde mit dem Mikroskop BX51 von Olympus durchgeführt. Als Software diente Stereoinvestigator 7.

Mittels Design-basierter Stereologie können sehr konkrete Aussagen über Volumen, durchschnittliche Dicke und Zellzahl einer jeweiligen Hirnregion getroffen werden. Die Ergebnisse sind repräsentativ und erwartungsgetreu für eine gesamte betrachtete Region und unterliegen nur einem sehr geringen systematischen Fehler. Die Grundlage der Designbasierten Stereologie ist die sogenannte systematische Stichprobe. Alle Schnitte haben einen festgelegten Abstand von $300 \mu \mathrm{m}$ zueinander, da jeder Schnitt $30 \mu \mathrm{m}$ dick ist und nur jeder 
zehnte Schnitt für die Auswertung genutzt wird. Die Herstellung der Schnitte wurde in 2.3.1 erläutert. Auf den jeweiligen Schnitten werden nun Zählbereiche, sogenannte Counting frames, durch zuvor angegebene Parameter festgelegt.

Tabelle 11: Parameter zur stereologischen Auswertung

\begin{tabular}{|l|l|}
\hline Counting Frame Area $(\mathrm{XY})\left(\mu \mathrm{m}^{2}\right)$ & 196 \\
\hline Disector Height $(\mathrm{Z})(\mu \mathrm{m})$ & 5 \\
\hline Disector Volumen $(\mathrm{XYZ})\left(\mu \mathrm{m}^{3}\right)$ & 980 \\
\hline Shape Factor & 13,18 \\
\hline Counting Frame Width $(\mathrm{X})(\mu \mathrm{m})$ & 14 \\
\hline Counting Frame Height $(\mathrm{Y})(\mu \mathrm{m})$ & 14 \\
\hline Sampling Grid $(\mathrm{X})(\mu \mathrm{m})$ & 133 \\
\hline Sampling Grid $(\mathrm{Y})(\mu \mathrm{m})$ & 75 \\
\hline Sampling Grid Area $(\mathrm{XY})\left(\mu \mathrm{m}^{2}\right)$ & 9975 \\
\hline Section Thickness $(\mu \mathrm{m})$ & 30 \\
\hline Section Periodicty & 10 \\
\hline Focus Method & Manual \\
\hline Refocus to the top of the section & Every grid site \\
\hline
\end{tabular}

Um eine Region für die Design-basierte Stereologie auszuwählen, wurde zunächst in der vierfachen Vergrößerung mit dem Mikroskop BX51 von Olympus der Objektträger abgefahren. Handelte es sich bei einer Region um einen Teil des GD, wurde diese manuell umrandet und somit für die Design-basierte Stereologie ausgewählt. In der 100-fachen Vergrößerung wurde die Neuronenzahl in der ausgewählten Region bestimmt. Die ausgewählte Region wurde anschließend mit einem Raster aus Zählbereichen überzogen. Innerhalb eines Zählbereichs wurde nach den unten beschriebenen Zählregeln die Anzahl der Neuronen bestimmt. Die Zählbereiche verteilen sich gleichmäßig auf den Schnitten und haben immer den gleichen Abstand zueinander. Dadurch besteht für alle Teile der zuvor ausgewählten Region die gleiche Wahrscheinlichkeit von einem Zählbereich erfasst zu werden.

Bei einem Zählbereich handelt es sich um eine dreidimensionale Region, die aus einer x-, y- und z-Achse besteht. Es entsteht somit ein sechsseitiger Würfel. Zunächst muss die zAchse, die der Dicke eines jeden Würfels entspricht, gemessen werden, um das Volumen des Zählbereiches konstant zu erhalten. Anderenfalls würde sich das Gesamtergebnis verfälschen. 
Anschließend kann die Neuronenzahl des jeweiligen Zählbereiches bestimmt werden. Um keine fälschlichen Ergebnisse zu produzieren, wurden zuvor Zählregeln festgelegt (Schmitz und Hof 2005). Ein Zählbereich ist in Abbildung 8 exemplarisch dargestellt.

\subsubsection{Zählregeln}

1. Zuerst wird die Dicke des Bereiches bestimmt. Hiernach können mittels Durchfokussierung die Nuclei der Zellen betrachtet und anschließend markiert werden. Dabei ist wichtig, dass nur Nuclei gezählt werden, die sich innerhalb der ermittelten Schnittdicke befinden. Zellen außerhalb dieser werden nicht erfasst.

2. Die jeweiligen Zählbereiche bestehen aus sechs Seiten. Drei aneinandergrenzende Seiten (in Abbildung 8 rot markiert) sind Ausschlussgrenzen. Die übrigen Grenzen (in Abbildung 8 grün markiert) sind Einschlussgrenzen. Berührt eine Zelle eine Ausschlussgrenze, selbst wenn sie eine Einschlussgrenze berührt, wird sie nicht mitgezählt. Es werden nur Zellen gezählt, die innerhalb des Zählbereichs liegen und dabei keine Ausschlussgrenze berühren sowie Zellen, die außerhalb des Zählbereichs liegen, jedoch eine Einschlussgrenze berühren. 

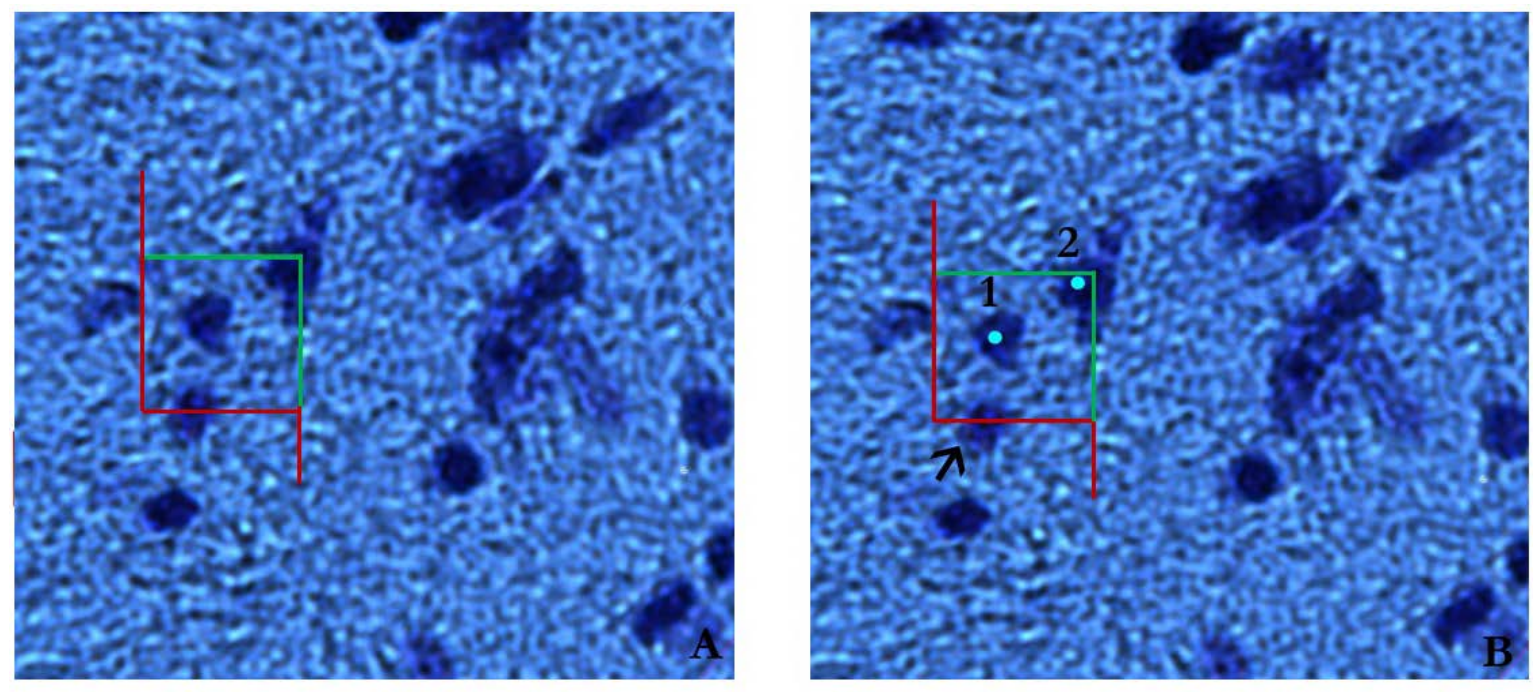

Abbildung 8: Darstellung des stereologischen Zählbereichs. Abbildung A: Zählbereich ohne ausgewählte Neurone. Abbildung B: Zwei Neurone wurden im Sinne der Zählregeln ausgewählt. 1: Neuron wird mitgezählt, da es sich im Zählbereich befindet, ohne eine Ausschlussgrenze (rote Markierungen) zu berühren. 2: Neuron wird mitgezählt, da es beide Einschlussgrenzen (grüne Markierungen) berührt. Pfeil: Neuron wird nicht mitgezählt, da es eine Ausschlussgrenze berührt, obwohl es sich zum Teil im Zählbereich befindet.

Nachdem die Neurone eines Zählbereichs erfasst wurden, wechselt die Software automatisch zum nächsten Zählbereich bis alle Zählbereiche der markierten Region ausgewertet wurden. Dies wurde so oft wiederholt bis alle Abschnitte des GD des Tieres betrachtet und ausgewertet waren.

\subsubsection{Berechnung der Gesamtzahl der Neuronen im Gyrus Dentatus}

Anschließend wurde mittels weiter untenstehender Formeln auf die Gesamtzahl der Neuronen und das Volumen der Gehirne geschlossen. Diese errechnet sich mittels der optical fractionator methode (West et al. 1991).

Die Gleichungen stellen sich wie folgt dar und geben Aufschluss über die Neuronenzahl einer Hemisphäre. Gleichung (1) gibt die Gesamtgleichung an. Gleichung (2), (3) und (4) geben an wie sich die einzelnen Faktoren aus Gleichung (1) zusammensetzen.

$$
p=\operatorname{as} f \times s s f \times t s f
$$




$$
\text { asf }=\frac{\text { sampling grid area }(x y)}{\text { counting frame area }(x y)}
$$

ssf $=10$ da nur jeder zehnte Schnitt verwendet wird

$$
\text { tsf }=\frac{\text { number weighted mean section thickness }}{\text { disector height }(Z)}
$$

$$
\text { Nschnittx }=p \times \text { markers counted }
$$

Im Anschluss werden die Gesamtneuronenzahlen $\left(\mathbf{N}_{\text {gesamt }}\right)$ der Abschnitte $\left(\mathbf{N}_{\text {schnittX }}\right)$ addiert und man erhält die Neuronenzahl des gesamten Gehirns.

$\boldsymbol{N g e s a m t}=\mathbf{N}$ schnitt $1+\boldsymbol{N}$ schnitt $2+\boldsymbol{N} \operatorname{schnit} 3+\cdots$ 


\subsubsection{Berechnung des Volumens des Gyrus Dentatus}

Zur Berechnung des Volumens des GD einer Hemisphäre wurde die Formel „Cavalieri’s Estimator of Morphometric Volume Vc" verwendet.

$$
V c=d\left[\sum_{i=1}^{n}(y i)\right]-(t) y \max
$$

$$
\begin{aligned}
& d=\text { Abstand zwischen den analysierten Schnitten }=300 \mu \mathrm{m} \\
& y_{i}=\text { Fläche von Schnitt }{ }_{\mathrm{i}}\left[\mu \mathrm{m}^{2}\right] \\
& t=\text { jeweilige Schnittdicke }[\mu \mathrm{m}] \\
& y_{\max }=\text { größte gemessene Fläche }[\mu \mathrm{m}]
\end{aligned}
$$

Das Produkt (t) $\mathbf{y}_{\max }$ wird zur Korrektur einer möglichen Überschätzung von der Basisformel ,d $\left[\sum_{\boldsymbol{i}=\mathbf{1}}^{\boldsymbol{n}}(\boldsymbol{y} \boldsymbol{i})\right]-(\mathrm{t}) \mathrm{y}_{\max }{ }^{\prime \prime}$ subtrahiert 


\subsection{Doublecortin-Färbung}

\subsubsection{Prinzip der indirekten Immunhistochemie}

Das Prinzip der indirekten Immunhistochemie wird für die Färbung mit den primären Antikörpern Doublecortin und GFAP genutzt. Die primären Antikörper sind gegen spezifische Epitope gerichtet, mit denen sie eine Antikörper-Antigen-Bindung eingehen. Um eine Färbung, ein Signal dieser Bindung, zu erhalten, wird die indirekten Immunhistochemie genutzt. Hierbei wird ein mit Biotin markierter sekundärer Antikörper hinzugegeben, der sich mit der Fc-Region des primären Antikörpers verbindet. Demzufolge muss der sekundäre Antikörper gegen die Spezies gerichtet sein, aus der der primäre Antikörper stammt. Im nächsten Schritt wird ein Avidin-Biotin-Comlpex (ABC), bestehend aus Avidin und Biotin, an welches das Enzym Meerrettichperoxidase gebunden ist, hinzugegeben. Das Avidin verbindet sich mit dem Biotin des sekundären Antikörpers, wodurch die Meerrettichperoxidase ebenfalls mit diesem gekoppelt wird. Wird Diaminobenzidin (DAB) und $\mathrm{H}_{2} \mathrm{O}_{2}$ hinzugegeben, wandelt die Meerrettichperoxidase ihr Substrat $\mathrm{H}_{2} \mathrm{O}_{2}$ in Protonen und Wasser um. Die freien Protonen färben das DAB bräunlich. Die Zielepitope werden sichtbar.

\subsubsection{Herstellung der histologischen Schnitte zur indirekten „Free-floating DAB- Immunfärbung“ mit Doublecortin}

Die Herstellung der histologischen Schnitte für die Doublecortinfärbung erfolgte genau wie die Herstellung der histologischen Schnitte für die stereologische Auswertung, die bereits in 2.3.1 beschrieben wurde.

Tabelle 12 gibt Auskunft über die verwendeten Tiere.

Tabelle 12: Verwendete Tiere zur Doublecortinfärbung

\begin{tabular}{|l|l|l|l|l|l|}
\hline & 2 Monate & 3 Monate & 4 Monate & 5 Monate & 6 Monate \\
\hline Tg4-42 & 3 & 3 & 4 & 3 & 4 \\
\hline WT & & 3 & & & 3 \\
\hline
\end{tabular}

Um Neurone im Zustand der Neurogenese darzustellen, wurden die gefrorenen Schnitte mit einem Antikörper gegen Doublecortin gefärbt. Doublecortin ist ein Marker-Protein, das von neugebildeten unreifen Neuronen exprimiert wird. Die Quantifizierung von Doublecortin- 
Neuronen stellt exakt die Veränderungen der adulten Neurogenese dar (Couillard-Despres et al. 2005). Der Antikörper wurde in einer Konzentration von 1:500 verwendet.

Nachfolgend werden die hierfür verwendeten Materialien alphabetisch aufgelistet.

\subsubsection{Chemikalien}

- DAB Stocksolution

- Doublecortin Antikörper (1:500) (Santa Cruz Biotechnology, Dallas, Texas, USA)

- Roti ${ }^{\circledR}$-Histokitt-Einschlussmittel Ethanol (70\%, 95\%, 100\%)

- FCS (Biochrom GmbH, Berlin, Deutschland)

- Hemotoxylin (Carl Roth GMBH + CO. KG, Karlsruhe, Deutschland)

- $\mathrm{H}_{2} \mathrm{O}_{2}(30 \%)$ (Carl Roth GMBH + CO. KG, Karlsruhe, Deutschland)

- Milchpuder (Carl Roth GMBH + CO. KG, Karlsruhe, Deutschland)

- PBS 0.01 M (Biochrom GmbH, Berlin, Deutschland)

- Tris / HCl (Carl Roth GMBH + CO. KG, Karlsruhe, Deutschland)

- Triton (0.1\%) (Carl Roth GMBH + CO. KG, Karlsruhe, Deutschland)

- Vectastain ABC-Kit (Vector Laboratories, Burlingame, Kalifornien, USA)

- Xylol (Carl Roth GMBH + CO. KG, Karlsruhe, Deutschland)

\subsubsection{Weitere Hilfsmittel}

- Free-floating-Siebe

Um eine suffiziente und gleichmäßige Färbung der $30 \mu \mathrm{m}$ dicken Schnitte von allen Seiten zu erreichen, wurde das „Free-floating-Verfahren“ verwendet. Im nachfolgenden Abschnitt ist der Ablauf der Free-floating DAB-Immunfärbung im Detail erläutert.

\subsubsection{Erster Tag der Färbung}

Zu Beginn wurde 0,01 M PBS-Lösung für 30 Minuten bei $4{ }^{\circ} \mathrm{C}$ herunter gekühlt und anschlieBend in einen Behälter mit Eis gestellt. Nach einer weiteren halben Stunde wurden die Hirnschnitte aus einem $-80{ }^{\circ} \mathrm{C}$ kalten Kühlschrank geholt und auf Eis zum Praktikumsplatz transportiert. Die Hirnschnitte wurden mit der heruntergekühlten 0,01 M PBS-Lösung in ihrem Glas befeuchtet. Wichtig war, dass dies mit kalter PBS geschieht, da die Schnitte sonst verkleben würden. Für fünf Minuten verblieben die Schnitte nun in ihren Gläsern. Anschließend wurden die Schnitte zusammen mit PBS in Free-floating-Siebe geschüttet. In den Sieben wurden die Schnitte erneut mit kalter 0,01 M PBS-Lösung befeuchtet. Die Schnitte mussten komplett mit PBS bedeckt sein. Für zehn Minuten verblieben die Schnitte in dieser Lösung. Dies war für die Hydration wichtig. Nachfolgenden wurde die Peroxidase mittels einer Lösung, 
bestehend aus $200 \mathrm{ml}$ 0,01 M PBS und $2 \mathrm{ml} \mathrm{30 \%} \mathrm{H}_{2} \mathrm{O}_{2}$, geblockt. Anschließend folgte ein zehn Minuten langer Waschschritt, bei dem mittels einer Lösung aus 0,01 M PBS und 0,1\% Triton eine Permeabilisation der Membranen erzeugt wurde. Dieser Vorgang wurde dreimal nach jeweils zehn Minuten wiederholt. Nach jedem Vorgang wurde die Lösung gewechselt. Um das Triton wieder zu entfernen, wurden die Schnitte für eine Minute mit frischer 0,01 M PBS gereinigt. Es folgte der unspezifische Block, damit später der Antikörper nur auf dem gewünschten Antigen haften bleibt. Der unspezifische Block setzte sich aus 10\% FCS und 4\% Milchpuder der gewünschten Gesamtlösung zusammen. Das restliche Volumen wurde mit 0,01 M PBS-Lösung aufgefüllt. In dieser Lösung verblieben die Schnitte für mindestens eine Stunde.

Im Anschluss wurden die Schnitte mit dem primären Antikörper bis zum nächsten Tag inkubiert. Die Lösung für die primären Antikörper enthielt Doublecortin in der Konzentration 1:500 und 10\% FCS des gewünschten Gesamtvolumens. Das restliche Volumen wurde mit 0,01 M PBS aufgefüllt.

\subsubsection{Zweiter Tag der Färbung}

Nach der nächtlichen Inkubation der Schnitte mit dem primären Antikörper folgte ein 30minütiger Waschvorgang. Hierfür wurden die Siebe für jeweils zehn Minuten in frische PBSLösung plus 0,1\% Triton gestellt, um eine Reduzierung der Oberflächenspannung zu erreichen und die Permeabilität zu steigern. Es folgte ein ein-minütiger Waschgang mit PBS, um die Zellen von der PBS-Triton-Lösung zu lösen. Im Folgenden konnte der sekundäre Antikörper hinzugegeben werden. Es handelte sich um einen biotinylierten Antikörper eines Kaninchens. Der sekundäre Antikörper wurde in einer Verdünnung von 1:250 auf die Zellen gegeben. In der Lösung waren weiterhin 10\% FCS und PBS 0,01 M enthalten. Die Lösung verblieb für zwei Stunden bei Raumtemperatur auf den Schnitten. Der sekundäre Antikörper bindet an den primären Antikörper und führt somit im nächsten Schritt zur Sichtbarwerdung der Biotinylierung durch die ABC-Lösung. Nach der Inkubation mit dem sekundären Antikörper wurden die Schnitte zunächst dreimal für jeweils zehn Minuten mit PBS 0,01 M gereinigt. Nach dem Waschschritt folgte eine Inkubation für 1,5 Stunden mit der ABC-Lösung. Die ABC-Lösung enthielt 10\% FCS, Lösung A und B in einer Verdünnung von jeweils 1:200 und PBS 0,01 M. Das Avidin in dieser Lösung kann an das Biotin des sekundären Antikörpers binden. Es folgte ein weiterer 30-minütiger Waschschritt mit PBS. Anschließend wurden die Schnitte für vier Minuten einer DAB-Lösung ausgesetzt. Diese enthielt $5 \mathrm{ml} 50 \mathrm{mM}$ Tris/HCl $\left(\mathrm{pH}\right.$ 7,5), $100 \mu \mathrm{ml}$ DAB-Stocksolution und 2,5 $\mu \mathrm{ml}$ 30\%iges $\mathrm{H}_{2} \mathrm{O}_{2}$. Das Wasserstoffperoxid wurde der Lösung erst kurz vor Beträufelung der Schnitte hinzugegeben. Anschließend folgte 
erneut ein 30-minütiger Waschschritt mit PBS 0,01 M. Im Anschluss konnten die Schnitte auf Objektträger gebracht und über Nacht getrocknet werden.

\subsubsection{Dritter Tag der Färbung}

Am dritten Tag wurde mit einem zehnminütigen Waschschritt mit PBS 0,01 M begonnen. Die Schnitte wurden für 40 Sekunden einer Gegenfärbung mit Hämatoxylin unterzogen. Anschließend folgte eine aufsteigende Alkoholreihe zur Dehydratisierung der Schnitte. Die Dehydratisierung wurde mit einer Inkubationszeit von einer Minute in 70\%igem Ethanol begonnen. Die Reihe wurde fortgesetzt mit fünf Minuten in 95\%igem Ethanol und zehn Minuten in 100\%igem Ethanol. Zuletzt wurden die Schnitte zweimal für jeweils fünf Minuten in Xylol gegeben. Anschließend wurden die Schnitte mit Deckgläschen und Rotiß-HistokittEinschlussmittel versehen.

\subsubsection{Auswertung der Doublecortinfärbung}

Die Auswertung fand mit der Software Stereoinvestigator 7 sowie dem Mikroskop BX51 von Olympus statt. Hierzu wurden zunächst in der vierfachen Vergrößerung des Mikroskops auf den angefärbten Schnitten die GD aufgesucht sowie markiert und anschließend in der 100fachen Vergrößerung genauer betrachtet und ausgewertet. Die Doublecortin-aufnehmenden Neurone stellen sich bräunlich dar. Perikarya, die sich bräunlich darstellen wurden manuell markiert und somit von der Software erfasst. Dabei wurde darauf geachtet, dass nur angefärbte Perikarya und nicht zusätzlich angefärbte Axone gezählt wurden, um fälschliche Ergebnisse zu vermeiden. Ein Perikaryon und ein Axon bilden zusammen ein Neuron (vgl. Abbildung 9). Es ergab sich eine bestimmte Menge von gezählten Perikarya pro ausgewähltem Bereich $\left(\mathbf{N}_{\text {Einzel }}\right)$. Anschließend wurden die Perikarya aller ausgewählten Bereiche addiert, sodass sich die Neuronenzahl aller betrachteten Schnitte $\left(\mathbf{N}_{\text {schnitt }}\right)$ ermitteln ließ.

$$
\text { Nschnitt }=\text { Neinzel } 1+\text { Neinzel } 2+\text { Neinzel } 3+\cdots
$$

Da wie bei der zuvor beschriebenen Methode der Stereologie nur jeder zehnte Schnitt eines

Tieres verwendet wurde, musste die Neuronenzahl aller betrachteten Schnitte $\left(\mathbf{N}_{\text {Schnitt }}\right)$ mit 
dem Faktor zehn multipliziert werden, um die Gesamtneuronenzahl $\left(\mathbf{N}_{\text {gesamt }}\right)$ des GD einer Hemisphäre zu bestimmen.

$$
\text { Ngesamt }=\text { Nschnitt } \times 10
$$

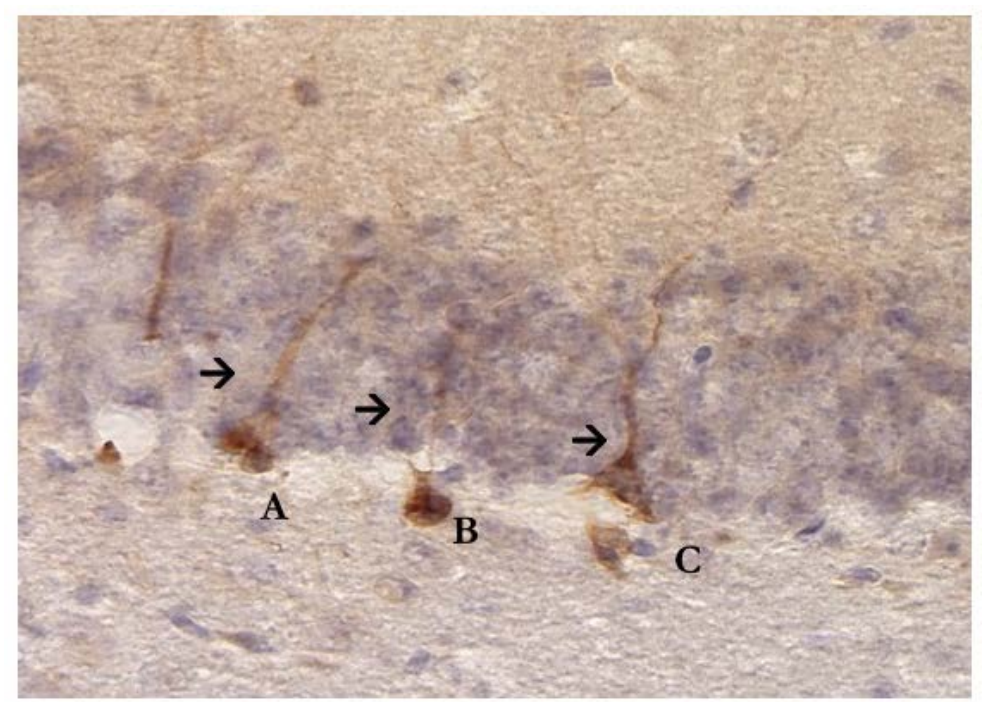

Abbildung 9: Darstellung der Doublecortinfärbung. Perikarya (A, B, C) mit ihren zugehörigen Axonen (Pfeile) werden als Neurone markiert

\subsection{GFAP-Färbung}

\subsubsection{Präparatherstellung zur immunhistochemischen Färbung mit GFAP und Quantifizierung der gefärbten Präparate}

Für die immunhistochemische Färbung des sauren Gliafaserprotein (GFAP) und die anschlieBende Quantifizierung der Präparate wurden Tiere im Alter von sechs Monaten verwendet. Die Anzahl der Tiere ist Tabelle 13 zu entnehmen. 
Tabelle 13: Verwendete Tiere zur GFAP-Quantifizierung

\begin{tabular}{|l|l|}
\hline & 6 Monate \\
\hline Tg4-42 & 3 \\
\hline WT & 3 \\
\hline
\end{tabular}

Nach Entnahme der Gehirne wurde die rechte Hemisphäre bei $-80^{\circ} \mathrm{C}$ eingefroren und die linke in Paraffin eingebettet. Aus der linken Hemisphäre stammten die für die immunhistochemische Färbung und Quantifizierung verwendeten Schnitte. Diese wurden mittels Mikrotom erstellt und hatten eine Dicke von $4 \mu \mathrm{m}$.

Zunächst wurden die Paraffinblöcke auf einer eiskalten Oberfläche gelagert, um ein Schmelzen des Paraffins zu verhindern. Anschließend wurden die Paraffinblöcke ins Mikrotom eingespannt und auf eine Schichtdicke von $4 \mu \mathrm{m}$ geschnitten. Danach wurden die Schnitte vom Mikrotom vorsichtig in kaltes destilliertes Wasser gelegt und von dort in ein $52{ }^{\circ} \mathrm{C}$ warmes Wasserbad zur Glättung überführt. Anschließend wurden sie auf Objektträger („SuperfrostPlus“, 25 x 75x 1,0 mm, Menzel GmbH \& Co KG, Braunschweig) gezogen. Um im weiteren Verlauf mit der Färbung der Schnitte beginnen zu können, mussten die Schnitte zunächst über Nacht bei $37^{\circ} \mathrm{C}$ getrocknet werden.

\subsubsection{Indirekte immunhistochemische Färbung der Paraffinschnitte zur nachfolgenden Quantifizierung}

\subsubsection{Erster Tag der Färbung}

Zu Beginn wurde eine Deparaffinierung der Präparate mit Xylol für zweimal fünf Minuten vollzogen. Anschließend folgte eine Rehydratisierung in aufsteigender Alkoholreihe. Für die Rehydratisierung wurden die Schnitte zuerst 100\%igem Ethanol für zehn Minuten, anschlieBend fünf Minuten 95\%igem und zuletzt drei Minuten 70\%igem Ethanol ausgesetzt. Es folgte eine ein-minütige Phase in destilliertem Wasser. Nach der Rehydratation folgte die Blockade der endogenen Peroxidasen, da diese bei einer DAB-Färbung Ursache für unspezifische Hintergrundfärbungen seien können. Der Peroxidaseblock setzte sich aus $200 \mathrm{ml}$ 0,01 M PBS und $2 \mathrm{ml} 30 \%$ igem $\mathrm{H}_{2} \mathrm{O}_{2}$ zusammen. Die Schnitte verblieben für 30 Minuten in der Lösung. Es folgte eine ein-minütige Phase in destilliertem Wasser. Um die Epitope des Gewebes ausreichend zum Vorscheinen bringen zu können, wurden die Schnitte für zehn Minuten in 0,1 M Citratpuffer in der Mikrowelle erhitzt. Es folgte eine 15-minütige Abkühlung bei Raumtemperatur. Hiernach folgte ein Waschvorgang für 15 Minuten mit 0,01 M PBS und 0,1\% Triton, 
um eine Permeabilisationssteigerung der Membranen der Schnitte zu erreichen. Als nächstes wurden die Schnitte für eine Minute 0,01 M PBS ausgesetzt. Um die Signalstärke des DABs zu verbessern, wurden die Schnitte für drei Minuten mit 88\% iger Ameisensäure vorbehandelt. Es folgte ein sechs-minütiger Waschvorgang mit 0,01 M PBS. Vor der Inkubation mit dem primären Antikörper wurden die Schnitte mit einem Fettstift umrahmt und anschließend mit einem Block gegen unspezifische Proteinbindestellen beträufelt, welcher für mindestens eine Stunde bei Raumtemperatur auf den Schnitten verbleiben musste. Der unspezifische Block setzte sich aus 10\% FCS und 4\% Milchpuder zusammen. Das restliche Volumen wurde durch 0,01 M PBS ergänzt. Nach der einstündigen Inkubation wurde der primäre Antikörper (GFAP) verwendet. Der primäre Antikörper wurde in einer Konzentration von 1:500 mit 10\% FCS und 0,01 M PBS auf die Schnitte gegeben. Die Schnitte verblieben über Nacht bei Raumtemperatur. Der primäre Antikörper lagerte sich in dieser Zeit an die Zielstrukturen im Gewebe an. Die Sichtbarwerdung der Verbindung vollzog am zweiten Tag der Färbung.

\subsubsection{Zweiter Tag der Färbung}

Am folgenden Tag wurden die Schnitte für 15 Minuten in 0,01 M PBS und 0,1\% Triton gewaschen. Es folgte die Inkubation mit dem biotinyliertem sekundären Antikörper (AntiMeerschweinchen) in einer Konzentration von 1:200 sowie mit 10\% FCS und 0,01 M PBS für eine Stunde bei $37^{\circ} \mathrm{C}$ im Wärmeschrank. Dieser sekundäre biotinylierte Antikörper lagerte sich an den primären Antikörper an, wodurch die Bindung des primären Antikörpers an seiner Zielstruktur sichtbar wurde. Während der Inkubation mit dem sekundären Antiköper wurde die ABC-Lösung, bestehend aus Lösung A und Lösung B, in einer Verdünnung von jeweils 1:100, 10\% FCS und 0,01 M PBS vorbereitet, da diese vor Anwendung für 30 Minuten bei $4{ }^{\circ} \mathrm{C}$ gekühlt werden musste. Nach Inkubation mit dem sekundären Antiköper folgte ein weiterer 15-minütiger Waschschritt mit 0,01 M PBS, um nachfolgend mit der ABC-Inkubation für eineinhalb Stunden bei $37^{\circ} \mathrm{C}$ im Wärmeschrank fortzufahren. Durch die Inkubation mit ABC wurde das Signal, welches vom sekundären Antikörper erzeugt wurde, deutlich verstärkt.

Das in der ABC-Lösung enthaltene Avidin bindet an das Biotin des sekundären Antikörpers. Das Avidin wiederum besitzt drei weitere Biotinbindestellen. An das Biotin kann erneut Avidin binden, wodurch das Signal potenziert wird.

Nach der Inkubation mit der ABC-Lösung folgte ein Waschschritt mit 0,01 M PBS für 15 Minuten. Anschließend folgte die DAB-Färbung. Hierzu wurden $5 \mathrm{ml} 50 \mathrm{mM}$ Tris/HCl mit einem pH von 7,5 sowie $100 \mu \mathrm{l}$ DAB-Stammlösung und $2.5 \mu \mathrm{l} 30 \%$ iges $\mathrm{H}_{2} \mathrm{O}_{2}$ miteinander vermengt. Das Wasserstoffperoxid wurde erst kurz vor Anwendung der Lösung hinzugegeben. 
Das Avidin aus der ABC-Lösung verbindet nun den sekundären Antikörper mit dem hinzugegebenen DAB. Dadurch wird DAB als Peroxidase aktiviert und nutzt das $\mathrm{H}_{2} \mathrm{O}_{2}$ als Substrat. Dabei werden Protonen und Wasser frei. Die freigewordenen Protonen oxidieren anschließend die Zielstruktur und färben das DAB braun.

Die Inkubation der Schnitte erfolgte unter mikroskopischer Kontrolle. Das DAB verweilte solange auf den Schnitten bis eine eindeutige Braunfärbung der Zielstruktur auszumachen war und somit die individuelle Färbedauer ermittelt werden konnte. Nach einem weiteren Waschschritt von 15 Minuten mit 0,01 M PBS folgte eine Gegenfärbung mit Hämatoxylin für 40 Sekunden. Die Schnitte wurden kurz in destilliertes Wasser getaucht und anschließend mit fließendem Leitungswasser abgespült. Nach einer aufsteigenden Alkoholreihe, beginnend mit einer Minute in 70\%igem Ethanol, fünf Minuten in 95\%igem 100\% igem Ethanol wurden die Schnitte für zweimal fünf Minuten mit Xylol behandelt, sodass die Präparate anschließend mit Roti®-Histokitt-Einschlussmittel eingebettet und mit Deckgläschen abgedeckt werden konnten.

\subsubsection{GFAP-Bestimmung}

Zur Quantifizierung wurden pro Genotyp drei Tiere im Alter von sechs Monaten ausgewählt (vgl. Tabelle 13). Pro Tier wurden drei Paraffinschnitte mit GFAP und DAB als Chromogen gefärbt. Anschließend wurden die gefärbten Schnitte mit einem BX-51 Mikroskop Olympus analysiert. Fotos wurden in der 20-fachen Vergrößerung mittels einer DP-50 Kamera, ebenfalls von Olympus, aufgenommen. Die quantitative Auswertung der mit GFAP gefärbten Fläche wurde mit der Software „ImageJ“ (NIH, USA) durchgeführt. Nachdem die aufgenommenen Bilder in „ImageJ“ in 8-bit-schwarz-weiß-Bilder binarisiert wurden, wurde für alle Bilder ein Schwellenwert festgelegt (siehe Abbildung 10). Sofern notwendig wurde für einzelne Bilder der Auswahlrahmen individuell neu kalibriert, um mögliche Hintergrundmessungen so gering wie möglich zu halten. Die von DAB bedeckten Areale wurden von „ImageJ“ in Prozent zur Gesamtfläche angegeben. Die prozentualen Anteile wurden anschließend in Excel kopiert und normalisiert. Hierzu wurde der Mittelwert aus den Prozentwerten aller WT-Tiere ermittelt und als Normalisierungskoeffizient genutzt. Alle Prozentwerte wurden nun durch diesen Normalisierungskoeffizienten dividiert und mit dem Faktor 100 multipliziert. Pro Tier ergaben sich drei normalisierte Prozentwerte, aus welchen wiederrum der Mittelwert gebildet wurde. Die neu entstandenen Mittelwerte wurden anschließend in „GraphPad Prism6“ importiert, um den Graphen zu erzeugen. 

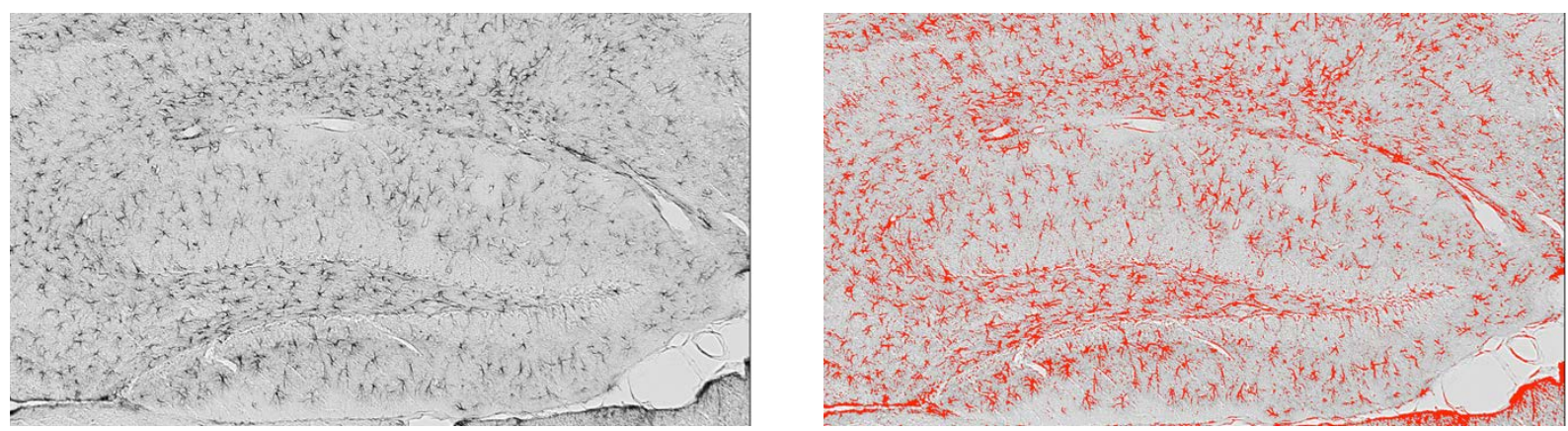

Abbildung 10: Quantifizierung GFAP-positiver Astrozyten. Die Originalaufnahme wurde in ein 8-bit-schwarz-weiß-Bild umgewandelt (linkes Bild). Anschließend wurde die Intensitätsschwelle zur Bestimmung der DAB-Färbung festgelegt (rechtes Bild). Die rotmarkierten Bereiche werden von ImageJ als DAB-Färbung erkannt und als Prozentwert zur Gesamtfläche angegeben.

\subsection{Real-time-PCR-Analyse}

Die Polymerase-Kettenreaktion (PCR) kann in drei Schritte untergliedert werden, welche alle in einem Thermocycler durchgeführt werden. Im ersten Schritt wird die Ausgangs-DNA für zehn Minuten einer Temperatur von $95^{\circ} \mathrm{C}$ unterzogen. Die führt zur Aktivierung der taqPolymerase. Die taq-Polymerase ist extrem hitzestabil und hält Temperaturen von über $95^{\circ} \mathrm{C}$ aus. Danach verbleibt die Temperatur für weitere 15 Sekunden bei $95^{\circ} \mathrm{C}$. Die DoppelstrangDNA wird in zwei Einzelstränge aufgespalten. Im zweiten Schritt folgt bei $58{ }^{\circ} \mathrm{C}$ für 30 Sekunden eine Anlagerung der Primer, das sogenannte annealing. Im dritten Schritt kommt es zur Elongation der Einzel-DNA-Stränge an den sich zuvor angelagerten Primer. Während dieses Schrittes wird das Lösung für 20 Sekunden einer Temperatur von $72{ }^{\circ} \mathrm{C}$ ausgesetzt. Die Elongation beginnt an dem am 3'-Ende angelagertem Primer und synthetisiert, dem alten DNA-Strang folgend, den neuen DNA-Strang in 5'-3'-Richtung. Danach wird das Gemisch wieder für 15 Sekunden auf $95^{\circ} \mathrm{C}$ erhitzt. Die Erhitzung hat einen erneuten Strangbruch zur Folge. Die zuvor hergestellten DNA-Stränge können nun als Matrizen für den neuen Zyklus dienen. Ein exponentielles Wachstum neuer DNA-Stränge ist die Folge. Es folgen wieder die Anlagerung der Primer und Elongation der DNA-Stränge. Dieser Vorgang wird 40mal wiederholt (in Tabelle 14 grau unterlegt). Die einzelnen Schritte und jeweiligen Temperaturen sind der untenstehenden Tabelle 14 zu entnehmen. 
Tabelle 14: qPCR-Arbeitsprotokoll

\begin{tabular}{|l|l|l|}
\hline Arbeitsschritt & Temperatur & Dauer \\
\hline 1 & $95^{\circ} \mathrm{C}$ & $10 \mathrm{~min}$ \\
\hline 2 & $95^{\circ} \mathrm{C}$ & $15 \mathrm{sec}$ \\
\hline 3 & $58^{\circ} \mathrm{C}$ & $30 \mathrm{sec}$ \\
\hline 4 & $72{ }^{\circ} \mathrm{C}$ & $20 \mathrm{sec}$ \\
\hline 5 & $\begin{array}{l}\text { Schritte } 2-4 \text { werden wieder- } \\
\text { holt }\end{array}$ & 40 -mal \\
\hline 6 & $95^{\circ} \mathrm{C}$ & $1 \mathrm{~min}$ \\
\hline 7 & $55^{\circ} \mathrm{C}$ & $30 \mathrm{sec}$ \\
\hline 8 & $95^{\circ} \mathrm{C}$ & $30 \mathrm{~min}$ \\
\hline
\end{tabular}

Die quantitative Real-Time-PCR (qPCR) ist eine Methode, um DNA-Mengen, die während eines PCR-Zyklus entstehen, in Echtzeit bestimmen zu können. Hierfür gibt es verschiedene Methoden. Für diese Arbeit wurde sich für den Cyaninfarbstoff SYBR-GREEN basierend auf DyNAmo Flash SYBR Green qPCR Kit (Thermo Fisher Scientific, Waltham, MA, USA) (Qiagen, Hilden) entschieden, welcher ROX als Referenzfärbemittel enthält. SYBER-GREEN interkaliert sequenzunspezifisch mit DNA-Doppelsträngen. Durch die Interkalierung steigt seine Fluoreszenz auf das 1000-fache im Vergleich zur freien Form an. Da dieser Anstieg proportional zur Einlagerung in DNA-Doppelstränge geschieht, kann SYBR-GREEN als Marker zur Bestimmung neu entstandener DNA-Doppelstränge genutzt werden. SYBR-GREEN absorbiert blaues Licht bei einer Wellenlänge von $\lambda_{\max }=494 \mathrm{~nm}$ und emittiert grünes Licht bei einer Wellenlänge von $\lambda_{\max }=521 \mathrm{~nm}$. Die qPCR-Analyse wurde im 384-well Maßstab mit Stratagene MX3000P-Real-Time-Cycle (Waldbronn) durchgeführt. Für die Auswertung wurde die Software MxPro Mx3000P software (Stratagene, Santa Clara, CA, USA) genutzt. Die genutzten Reaktionsansätze sind Tabelle 15 zu entnehmen. Die cDNA-Reagenzien wurden mit der qPCR-Mischung in $200 \mu \mathrm{l}$ großen PCR-Röhrchen (Biozym, Oldendorf, Germany) vermengt und kurz darauf im Spectrafuge Mini (Labnet Inc., Edison, NJ, USA) zentrifugiert. Alle Ansätze wurden mit Hilfe des house-keeping Genes $\beta$-Aktin normalisiert und waren doppelt vorhanden. Messungen wurden erst nach Überschreitung des Ct-Wertes gewertet, welcher den Punkt angibt, ab dem die Fluoreszenzfärbung erstmals die bloße Hintergrundfärbung überschreitet und somit den Beginn des exponentiellen Wachstums beschreibt. 
Tabelle 15: Reagenzien und Volumen der qPCR-Reagenzien

\begin{tabular}{|l|l|}
\hline Reagenzien & Volumen \\
\hline cDNA (1:10 verdünnt) & $2 \mu \mathrm{l}$ \\
\hline MasterMix & $10 \mu \mathrm{l}$ \\
\hline Primer-for & $0,5 \mu \mathrm{l}$ \\
\hline Primer-rev & $0,5 \mu \mathrm{l}$ \\
\hline ROX & $0,4 \mu \mathrm{l}$ \\
\hline ddH $_{2} \mathrm{O}$ & $6,6 \mu \mathrm{l}$ \\
\hline
\end{tabular}

In der vorliegenden Arbeit wurden Wildtyp- und Tg4-42-Tiere hinsichtlich ihrer Expression von GFAP untersucht. Die verwendeten Tiere sind Tabelle 16 zu entnehmen.

Tabelle 16: Verwendete Tiere zur qPCR-Analyse

\begin{tabular}{|l|l|l|l|}
\hline & 2 Monate & 4 Monate & 8 Monate \\
\hline Tg4-42 & 5 & 5 & 5 \\
\hline WT & 5 & 5 & 5 \\
\hline
\end{tabular}

\subsection{Statistische Auswertung}

Statistische Auswertung der erhobenen Daten und Generierung der entsprechenden Graphen erfolgten mit der Software GraphPad Prism 6. Die Rohdaten wurden zunächst mittels one-wayANOVA ausgewertet und mit der Bonferroni-Methode korrigiert. Im Anschluss wurde ein ungepaarter t-Test durchgeführt. In allen Versuchen wurde für jede Altersstufe ein $n \geq 3$ verwendet. P-Werte $<0,05$ wurden als statistisch signifikant bewertet $(* \mathrm{p}<0,05 ; * * \mathrm{p}>0,01$; *** $\mathrm{p}<0,001)$. In allen Graphen sind die Mittelwerte +- Standardabweichung dargestellt. 


\section{Ergebnisse}

\subsection{Quantifizierung der Neuronenzahl im Gyrus Dentatus im Tg4-42- Mausmodell}

Zur vergleichenden Beurteilung der Neuronenzahl im Gyrus Dentatus (GD) des Mausmodells Tg4-42 mit WT-Tieren wurden, wie in Tabelle 10 aufgelistet, transgene Tiere im Alter von zwei bis sechs Monaten und WT-Tiere im Alter von drei und sechs Monaten verwendet. Die Neuronenzahl im GD wurde stereologisch, wie in Abschnitt 2.4 beschrieben, ermittelt. In der statistischen Auswertung mittels GraphPad zeigte sich im Mittel ein Abfall der Neuronenzahl im GD von jungen zu alten Tieren. Diese Beobachtung betraf die transgenen Tiere. Die Rohdaten wurden mittels one-way-ANOVA ausgewertet und mit der Bonferroni-Methode korrigiert. In mehreren Fällen ließ sich ein signifikanter Unterschied der Gesamtneuronenzahl im GD zwischen verschiedenen Altersstufen feststellen. Von drei Monate alten WT-Tieren ausgehend, ließen sich signifikante Unterschiede zu drei Monate $(p<0,05)$, fünf Monate $(p<0,001)$ und sechs Monate $(\mathrm{p}<0,001)$ alten transgenen Tieren feststellen. Von zwei Monate alten transgenen Tieren ausgehend, ergaben sich ebenfalls signifikante Unterschiede zu drei Monate $(p<0,05)$, fünf Monate $(p<0,001)$ und sechs Monate $(p<0,01)$ alten transgenen Tieren. Abbildung 11 bildet den beschriebenen Verlauf graphisch ab und zeigt die mittels one-way-ANOVA berechneten signifikanten Unterschiede. Der p-Wert für die gesamte one-way-ANOVA beträgt $\mathrm{p}=0,0001$. Um die gleichen Altersstufen der beiden Genotypen direkt miteinander zu vergleichen, wurde ein t-Test zwischen drei Monate alten Tieren beider Genotypen und zwischen sechs Monate alten Tieren beider Genotypen durchgeführt. Die Neuronenzahl der transgenen Tiere lag in beiden Fällen deutlich unter der Neuronenzahl der WT-Tiere. In der Gruppe der drei Monate alten Tiere ergab sich ein Unterschied mit einem $p$-Wert von $p=0,026$ und in der Gruppe der sechs Monate alten Tiere mit einem $\mathrm{p}$-Wert von $\mathrm{p}=0,0302$. Tabelle 17 listet die mittels one-way-ANOVA und Tabelle 18 die mittels t-Test ermittelten jeweiligen p-Werte auf. 


\section{Quantifizierung der Neuronenzahl WT versus Tg4-42}
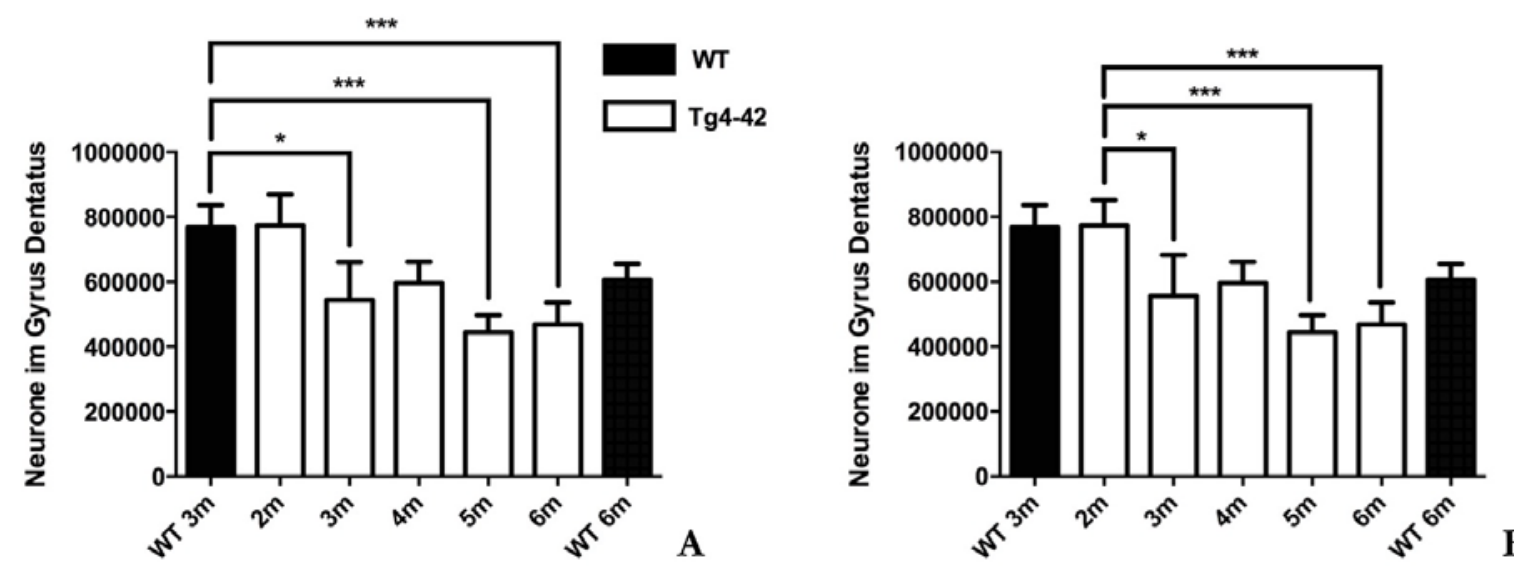

Abbildung 11: Vergleichende Darstellung der quantifizierten Neuronen im Gyrus Dentatus zwischen Wildtyptieren und transgenen Tieren. Es wird der Verlauf der Neuronenzahl von zwei Monate alten zu sechs Monate alten transgenen Tieren (Tg4-42) im Abstand von jeweils einem Monat dargestellt. Als Referenz werden zusätzlich drei und sechs Monate alte WT-Tiere (WT) abgebildet. Von drei bis sechs Monate erkennt man bei den transgenen Tieren einen abfallenden Trend, der durch Fluktuationen bei vier Monate alten Tieren unterbrochen ist. Der besseren Übersicht geschuldet, wurden in Abbildung A die signifikanten Unterschiede von drei Monate alten WT-Tieren zu den transgenen Tieren und in Abbildung $\mathbf{B}$ die signifikanten Unterschiede von zwei Monate alten transgenen Tieren zu den restlichen transgenen Tieren dargestellt. Die mittels one-way-ANOVA bestimmten signifikanten p-Werte sind in Tabelle 17 aufgelistet.

Tabelle 17: Auflistung der in Abbildung 11 dargestellten und mittels one-way-ANOVA berechneten signifikanten $\mathrm{p}$-Werte

\begin{tabular}{|l|l|}
\hline Verglichene Tiere & p-Wert \\
\hline WT 3m versus Tg4-42 3m & $<0,05$ \\
\hline WT3m versus Tg4-42 5m & $<0,001$ \\
\hline WT3m versus Tg4-42 6m & $<0,001$ \\
\hline Tg4-42 $2 \mathrm{~m}$ versus $\operatorname{Tg} 4-423 \mathrm{~m}$ & $<0,05$ \\
\hline Tg4-42 $2 \mathrm{~m}$ versus $\operatorname{Tg} 4-425 \mathrm{~m}$ & $<0,001$ \\
\hline Tg4-42 $2 \mathrm{~m}$ versus $\mathrm{Tg} 4-426 \mathrm{~m}$ & $<0,001$ \\
\hline
\end{tabular}



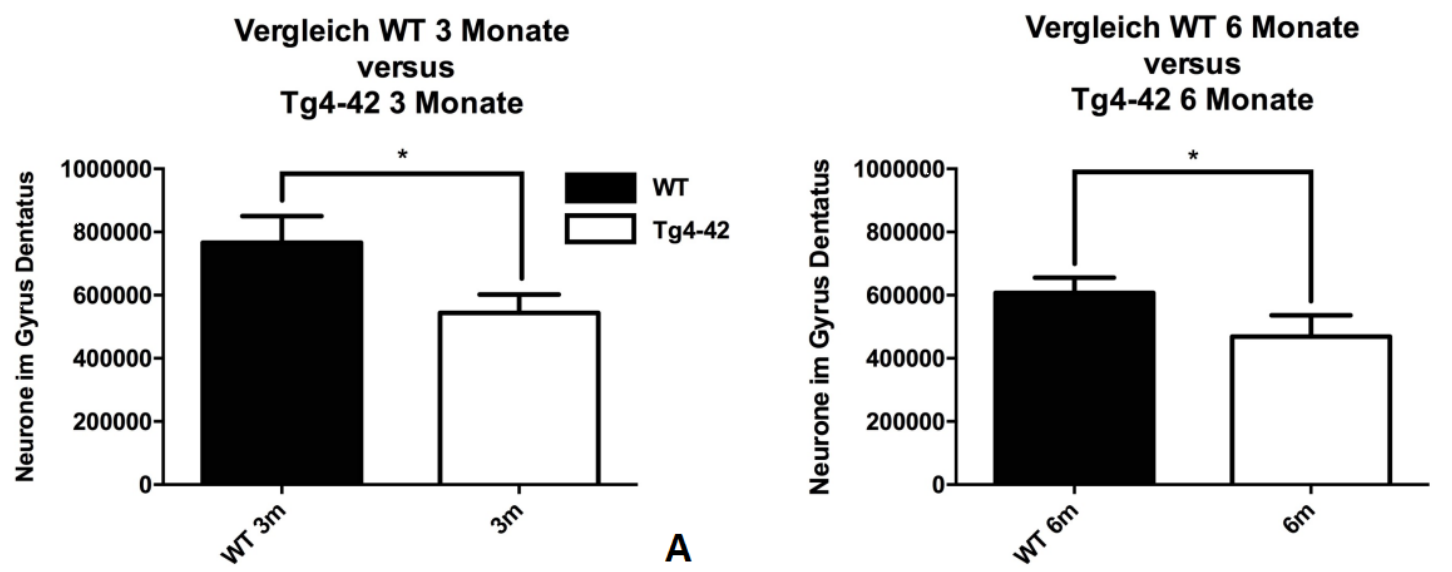

Abbildung 12: Gegenüberstellung der Neuronenzahl im direkten Altersvergleich der beiden Genotypen. In Abbildung A sind drei Monate alte WT-Tiere und transgene Tiere gegenübergestellt. In Abbildung $\mathbf{B}$ sind sechs Monate alte WT-Tiere und transgene Tiere verglichen. In beiden Fällen ergibt sich ein signifikanter Unterschied in der Neuronenzahl. Die im t-Test ermittelten exakten p-Werte sind Tabelle 18 zu entnehmen.

Tabelle 18: Auflistung der in Abbildung 12 dargestellten und mittels t-Test berechneten pWerte zwischen beiden Genotypen im direkten Altersvergleich

\begin{tabular}{|l|l|}
\hline Verglichene Tiere & p-Wert \\
\hline WT $3 \mathrm{~m}$ versus $\operatorname{Tg} 4-423 \mathrm{~m}$ & 0,026 \\
\hline WT $6 \mathrm{~m}$ versus $\operatorname{Tg} 4-426 \mathrm{~m}$ & 0,0302 \\
\hline
\end{tabular}

In Tabelle 19 findet sich eine detaillierte Auflistung aller gezählten Neurone im GD der transgenen Tiere. In Tabelle 20 sind die Werte der WT-Tiere aufgelistet. Beide Tabellen verdeutlichen den in Abbildung 11 und Abbildung 12 graphisch dargestellten zeitlichen Verlauf der Gesamtneuronenzahl im GD. Beim Vergleich der Mittelwerte der ermittelten Gesamtneuronenzahl der verschiedenen Altersstufen der transgenen Tiere ließ sich eine Abnahme der mittleren Gesamtneuronenzahl von zwei Monate alten transgenen Tieren zu sechs Monate alten transgenen Tieren beobachten. Der Verlauf der Gesamtneuronenzahl im GD stellte sich bei transgenen Tieren wie folgt dar: Bei zwei Monate alten transgenen Tieren bestand im Mittel eine Gesamtneuronenzahl im GD von 773930. Dies entspricht in etwa einer physiologischen Anzahl, die mit der mittleren Gesamtneuronenzahl von drei Monate alten WT-Tieren - im Mittel 765839 - vergleichbar ist. Von zwei Monate zu drei Monate alten transgenen Tieren sank die Gesamtneuronenzahl im GD im Mittel auf 556600. Die Neuronenzahl verringerte 
sich zwischen diesen beiden Altersstufen um 217329 Neurone und somit um 28,08\%. Zwischen drei und vier Monate alten transgenen Tieren ließ sich kein Verlust der Gesamtneuronenzahl im GD beobachten. Zwischen vier auf fünf Monate alten transgenen Tieren verringerte sich die Gesamtneuronenzahl im GD um 151282 Neurone. Vier Monate alte transgene Tiere wiesen 596052 Neurone und fünf Monate alte transgene Tiere wiesen 444769 Neurone auf. Dies entsprach einem Abfall um 25,4\% und war in der Stärke vergleichbar mit dem Verlust zwischen zwei und drei Monate alten Tieren. Zwischen fünf und sechs Monate alten transgenen Tieren ließ sich - wie zwischen drei und vier Monate alten Tieren - kein Verlust beobachten.

Im Vergleich der Gesamtneuronenzahl des GD der transgenen Tiere mit Tieren vom WT ergab sich folgendes Bild. Die Gesamtneuronenzahl im GD bei zwei Monate alten Tieren entsprach mit 773930 in etwa der Gesamtneuronenzahl im GD bei drei Monate alten WTTieren mit 765839. Drei Monate alte transgene Tiere zeigten mit 556600 Neuronen einen deutlichen Verlust in der Gesamtneuronenzahl. Zu den gleichalten Tieren vom W'T ergab sich ein absoluter Verlust von 209238 Neuronen und ein relativer Verlust von 27,32\%. Im t-Test zeigte sich ein p-Wert von 0,026. Fünf Monate alte transgene Tiere zeigten einen Verlust von 321069 Neuronen und von 42\% und sechs Monate alte transgene Tiere einen Verlust von 296754 Neuronen und von 39,8\% im Vergleich zu drei Monate alten WT-Tieren. Zwischen fünf und sechs Monate alten Tieren stagnierte der Neuronenverlust im GD. Sechs Monate alte transgene Tiere wiesen 469084 Neurone im GD auf. Bei gleichalten WT-Tieren finden sich 607148 Neurone im GD. Zwischen beiden Genotypen ergab sich ein absoluter Unterschied von 138063 Neuronen. Die transgenen Tiere wiesen einen Verlust von 22,8\% auf. Im t-Test zeigte sich ein $\mathrm{p}$-Wert von 0,0302 . Sechs Monate alte WT-Tiere wiesen signifikant mehr Neurone im GD als gleichalte transgene Tiere auf.

Der starke Abfall der Neuronenzahl bei transgenen Tieren im Vergleich zu WT-Tieren im GD ist in Abbildung 13 (10-fache Vergrößerung) und Abbildung 14 (40-fache Vergrößerung) dargestellt. Es sind ein drei Monate altes WT-Tier (linke Abbildung) und ein sechs Monate altes transgenes Tier (rechte Abbildung) gegenübergestellt. Bei dem transgenen Tier zeigt sich im Vergleich zum WT-Tier als visuelles Korrelat für den Neuronenverlust eine deutlichere Auflockerung des Neuronenverbandes im GD. 
Tabelle 19: Übersicht über die quantifizierten Neurone und Mittelwerte der transgenen Tiere aller Altersstufen

\begin{tabular}{|c|c|}
\hline Quantifizierte Werte der Tg4-42 Mäuse & Errechnete Mittelwerte \\
\hline \multicolumn{2}{|c|}{2 Monate } \\
\hline 846480,6 & \multirow{4}{*}{773930,22} \\
\hline 809226,9 & \\
\hline 665088,2 & \\
\hline 774925,2 & \\
\hline \multicolumn{2}{|c|}{3 Monate } \\
\hline 578509,3 & \multirow{4}{*}{556600,875} \\
\hline 635580,6 & \\
\hline 640313,6 & \\
\hline 372000 & \\
\hline \multicolumn{2}{|c|}{4 Monate } \\
\hline 624160,2 & \multirow{4}{*}{596052,05} \\
\hline 670401,4 & \\
\hline 569643,8 & \\
\hline 520002,8 & \\
\hline \multicolumn{2}{|c|}{5 Monate } \\
\hline 488968,4 & \multirow{4}{*}{444769,5} \\
\hline 490592,9 & \\
\hline 395417,2 & \\
\hline 404099,5 & \\
\hline \multicolumn{2}{|c|}{6 Monate } \\
\hline 523555,2 & \multirow{4}{*}{469084,55} \\
\hline 398165,3 & \\
\hline 529458,8 & \\
\hline 425158,9 & \\
\hline
\end{tabular}


Tabelle 20: Übersicht über die quantifizierten Neurone und Mittelwerte der Wildtyptiere beider Altersstufen

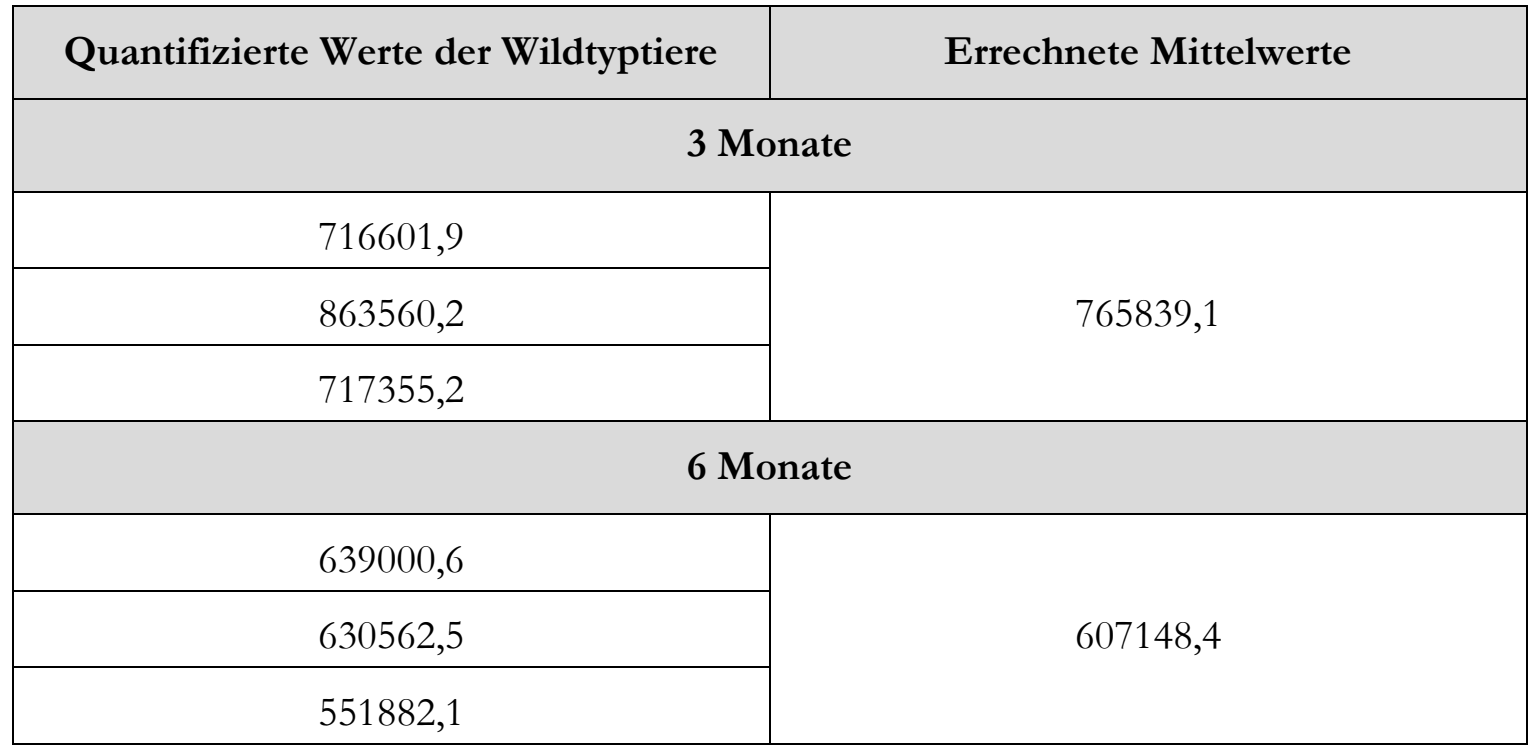

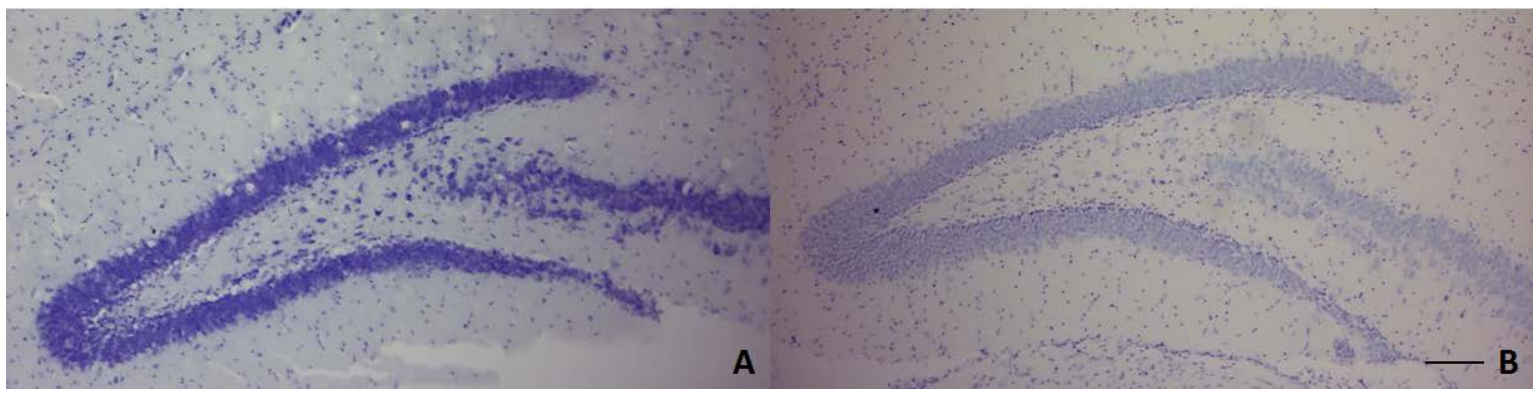

Abbildung 13: Vergleichende Übersichtsaufnahme der Cresyl-Violett-Färbung der Neurone des Gyrus Dentatus. Die Neurone färben sich blau an. Bild A zeigt ein drei Monate altes WT-Tier. In Bild $\mathbf{B}$ ist ein sechs Monate altes transgenes Tier gegenübergestellt. Maßstab: $500 \mu \mathrm{m}$ 


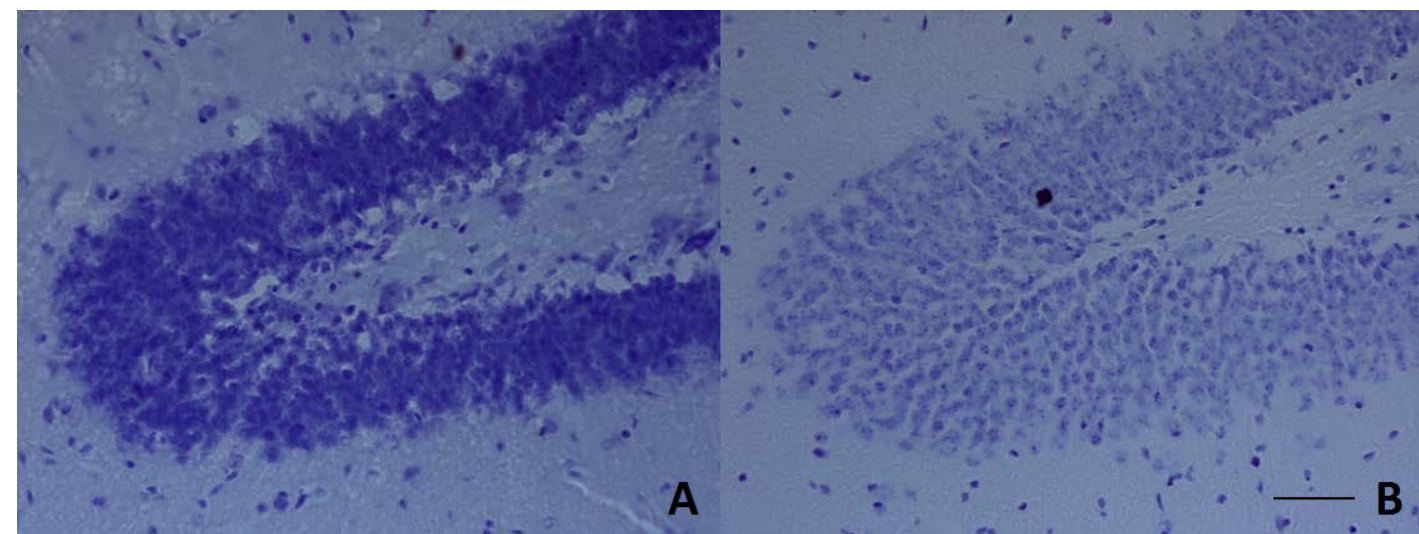

\section{Abbildung 14: Vergleichende Detailaufnahme der Cresyl-Violettfärbung der Neurone des Gyrus Dentatus. Die Neurone färben sich blau an. Bild A zeigt ein drei Monate altes Tier vom WT. In Bild $\mathbf{B}$ ist ein sechs Monate altes transgenes Tier gegenübergestellt. Bei dem transgenen Tier stellt sich der bei der bei der stereologischen Quantifizierung festgestellte Ver- lust von Neuronen im GD als Auflockerung des Neuronenverbandes dar. Im Vergleich weist Bild A einen deutlich dichteren Neuronenverband auf. Maßstab: $250 \mu \mathrm{m}$ \\ 3.2 Quantifizierung des Volumens des Gyrus Dentatus im Tg4-42- Mausmodell}

Zur Erhebung des Gesamtvolumens wurden dieselben Tiere wie zuvor für die Ermittlung der Gesamtneuronenzahl genutzt. Tabelle 10 gibt eine Übersicht über die verwendeten Tiere. Die hierfür benötigten Daten wurden ebenfalls bei der stereologischen Auswertung der Tiere ermittelt. Abbildung 15 gibt einen Überblick über die Verteilung der Gesamtvolumina der beiden Genotypen und vergleicht die verschiedenen Altersstufen miteinander. Zwischen den einzelnen Altersstufen und Genotypen ließ sich kein signifikanter Unterschied hinsichtlich der Gesamtvolumina feststellen. Die Gesamtvolumina variierten von einem mittleren maximalen Gesamtvolumen von $561535957 \mu \mathrm{m}^{3}$ bei sechs Monate alten transgenen Tiere zu einem mittleren minimalen Gesamtvolumen von $402357382 \mu \mathrm{m}^{3}$ bei drei Monate alten transgenen Tieren. Ein signifikanter Unterschied zwischen diesen beiden Werten bestand jedoch weder in der one-way-ANOVA noch im t-Test. Ein p-Wert von $<0,05$ wurde zwischen diesen beiden Extrema nicht erreicht. Bei Berechnung des Mittelwerts des Gesamtvolumens über alle Altersstufen der transgenen Tiere $\left(508783448 \mu \mathrm{m}^{3}\right)$ und beim Vergleich diesen Mittelwetres mit dem Mittelwert beider Altersstufen der WT-Tiere $\left(511100110 \mu \mathrm{m}^{3}\right)$ ergab sich kein signifikanter Unterschied hinsichtlich des Gesamtvolumens. In Tabelle 21 und Tabelle 22 findet sich eine detaillierte Darstellung der Gesamtvolumina der jeweiligen Tiere sowie die errechneten Mittelwerte der jeweiligen Altersstufen. 


\title{
Gesamtvolumen des Gyrus Dentatus WT versus Tg4-42
}

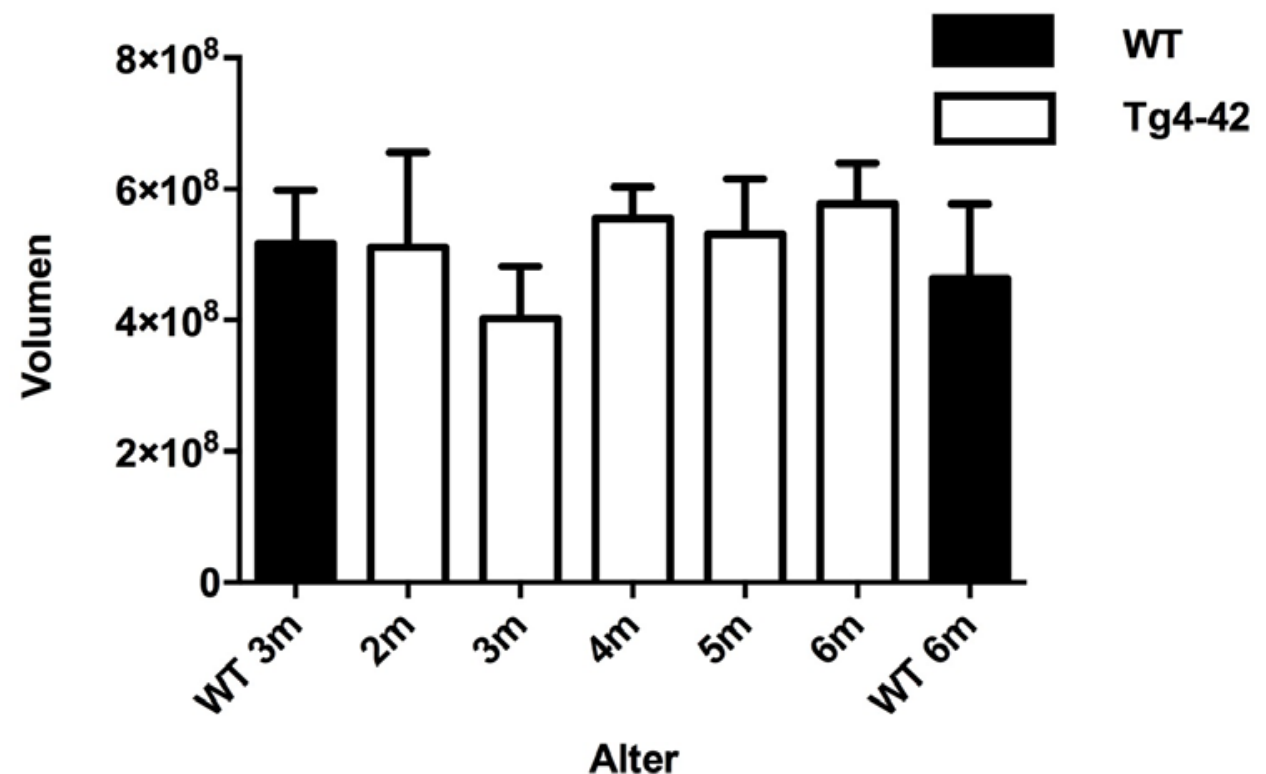

\begin{abstract}
Abbildung 15: Überblick über die Volumina des Gyrus Dentatus der transgenen Tiere und der Wildtyptiere. Das maximale Gesamtvolumen liegt mit $561535957 \mu^{3}$ bei sechs Monate und das minimale mittlere Gesamtvolumen mit $402357382 \mu \mathrm{m}^{3}$ drei Monate alten transgenen Tieren. Sowohl zwischen den einzelnen Altersstufen innerhalb des jeweiligen Genotyps als auch beim Vergleich der beiden Genotypen miteinander besteht kein signifikanter Unterschied zwischen den Gesamtvolumina der jeweiligen GD.
\end{abstract}


Tabelle 21: Übersicht über Volumina und Mittelwerte der transgenen Tiere

\begin{tabular}{|c|c|}
\hline Volumen der Tg4-42 Mäuse in $\mu \mathrm{m}^{3}$ & Errechnete Mittelwerte \\
\hline \multicolumn{2}{|c|}{2 Monate } \\
\hline 633764340 & \multirow{4}{*}{511210174,5} \\
\hline 637799130 & \\
\hline 369087120 & \\
\hline 404190108 & \\
\hline \multicolumn{2}{|c|}{3 Monate } \\
\hline 456584580 & \multirow{4}{*}{402357382,5} \\
\hline 318837660 & \\
\hline 482481870 & \\
\hline 351525420 & \\
\hline \multicolumn{2}{|c|}{4 Monate } \\
\hline 566733180 & \multirow{4}{*}{555182280} \\
\hline 617356230 & \\
\hline 511322940 & \\
\hline 525316770 & \\
\hline \multicolumn{2}{|c|}{5 Monate } \\
\hline 555373920 & \multirow{4}{*}{513631447,5} \\
\hline 548885940 & \\
\hline 412567110 & \\
\hline 537698820 & \\
\hline \multicolumn{2}{|c|}{6 Monate } \\
\hline 499759830 & \multirow{4}{*}{561535957,5} \\
\hline 644336430 & \\
\hline 512871360 & \\
\hline 589176210 & \\
\hline
\end{tabular}


Tabelle 22: Übersicht über Volumina und Mittelwerte der Wildtyptiere

\begin{tabular}{|c|c|}
\hline $\begin{array}{l}\text { Quantifizierte Werte der Wildtyptiere in } \\
\qquad \mathrm{m}^{3}\end{array}$ & Errechnete Mittelwerte \\
\hline \multicolumn{2}{|c|}{3 Monate } \\
\hline 511620870 & \multirow{3}{*}{517071490} \\
\hline 600766590 & \\
\hline 438827010 & \\
\hline \multicolumn{2}{|c|}{6 Monate } \\
\hline 614747790 & \multirow{3}{*}{505128730} \\
\hline 445810740 & \\
\hline 454827660 & \\
\hline
\end{tabular}

\subsection{Quantifizierung der Neurogenese im Gyrus Dentatus im Tg4-42- Mausmodell}

Zur Beurteilung der Neurogenese im Mausmodell Tg4-42 wurden, wie in Abschnitt 2.5 beschrieben, transgene Tiere im Alter von zwei bis sechs Monaten mit WT-Tieren im Alter von drei und sechs Monaten verglichen. Die gefrorenen Schnitte wurden mit einem Antikörper gegen Doublecortin gefärbt. Doublecortin ist ein Marker-Protein, das von neugebildeten unreifen Neuronen exprimiert wird. Die Quantifizierung von Doublecortin-Neuronen stellt exakt die Veränderungen der adulten Neurogenese dar (Couillard-Despres et al. 2005). In der statistischen Auswertung mittels GraphPad zeigte sich, dass die Neurogenese über die Altersstufen hinweg bei transgenen Tieren abnahm. Die Rohdaten wurden mittels one-way-ANOVA ausgewertet und mit der Bonferroni-Methode korrigiert. Der p-Wert für die gesamte one-wayANOVA beträgt $p=0,0033$. In zwei Fällen ließ sich ein signifikanter Unterschied der Neurogenese im GD feststellen. Im Vergleich von zwei und fünf Monate alten transgenen Tieren ergab sich ein $\mathrm{p}$-Wert von $\mathrm{p}<0,05$ und im Vergleich von zwei und sechs Monate alten transgenen Tieren ein $\mathrm{p}$-Wert von $\mathrm{p}<0,01$. Abbildung 16 bildet den beschriebenen Verlauf graphisch ab und zeigt die mittels one-way-ANOVA berechneten signifikanten Unterschiede. Um die gleichen Altersstufen der beiden Genotypen direkt miteinander zu vergleichen, wurde ein t-Test zwischen drei Monate alten Tieren beider Genotypen und zwischen sechs Monate alten Tieren beider Genotypen durchgeführt. In der Gruppe der drei Monate alten Tiere bestand mit einem $\mathrm{p}$-Wert von $\mathrm{p}=0,981$ kaum ein Unterschied zwischen den beiden Genotypen. In der Gruppe der sechs Monate alten Tiere zeigte sich ein statistischer Trend mit einem p-Wert von $\mathrm{p}=0,054$. Tabelle 23 und Tabelle 24 listen die jeweiligen $\mathrm{p}$-Werte auf. 
In Abbildung 18 und Abbildung 19 sind ein zwei Monate altes und ein sechs Monate altes transgenes Tier zum direkten Vergleich gegenübergestellt. Die neugebildeten Neurone stellen sich in beiden Abbildungen als braune Signalanreicherungen im GD dar. In Bild A der jeweiligen Abbildung bestätigt die deutliche Signalverstärkung im Vergleich zu Bild B der jeweiligen Abbildung, die in der Quantifizierung (vgl. Abbildung 16 und Abbildung 17) ermittelten Unterschiede der Neurogenese. 


\section{Quantifizierung der Neurogenese WT versus Tg4-42}

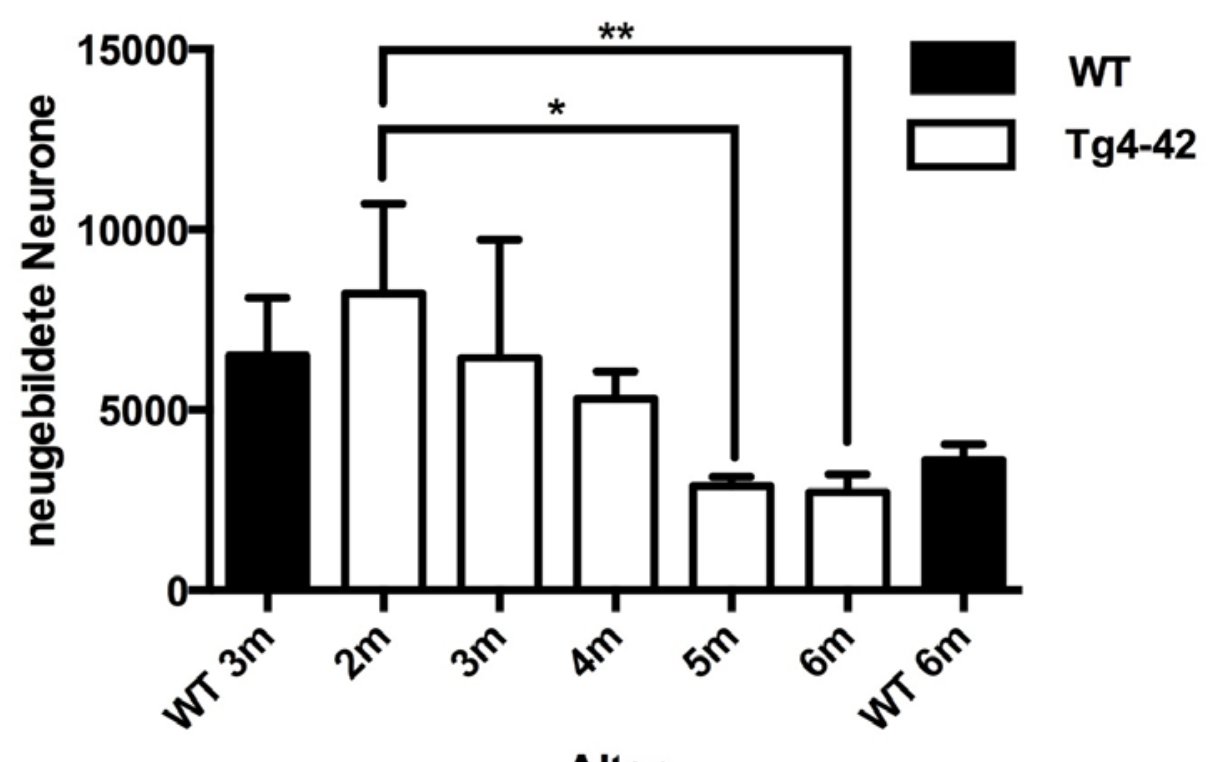

Alter

Abbildung 16: Vergleichende Darstellung der Quantifizierung der Neurogenese im Gyrus Dentatus bei transgenen Tieren und Wildtyptieren. Die Abbildung gibt eine Übersicht über den zeitlichen Verlauf der Neurogenes von zwei Monate alten transgenen bis hin zu sechs Monate alten transgenen Tieren. Die Neubildung von Neuronen nimmt über den zeitlichen Verlauf ab. Signifikante Unterschiede ergeben sich in der Gruppe der transgenen Tiere zwischen zwei und fünf sowie zwischen zwei und sechs Monate alten Tieren. Zwischen zwei und sechs Monate alten Tieren fällt der Unterschied etwas stärker aus. Die mittels one-wayANOVA errechneten p-Werte sind Tabelle 23 zu entnehmen

Tabelle 23: Auflistung der in Abbildung 16 dargestellten und mittels one-way-ANOVA bestimmten signifikanten Unterschiede

\begin{tabular}{|l|l|}
\hline Verglichene Tiere & p-Werte \\
\hline $\operatorname{Tg} 4-422 \mathrm{~m}$ versus $\operatorname{Tg} 4-425 \mathrm{~m}$ & $<0,05$ \\
\hline $\operatorname{Tg} 4-422 \mathrm{~m}$ versus $\operatorname{Tg} 4-426 \mathrm{~m}$ & $<0,01$ \\
\hline
\end{tabular}


Vergleich WT 3 Monate

versus

Tg4-42 3 Monate
Vergleich WT 6 Monate

versus

Tg4-42 6 Monate

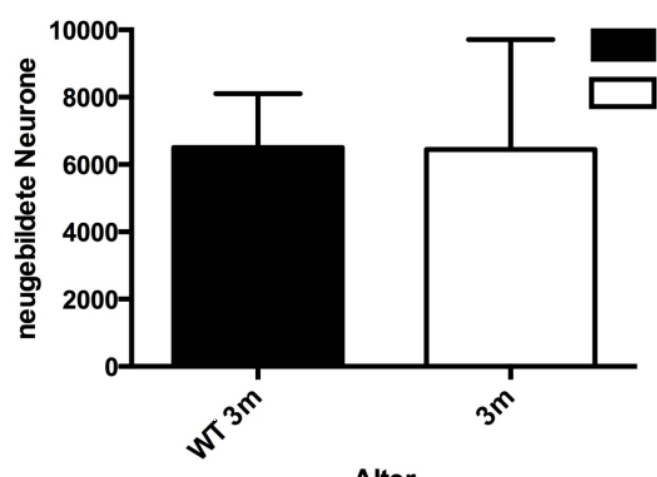

Alter

A

WT
Tg4-42

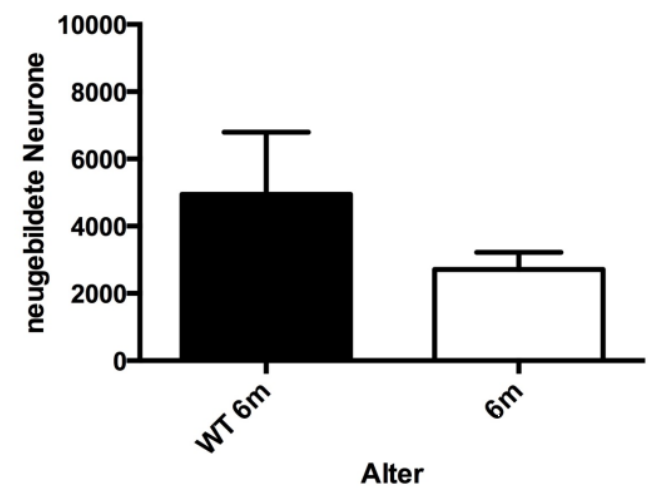

Alter

B

Abbildung 17: Gegenüberstellung der Neurogenese im direkten Altersvergleich der beiden Genotypen. In der Gruppe der drei Monate alten Tiere besteht nahezu kein Unterschied in der Gesamtzahl der neugebildeten Neurone im GD (A). In der Gruppe der sechs Monate alten Tiere sinkt die Gesamtzahl der neugebildeten Neurone der transgenen Tiere etwas unter die Gesamtzahl der W'T-Tiere (B). In beiden Vergleichen besteht jedoch kein signifikanter Unterschied. In Tabelle 24 sind die im t-Test ermittelten p-Werte aufgelistet.

Tabelle 24: Auflistung der in Abbildung 17 dargestellten und mittels t-Test bestimmten p-Werte, die sich zwischen den Genotypen im direkten Altersvergleich ergeben

\begin{tabular}{|l|l|}
\hline Verglichene Tiere & p-Werte \\
\hline WT $3 \mathrm{~m}$ versus $\operatorname{Tg} 4-423 \mathrm{~m}$ & 0,981 \\
\hline WT $6 \mathrm{~m}$ versus $\operatorname{Tg} 4-426 \mathrm{~m}$ & 0,0544 \\
\hline
\end{tabular}




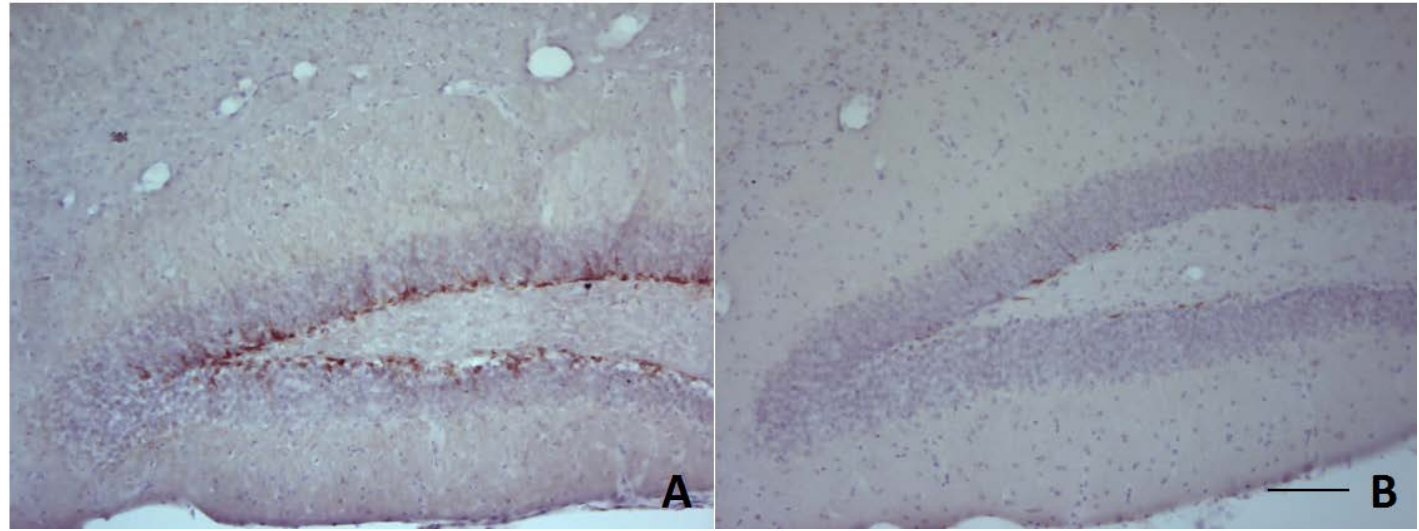

Abbildung 18: Vergleichende Übersichtsaufnahme der neugebildeten Neurone im Gyrus Dentatus. Abbildung des GD eines zwei Monate alten transgenen Tieres (A) und eines sechs Monate alten transgenen Tieres $(\mathbf{B})$. Die Schnitte wurden mit Doublecortin angefärbt. Die braunen Signalanhebungen im GD bilden die adulte Neurogenese des Tieres ab. Das zwei Monate alte transgene Tier weist eine deutlich stärkere Neurogenese als das sechs Monate alte transgene Tier auf. Maßstab: $500 \mu \mathrm{m}$

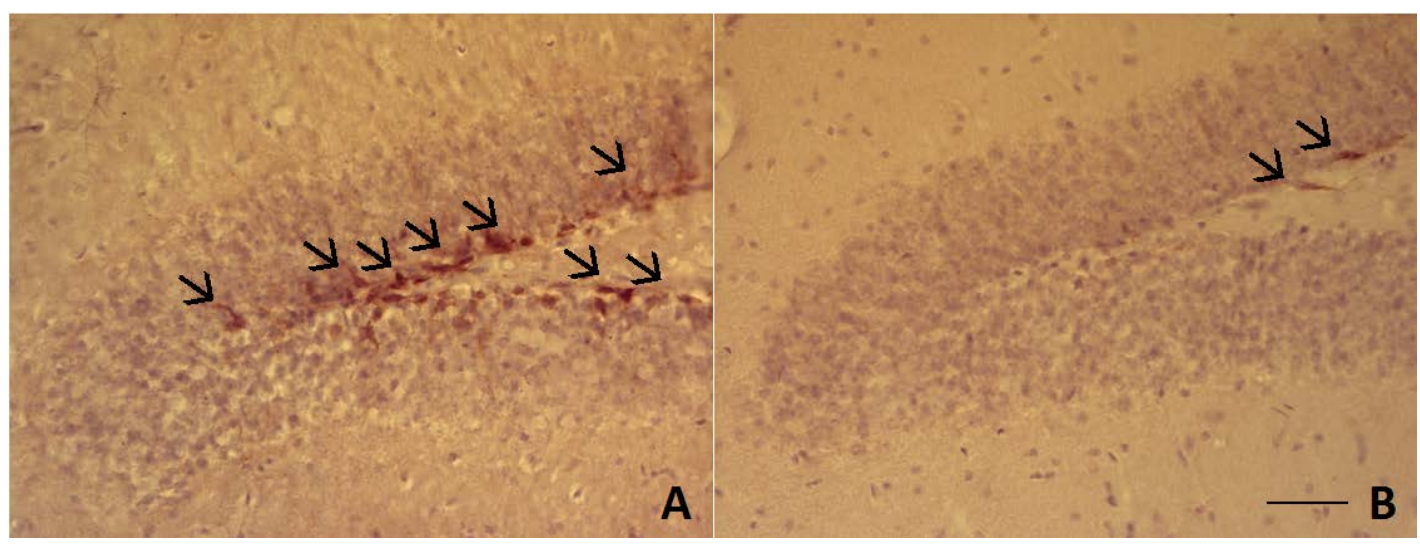

Abbildung 19: Vergleichende Detailaufnahme der neugebildeten Neurone im Gyrus Dentatus. Detaillierte Aufnahme des GD eines zwei Monate alten transgenen Tieres (A) und eines sechs Monate alten transgenen Tieres $(\mathbf{B})$. Die Schnitte wurden mit Doublecortin angefärbt. Die braunen Signalanhebungen im GD bilden die adulte Neurogenese des Tieres ab. Beim jüngeren Tier folgt die Neurogenese bandähnlich ohne große Unterbrechungen der Innenseite des GD. Beim älteren Tier finden sich hingegen nur vereinzelt neugebildete Neurone. Maßstab: $250 \mu \mathrm{m}$

In Tabelle 25 findet sich eine detaillierte Auflistung der gezählten neugebildeten Neurone im GD. Es wurden alle Altersstufen des Tg4-42 Mausmodells aufgenommen. In Tabelle 26 wurden die Werte der WT-Tiere aufgelistet. Beide Tabellen verdeutlichen den in Abbildung 16 und Abbildung 17 graphisch dargestellten zeitlichen Verlauf der Neurogenese im GD. Beim 
Vergleich der Mittelwerte der ermittelten Neurogenese der verschiedenen Altersstufen der transgenen Tiere ließ sich eine Abnahme der mittleren Neurogenese von zwei Monate zu sechs Monate alten Tieren ermitteln. Bei zwei Monate alten transgenen Mäusen ließen sich im Mittel 8230 neugebildete Neurone bestimmen. Bei sechs Monate alten Mäusen hingegen fiel die Neurogeneserate im Schnitt auf 2715 ab. Vom zweiten auf den dritten Lebensmonat sank die Neurogenese im GD im Mittel auf 6446 neugebildete Neurone. Die Neurogenese verringerte sich zwischen diesen beiden Altersstufen um 1784 Neurone und somit um 21,7\%. Zwischen drei und vier Monate alten transgenen Tieren verringerte sich die Zahl der neugebildeten Neurone im GD um 1141. Drei Monate alte transgene Tiere wiesen 6446 neugebildete Neurone und vier Monate alte transgene Tiere wiesen 5305 neugebildete Neurone auf. Dies entsprach einem Rückgang um 17,8\%. Zwischen vier und fünf Monate alten transgenen Tieren sank die Neurogenese um 2412 neugebildete Neurone. Vier Monate alte transgene Tiere wiesen 5305 neugebildete Neurone und fünf Monate alte transgene Tiere 2893 neugebildete Neurone auf. Der prozentuale Abfall zwischen den Altersstufen betrug 45,5\%. Zwischen fünf und sechs Monate alten transgenen Tieren stagnierte die Abnahme der Neurogeneserate.

Beim direkten Vergleich der Neurogeneserate im GD zwischen gleichalten transgenen Tieren und WT-Tieren ergaben sich folgende Werte: in der Gruppe der drei Monate alten Tiere zeigte sich ein Unterschied in der Neurogeneserate von 54 neugebildeten Neuronen und 0,9\%. Im t-Test ergab sich ein p-Wert von 0,981. Die Neurogeneserate erwies sich zwischen den Genotypen bei drei Monate alten Tieren als nahezu identisch. In der Gruppe der sechs Monate alten Tiere zeigte sich ein Unterschied in der Neurogeneserate von 901 neugebildeten Neuronen und $35 \%$. Im t-Test ergab sich ein p-Wert von 0,0544. Es zeigte sich sowohl bei transgenen als auch bei WT-Tieren eine Abnahme der Neurogeneserate mit zunehmendem Alter. Der Unterschied war zwischen beiden betrachteten Altersstufen nicht signifikant. 
Tabelle 25: Detaillierte Auflistung und Gegenüberstellung der quantifizierten Neurone der Tg4-42 Mäuse aller Altersstufen sowie Auflistung und Gegenüberstellung der Mittelwerte.

\begin{tabular}{|c|c|}
\hline Quantifizierte Werte der Tg4-42 Mäuse & Errechnete Mittelwerte \\
\hline \multicolumn{2}{|c|}{2 Monate } \\
\hline 9460 & \multirow{3}{*}{8230} \\
\hline 9870 & \\
\hline 5360 & \\
\hline \multicolumn{2}{|c|}{3 Monate } \\
\hline 3420 & \multirow{3}{*}{6446} \\
\hline 9910 & \\
\hline 6010 & \\
\hline \multicolumn{2}{|c|}{4 Monate } \\
\hline 4700 & \multirow{4}{*}{5305} \\
\hline 4640 & \\
\hline 6200 & \\
\hline 5680 & \\
\hline \multicolumn{2}{|c|}{5 Monate } \\
\hline 2670 & \multirow{3}{*}{2893} \\
\hline 2850 & \\
\hline 3106 & \\
\hline \multicolumn{2}{|c|}{6 Monate } \\
\hline 3120 & \multirow{4}{*}{2715} \\
\hline 2000 & \\
\hline 2740 & \\
\hline 3000 & \\
\hline
\end{tabular}


Tabelle 26: Detaillierte Auflistung und Gegenüberstellung der quantifizierten Neurone der Wildtyptiere beider Altersstufen sowie Auflistung und Gegenüberstellung der Mittelwerte.

\begin{tabular}{|c|c|}
\hline Quantifizierte Werte der Wildtyptiere & Errechnete Mittelwerte \\
\hline \multicolumn{2}{|c|}{3 Monate } \\
\hline 6730 & \multirow{3}{*}{6500} \\
\hline 7980 & \\
\hline 4790 & \\
\hline \multicolumn{2}{|c|}{6 Monate } \\
\hline 3150 & \multirow{3}{*}{3616} \\
\hline 3720 & \\
\hline 3980 & \\
\hline
\end{tabular}

\subsection{Quantifizierung der Astrogliose im Gyrus Dentatus im Tg4-42- Mausmodell}

Zur Quantifizierung der Neuroinflammation im GD bei Tg4-42 Mäusen und Mäusen vom WT wurden, wie in Tabelle 13 angegebenen, je Genotyp drei Tiere im Alter von sechs Monaten verwendet. Pro Tier wurden drei Schnitte ausgewertet. Die ausgewerteten Schnitte des jeweiligen Tieres wurden als Mittelwerte zusammengefasst, sodass sich pro Genotyp drei Mittelwerte ergaben. Um Rückschlüsse auf das Ausmaß der Neuroinflammation im GD zu ziehen, wurde ein Antikörper für GFAP genutzt. GFAP ist Hauptbestandteil von Intermediärfilamenten im Zytoplasma von Astrozyten und kann deshalb als Marker für das Vorhandensein von Astrozyten herangezogen werden (Bignami et al. 1972). Um eine quantitative Aussage über die bei Neuroinflammation beteiligte Fläche des GD zu treffen, wurde der von Neuroinflammation betroffene prozentuale Teil des GD an der Gesamtfläche des GD ermittelt. Die prozentualen Anteile der Neuroinflammation im GD wurden anhand des Mittelwertes der WT-Tiere normalisiert und zu diesem in Relation gesetzt. Das genaue Vorgehen bei der Auswertung ist in Abschnitt 2.6 erläutert. In Abbildung 20 wurden die Mittelwerte der WT-Tiere den Mittelwerten der transgenen Tiere gegenübergestellt. Sechs Monate alte transgene Tiere wiesen eine stärkere Astrogliose als gleichalte WT-Tiere auf. Im t-Test zeigte sich ein signifikanter Unterschied zwischen beiden Gruppen mit einem $\mathrm{p}-$ Wert von $\mathrm{p}<0,044$. 


\section{Quantifizierung der GFAP-Akkumulation \\ WT versus Tg4-42}

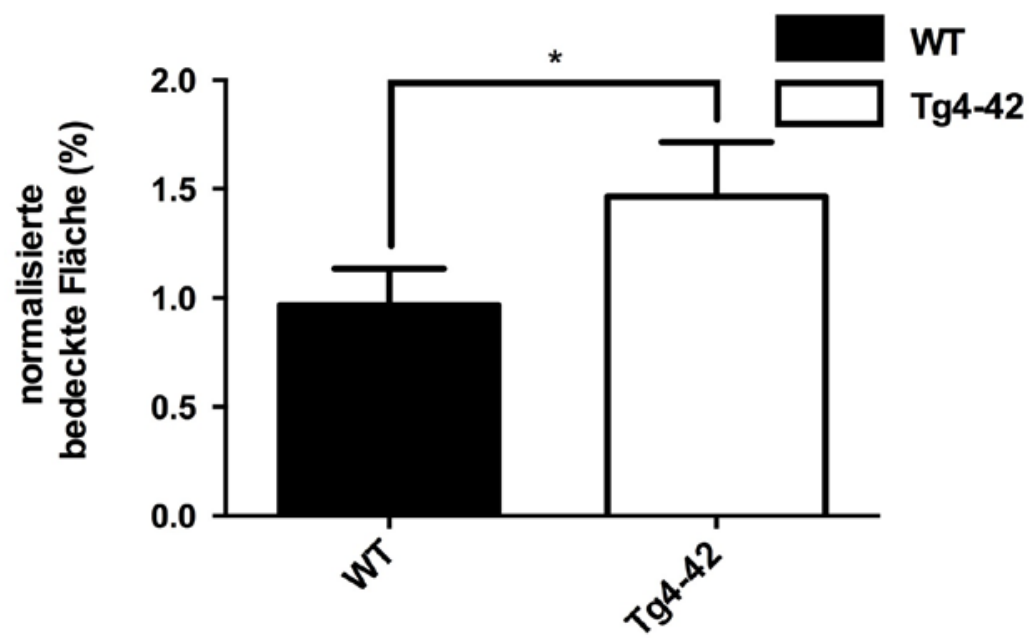

Abbildung 20: Vergleichende Darstellung der relativen Neuroinflammation im Gyrus Dentatus. Es sind sechs Monate alte WT-Tiere und sechs Monate alte transgene Tiere gegenübergestellt. Die Werte werden normalisiert als prozentuale Bedeckung der Gesamtfläche angegeben. Die Neuroinflammation fällt bei transgenen Tieren signifikant höher aus als bei WTTieren. In Tabelle 27 ist der im t-Test berechnete p-Wert aufgeführt.

Tabelle 27: Auflistung des in Abbildung 20 dargestellten und mittels t-Test bestimmten pWertes, der sich zwischen den Genotypen bei sechs Monate alten Tieren ergibt

\begin{tabular}{|l|l|}
\hline Verglichene Tiere & p-Wert \\
\hline WT 6m versus Tg4-42 6m & 0,044 \\
\hline
\end{tabular}

Abbildung 21 stellt die Neuroinflammation im GD bei einem transgenen Tier exemplarisch dar. Das sichtbare Hirngewebe ist von Astrozyten stark durchsetzt. 


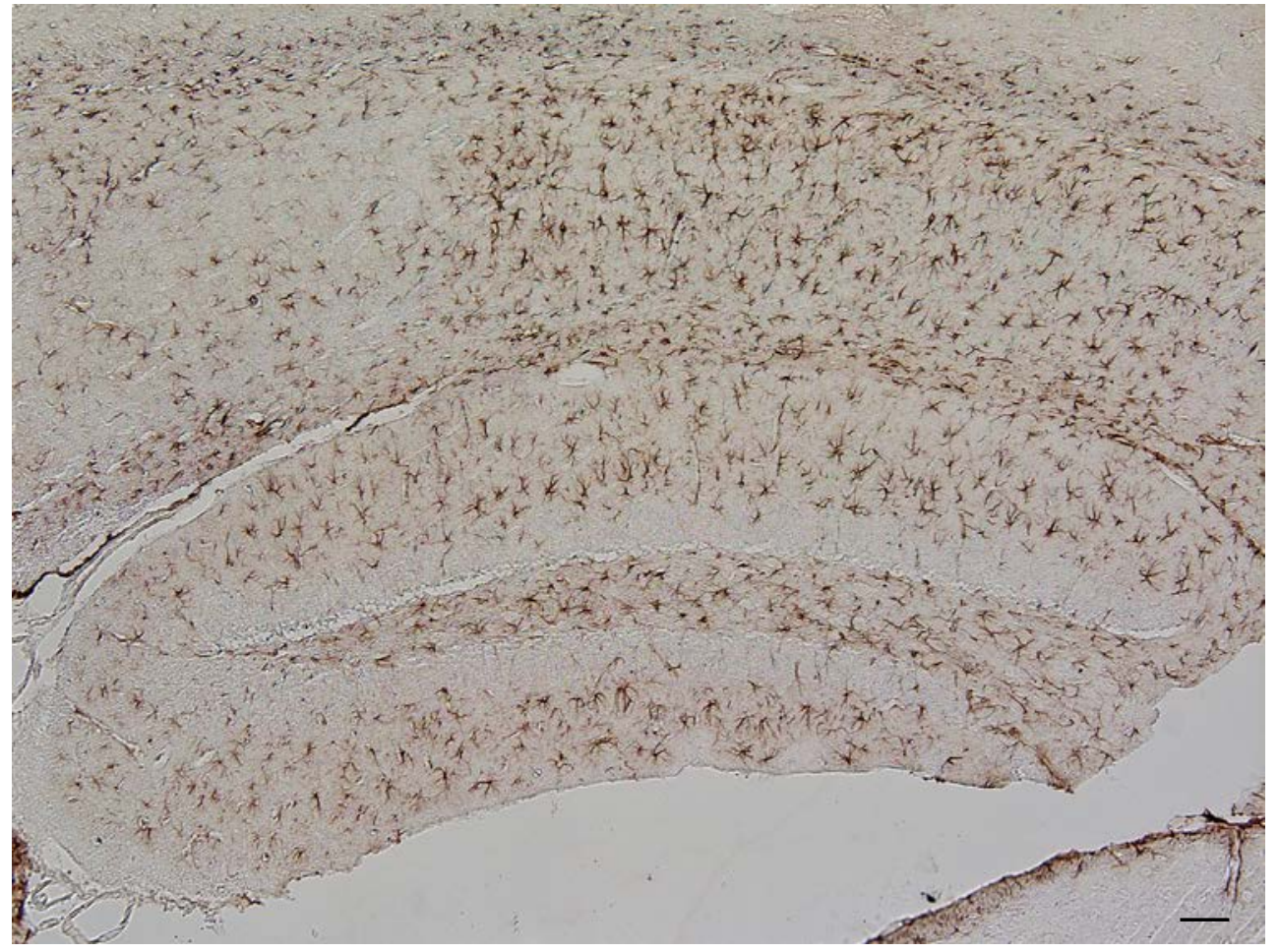

Abbildung 21: Exemplarische Darstellung der Neuroinflammation im Gyrus Dentatus eines sechs Monate alten transgenen Tieres. Das gesamte Gewebe ist stark von Astrozyten durchsetzt. Zentral ist der GD als c-förmige Struktur zu erkennen. Maßstab: $1000 \mu \mathrm{m}$

\subsection{Bestimmung der GFAP-Expression im Tg4-42-Mausmodell}

Zur Bestimmung der mRNA-Expression von GFAP bei zwei Monate, vier Monate und acht Monate alten WT-Tieren und transgenen Mäusen derselben Altersstufen wurden die in Tabelle 13 aufgelisteten Tiere verwendet. Mittels qPCR-Analyse wurde die mRNA-Expression von GFAP genau erfasst. Die ermittelten Ergebnisse von GFAP wurden zur mRNA-Expression von $\beta$-Aktin normalisiert und als dessen relative Expression wiedergegeben. Der genaue Ablauf der Methodik ist in 2.7 wiedergegeben.

Die Genexpression von GFAP stieg von zwei Monate alten zu acht Monate alten Tieren stetig an. Dies galt sowohl für WT-Tiere als auch für transgene Tiere. Die relative Expression von GFAP blieb bei allen Altersstufen der WT-Tiere unter der Expression der jeweiligen Altersstufe der transgenen Tiere. Bei den transgenen Tieren ließ sich zwischen zwei und vier Monate alten Tieren ein Anstieg in der Genexpression von GFAP feststellen. Zwischen vier und acht Monate alten Tieren sistierte die Genexpression von GFAP bei den transgenen Tieren weitestgehend. Die GFAP-Expression bei WT-Tieren unterschied sich nicht stark zwischen zwei und vier Monate alten Tieren. Von vier auf acht Monate zeigte sich bei den WTTieren ein etwas stärkerer Anstieg der GFAP-Expression. Beim Vergleich der gleichen Alters- 
gruppen der verschiedenen Genotypen miteinander ergab sich zwischen zwei Monate alten transgenen Tieren und WT-Tieren im t-Test kein signifikanter Unterschied. In der Gruppe der vier Monate alten Tiere ergab sich im t-Test zwischen den beiden Genotypen ein p-Wert von $<0,05$. Die Expression von GFAP lag bei WT-Tieren zu diesem Zeitpunkt signifikant unter der Expression der transgenen Tiere. Einen vergleichenden Überblick über die GFAPExpression der beiden Genotypen bietet Abbildung 22. Tabelle 28 stellt die mittels t-Test berechneten p-Werte zwischen den Genotypen der gleichen Altersstufe gegenüber.

\section{Bestimmung der GFAP-Expression WT versus Tg4-42}

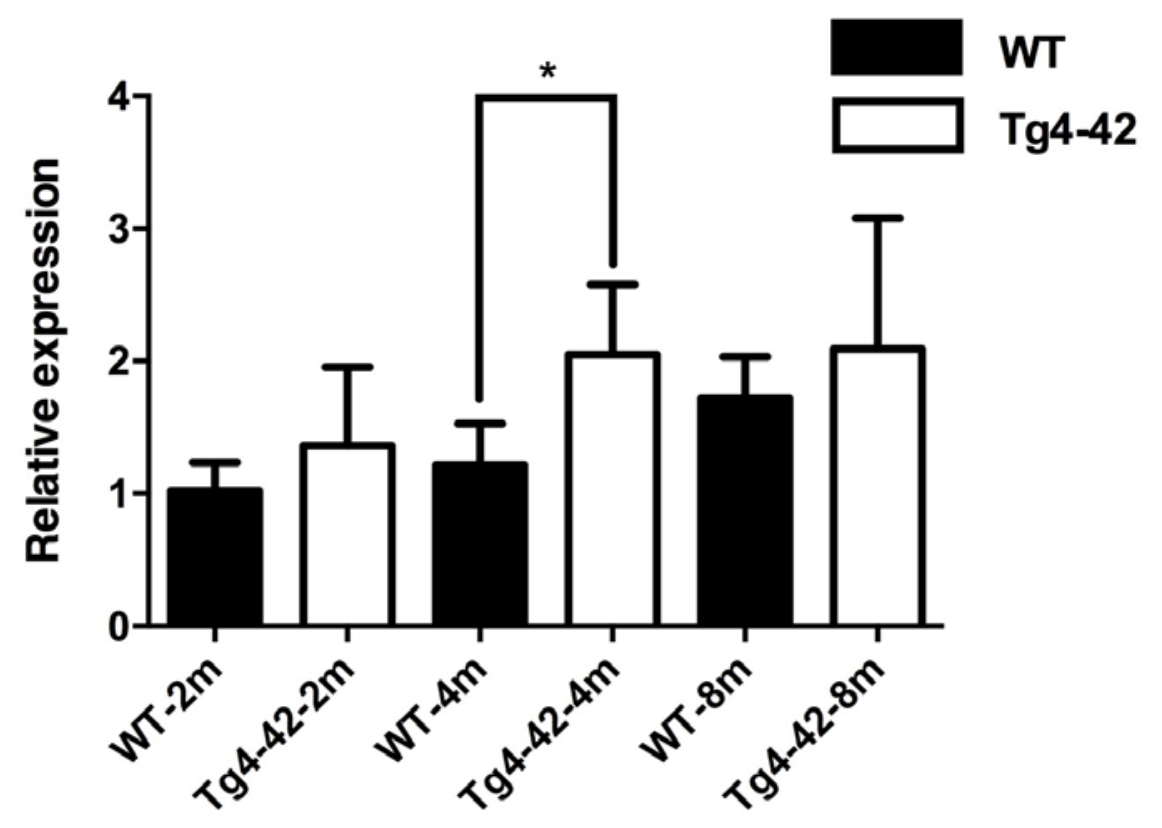

Abbildung 22: Vergleichende Darstellung der GFAP-Expression bei transgenen Tieren und Wildtyptieren. Die GFAP-Expression wurde bei zwei, vier und fünf Monate alten Tieren mittels qPCR bestimmt. Bei beiden Genotypen kommt es zu einem Anstieg der Expression. In Tabelle 28 sind die mittels t-Test berechneten p-Werte aufgelistet.

Tabelle 28: Auflistung der in Abbildung 22 dargestellten und mittels t-Test bestimmten pWerte, die sich zwischen den Genotypen im direkten Altersvergleich ergeben

\begin{tabular}{|l|l|}
\hline Verglichene Tiere & p-Wert \\
\hline WT $2 \mathrm{~m}$ versus $\operatorname{Tg} 4-422 \mathrm{~m}$ & 0,2614 \\
\hline WT $4 \mathrm{~m}$ versus $\operatorname{Tg} 4-424 \mathrm{~m}$ & 0,0165 \\
\hline WT $8 \mathrm{~m}$ versus $\operatorname{Tg} 4-428 \mathrm{~m}$ & 0,4467 \\
\hline
\end{tabular}




\section{Diskussion}

Die folgende Diskussion ist in vier Teile untergliedert. Alle Teile diskutieren die Bedeutung von $A \beta_{4-42}$ in Hinblick auf neuropathologische Manifestationen im GD.

$\mathrm{A} \beta_{4-42}$ ist eine im Kortex und Hippocampus von AD-Patienten sehr häufig vorkommende A $\beta$-Isoform (Portelius et al. 2010). Jedoch ist bisher wenig über die Auswirkungen von $A \beta_{4-42}$ auf die Pathologie und Symptomatik der AD bekannt. Zudem weisen die meisten ADMausmodelle neben einer Akkumulation von $A \beta$ eine Überexpression mutierten APPs auf. Das Tg4-42-Mausmodell exprimiert $A \beta_{4-42}$ in großer Menge, ohne eine entsprechende APPÜberexpression aufzuweisen. Aus diesen Gründen, um die neuropathologischen Eigenschaften von $A \beta_{4-42}$ ohne die Beeinflussung von mutiertem APP zu untersuchen, wurde von Bouter et al. (2013) das Tg4-42-Mausmodell entwickelt. In vergangenen Studien wurden Erkenntnisse über den Einfluss von $A \beta_{4-42}$ auf die CA1-Region und das Verhalten von Tg4-42-Mäusen erlangt. In der vorliegenden Arbeit wurde der Einfluss von $A \beta_{4-42}$ auf den GD untersucht.

Im ersten Kapitel der Diskussion wird der Einfluss von $A \beta_{4-42}$ auf den Neuronenverlust im GD in Zusammenschau mit dem Neuronenverlust in der CA1-Region desselben Tiermodells sowie mit gemessenen Neuronenverlusten in anderen Tiermodellen diskutiert. Das zweite Kapitel beleuchtet, inwieweit der gemessene Neuronenverlust im GD Einfluss auf das Volumen des GD hat. Abschnitt drei befasst sich mit der Neurogenese im GD und diskutiert, ob eine verminderte Neurogeneserate maßgeblich für den Neuronenverlust verantwortlich ist. Das letzte Kapitel der Diskussion stellt heraus, inwieweit es zur Astrogliose im GD von Tg442-Mäusen kommt und vergleicht das Ausmaß der Astrogliose mit der im Tiermodell gemessenen GFAP-Expression.

\subsection{Neuronenverlust im Gyrus Dentatus im Tg4-42-Modell}

Der Verlust von Neuronen und die damit einhergehende zerebrale Atrophie sind wichtige neuropathologische Manifestationen bei AD-Patienten (Simić et al. 1997). Seit einigen Jahren ist es möglich, einige bekannte neuropathologische Manifestationen der $\mathrm{AD}$ in transgenen Mausmodellen abzubilden. Eine Vielzahl transgener Mausmodelle wurde entwickelt, die eine alleinige Überexpression von APP oder in Kombination von Tau und/oder PSEN1 abbildeten. Die meisten Modelle zeigten extrazelluläre Plaqueformationen. Ein signifikanter Neuronenverlust wurde zunächst nicht nachgewiesen (Irizarry et al. 1997). In einigen späteren transgenen Mausmodellen konnte jedoch in verschiedenen Hirnregionen, wie im EK (Ribé et al. 
2005), in der CA1-Region des Hippocampus (Calhoun et al. 1998; Casas et al. 2004; Schmitz et al. 2004; Bouter et al. 2013), im GD des Hippocampus (Cotel et al. 2008), im frontalen Kortex (Christensen et al. 2010) und in der fünften kortikalen Schicht (Jawhar et al. 2012) ein signifikanter Neuronenverlust nachgewiesen werden. Zeigte sich bei Calhoun et al. (1998) im transgenen Mausmodell APP23 ein antiproportionaler Zusammenhang zwischen einem signifikanten Neuronenverlust von 25\% und einem starken Anstieg der A $\beta$-Plaqueablagerungen in der CA1-Region, erwies sich bei Schmitz et al. (2004) im APP/PS1 transgenen Mausmodell, dass der Neuronenverlust in der CA1-Region der extraneuronalen Plaqueformation vorausgeht und mit intraneuronalen $A \beta$-Ablagerungen assoziiert ist. Im transgenen Tiermodell APP/PS1KI zeigte sich ebenfalls eine Assoziation zwischen Neuronenverlust und intraneuronaler A $\beta$-Ablagerung in der CA1-Region (Casas et al. 2004). In dem kürzlich entwickelten transgenen $\operatorname{Tg} 4-42-$ Mausmodell, welches ausschließlich $A \beta_{4-42}$ exprimiert und keine Plaques bildet, ließ sich in der CA1-Region vermehrt intraneuronales $A \beta$ nachweisen, welches mit einem starken Neuronenverlust in dieser Region assoziiert war (Bouter et al. 2013). Diese Ergebnisse führten zu der Vermutung, dass vorhandenes intraneuronales $A \beta_{4-42}$ in der CA1Region stark neurotoxisch wirke und ein wichtiger Einflussfaktor für die gesteigerte Neurodegeneration bei der AD sei.

Ein Neuronenverlust im GD ließ sich beispielsweise im APP/PS1KI-Mausmodell beobachten. Interessanterweise ließ sich immunhistochemisch im GD im Gegensatz zur CA1Region kein intraneuronales A $\beta$ nachweisen. Stattdessen fiel ein vermehrtes Auftreten von sichtbaren extrazellulären A $\beta$-Plaques auf, die in anderen Hirnregionen, wie der CA1-Region, nur bedingt auftraten (Cotel et al. 2008). Die fehlenden intraneuronalen A $\beta$-Ablagerungen im GD bei APP/PS1KI-Mäusen passen zu den aus dem Tg4-42-Modell erhaltenen Ergebnissen. In letzterem wurde im GD ebenfalls kein intraneuronales $A \beta$ nachgewiesen. Zudem fanden sich im GD bei Tg4-42-Mäusen im Gegensatz zum APP/PS1KI-Mausmodell keine extrazellulären Plaques (Bouter 2015). Dennoch konnte in dieser Arbeit ohne nachweisbare extrazelluläre Plaques im GD, äquivalent zu den von Cotel et al. (2008) gemachten Beobachtungen, ein signifikanter Verlust der Gesamtneuronenzahl im GD bei transgenen Tieren im Vergleich zu W'T-Tieren mit zunehmendem Alter gemessen werden. Bei Tg4-42-Mäusen kommt es zu einem altersabhängigen Verlust der Neuronenzahl im GD. Design-basierte stereologische Quantifizierungen des GD zeigten bei drei Monate alten Tg4-42-Mäusen einen Neuronenverlust von 29,1\% im Vergleich zu gleichalten Tieren vom WT und einen Neuronenverlust von 29,8\% im Vergleich zu zwei Monate alten transgenen Tieren. Fünf Monate alte transgene Tiere zeigten einen Verlust von 42,5\% und sechs Monate alte Tiere einen Verlust von 39,3\% im Vergleich zu zwei Monate alten Tg4-42-Mäusen. Sechs Monate alte transgene Tiere zeigten 
zudem im Vergleich zu gleichalten WT-Tieren immer noch einen Verlust von 22,8\%. Der Neuronenverlust im GD nahm somit bei Tg4-42-Mäusen mit steigendem Alter zu und erreichte zwischen fünf und sechs Monaten einen Stillstand. Interessant wäre zu untersuchen, ob es bei älteren transgenen Tieren ebenfalls im GD, äquivalent zum bei älteren Tieren beobachteten voranschreitenden Neuronenverlust in der CA1-Region (Antonios et al. 2015), zu einem weiteren Neuronenverlust kommt oder ob die Neuronenzahl, wie zwischen fünf und sechs Monate ermittelt, auch mit zunehmendem Alter stabil bleibt. Der in dieser Arbeit gemessene mit zunehmendem Alter steigende Neuronenverlustes im GD zeigt, dass im Tg4-42Mausmodell nicht nur die CA1-Region, sondern auch andere hippocampale Regionen, wie der GD, von einer signifikanten Neurodegeneration betroffen sind. Stereologische Untersuchungen weiterer Hirnareale könnten einen umfassenderen Blick über die Neurodegeneration im Tg4-42-Mausmodell geben. Zudem reflektieren die in diesem Mausmodell ermittelten Neuronenverluste im GD partiell die bei AD-Patienten in derselben Region ermittelten Neuronenverluste. So zeigte sich in einer früheren Studie ein Neuronenverlust von 23\% im GD von AD-Patienten im Vergleich zu gleichalten gesunden Menschen (Šimić et al. 1997). Dieser Verlust steht in Übereinstimmung zu dem in dieser Arbeit gemessenen Unterschied von 22,8\% zwischen sechs Monate alten transgenen und WT-Tieren. Auch in anderen Studien wurden ähnliche Verluste im GD bei AD-Patienten beobachtet (West 1993; Bobinski et al. 1996).

Interessant wäre zu untersuchen, welche pathologischen Veränderungen ursächlich für den Neuronenverlust im GD des Tg4-42-Mausmodell sind. Anscheinend kann in dieser Region nicht direkt intraneuronales $A \beta$ als Ursache vermutet werden, da sich in Zellen des GD im Gegensatz zur CA1-Region keine intrazellulären Ablagerungen nachweisen lassen (Bouter 2015). Außerdem kommen in diesem Mausmodell im Gegensatz zum APP/PS1KIMausmodell (Cotel et al. 2008) auch nicht extrazelluläre Plaques als Ursache in Betracht, da das Tg4-42-Mausmodell keine extrazellulären A $\beta$-Ablagerungen bildet (Bouter 2015). Möglich ist, dass Zellen des GD dennoch somatodendrititsche Akkumulationen aufweisen, die aufgrund des dichten Neuronenverbandes (Wirths 2017) in dieser Region jedoch nicht detektierbar sind, beziehungsweise die Nachweismethode nicht sensitiv genug ist. Wahrscheinlich ist jedoch, dass es zusätzlich zu möglicherweise nicht darstellbaren intrazellulären Akkumulationen im GD durch Expression des Transgens in der CA1-Region zur negativen Beeinflussung des Neuronenverlustes im GD aufgrund sekretierter löslicher $A \beta_{4-42}$-Peptide kommt. Möglicherweise spielen auch neuroinflammatorische Prozesse als Ursache eine Rolle, da sich sowohl bei Cotel et al. (2008) als auch bei Bouter et al. (2013) sowie in der vorliegenden Arbeit eine gesteigerte Neuroinflammation in Bereichen des Neuronenverlustes beobachten ließ. Neuroinflammatorische Prozesse könnten jedoch auch eine reaktive neuropathologische Manifesta- 
tion auf den Neuronenverlust in den jeweiligen Regionen darstellen. Denkbar ist auch, dass es zwischen Neuronenverlust und abgeschwächter Neurogenese im GD einen Zusammenhang gibt. Wie in dieser Arbeit ermittelt, kommt es mit steigendem Alter zu den gleichen Zeitpunkten (fünf und sechs Monate), zu denen es auch zu einem signifikanten Neuronenverlust kommt, ebenfalls zu einer signifikant verminderten Neurogenese im Vergleich zu zwei Monate alten Tieren. Es kann daher vermutet werden, dass die abgeschwächte Neurogeneserate den vermehrten Neuronenverlust zumindest unterstützt. Als alleinige Ursache für den heftigen Neuronenverlust kann die abgeschwächte Neurogeneserate nicht angesehen werden, da selbst eine hohe Neurogeneserate den enormen Neuronenverlust nicht kompensieren könnte. Zudem ist bekannt, dass es beispielsweise auch bei naiven WT-Tieren im Altersverlauf zu einer deutlichen Abnahme der Neurogeneserate kommt (Kuhn et al. 1996).

\subsection{Unverändertes Volumen des Gyrus Dentatus im Tg4-42-Modell}

Mit fortschreitender Erkrankung kommt es bei AD-Patienten zur Atrophie des Gehirns (Simić et al. 1997). Hauptursache sind der starke Neuronen- und Synapsenverlust mit zunehmender Progression der Erkrankung. Vorwiegend sind der superiore Frontal-, der inferiore Parietallappen sowie Hippocampus, Amygdala und der EK des medialen Temporallappens von Atrophie betroffen (Bottino et al. 2002; Nestor et al. 2008; Dickerson et al. 2009; Dickerson et al. 2011). In AD-Tiermodellen finden sich jedoch widersprüchliche Beobachtungen. Einige transgene Mäuse zeigten Atrophien in bestimmten Bereichen des Gehirns, wohingegen andere keine Veränderung des Volumens aufwiesen. Gehirnatrophien wurden hauptsächlich in Studien gemessen, die sich mit dem PDAPP-Mausmodell befassten (Weiss et al. 2002; Redwine et al. 2003). In einem Experiment zeigte sich mittels Cavalieri-Analyse, dass es bei PDAPP-Mäusen, lange bevor erste Plaques sichtbar waren, zu einer selektiven signifikanten Volumenreduktion des GD kam, ohne dass andere Areale des Hippocampus, wie CA1und CA3-Region, betroffen waren. Die anfängliche Volumenreduktion in dem genannten Experiment zeigte jedoch im Gegensatz zu AD-Patienten keinen progressiven Verlauf (Redwine et al. 2003). Im Gegensatz dazu zeigten Studien, die Tiermodelle mit intraneuronalen A $\beta$-Akkumulationen, wie das APP/PS1KI-Modell, mittels Cavalieri-Analyse untersuchten, keine Veränderungen des Volumens des GD (Cotel et al. 2008; Faure et al. 2011). Die in dieser Arbeit bezüglich des Volumens des GD von Tg4-42-Mäusen ebenfalls mittels CavalieriAnalyse erhobenen Ergebnisse stehen in Übereinstimmung zu den fehlenden Volumenänderungen des GD im APP/PS1KI-Modell. In beiden Modellen kommt es in Assoziation mit intraneuronalen $\mathrm{A} \beta$-Ablagerungen zu einem gesteigerten Neuronenverlust und einer abge- 
schwächten Neurogeneserate im GD mit zunehmendem Alter. Obwohl die Zellzahl im GD verringert ist, lässt sich eine Volumenreduktion nicht erfassen. Jedoch spiegeln diese Ergebnisse nicht den bei AD-Patienten beobachteten Volumenverlust im GD wieder (Simić et al. 1997). Die im PDAPP-Model gemessene Volumenänderung steht in Übereinstimmung zu den bei AD-Patienten gemachten Beobachtungen. Jedoch kommt es nach einer anfänglichen Volumenreduktion zu einem Stillstand und einer nicht weiter fortschreitenden Progression. Dies ist ebenfalls untypisch für die AD.

Aktuell existiert kein Mausmodell, dass den Volumenverlust bei AD-Patienten korrekt abbildet. Es muss jedoch bedacht werden, dass AD-Tiermodelle immer nur einen kleinen Teil der gesamten Pathologie wiederspiegeln und somit viele unbekannte Einflussfaktoren nicht erfasst werden können. Trotz der fehlenden Volumenreduktion kommt es bei Tg4-42-Mäusen zu Verhaltensauffälligkeiten. Ein Neuronenverlust, der sich letzten Endes nicht in einem Volumenverlust der betreffenden Region wiederspiegelt, scheint für die Symptomatik der AD von größerer Bedeutung als der Volumenverlust zu sein. Interessant wäre eine Volumenbestimmung anderer Hirnareale sowie des GD zu späteren Zeitpunkten im Tg4-42Mausmodells.

\subsection{Verminderte Neurogenese im Gyrus Dentatus im Tg4-42-Modell}

Adulte Neurogenese findet beim Menschen im anterioren Teil der subventrikulären Zone des lateralen Ventrikels (Luskin 1993) und in der subgranulären Zone des GD statt (Eriksson et al. 1998). Pro Tag bildet der GD etwa 9000 neuronale Stammzellen, dies entspricht 6\% der granulären Zellpopulation des GD, mit einer Überlebensrate von etwa 50\% (Cameron und Mckay 2001). Mit steigendem Alter kommt es zur Abnahme der Neurogeneserate (Kuhn et al. 1996). Die verminderte Neurogenese könnte in den altersbedingten Rückgang des Hippocampus-abhängigen Lernens involviert sein. Die in der subgranulären Zone des GD gebildeten neuronalen Vorläuferzellen differenzieren sich in der granulären Schicht des GD in Neurone oder Gliazellen (Cameron et al. 1993). Die neugebildeten Neurone im GD entsenden Dendrite in die molekulare Schicht des GD, um Informationen vom EK zu erhalten und sind gleichzeitig über axonale Projektionen mit der CA3-Region verbunden. Sie gliedern sich dadurch in den bestehenden Neuronenverband ein (van Praag et al. 2002; Toni et al. 2007). Die durch die Neurogenese bedingten neuen synaptischen Verschaltungen führen zur Verstärkung der neuronalen Plastizität, unterstützen Lernprozesse und die Gedächtnisbildung. Im Umkehrschluss könnte eine eingeschränkte beziehungsweise sistierende Neurogenese das Ausmaß der neuronalen Plastizität im Hippocampus kompromittieren. Dies kann zu einer gesteigerten neurona- 
len Verletzlichkeit im Hippocampus sowie zu funktionellen Einschränkungen, wie einer reduzierten Kapazität für Lernprozesse und die Gedächtnisbildung führen (Lazarov und Marr 2010). Reduzierte Lernfähigkeit und verminderte Gedächtnisleistung sind Kernsymptome der AD. Aus diesen Gründen ist es möglich, dass dem GD eine besondere Bedeutung für die Symptomatik der AD zukommt, da er als Teil des Hippocampus eine der Hirnregionen ist, die als erste von neurodegenerativen Prozessen betroffen ist.

Einer eingeschränkten Neurogenese kann möglicherweise durch eine Umgebung, die vielfältige Reize bietet und durch körperliche Aktivität entgegengewirkt werden. In verschiedenen Experimenten ergab sich dadurch zum einen ein signifikanter Anstieg der gesamten Zellzahl im GD und zum anderen ein Anstieg neugebildeter Neurone (Kempermann et al. 1998; Jeong et al. 2011; Hüttenrauch et al. 2016). Letzteres weist nicht nur auf eine verminderte Degeneration bestehender Neurone, sondern auch auf eine signifikant gesteigerte Neurogeneserate hin. Dem gegenüber stehen Experimente an anderen Tiermodellen, in denen sich kein positiver Einfluss durch die oben genannten Faktoren auf die Neurogenese beobachtet ließ (Cotel et al. 2012).

Die Mehrzahl der transgenen AD-Mausmodelle, in denen neurogenetische Prozesse untersucht wurden, sind APP- und/oder PSEN1- sowie mit geringerem Ausmaß Tau-Modelle (Kuhn et al. 2007; Lazarov und Marr 2010). Eine Veränderung der Neurogenese in ADModellen kann durch eine Vielzahl von Gründen bedingt sein. Zunächst kommt es während des physiologischen Alterungsprozesses zu einem Verlust von Wachstumsfaktoren im Hippocampus, die potente Stimulatoren der adulten Neurogenese sind (Hattiangady et al. 2005). Eine Verminderung der Wachstumsfaktoren findet sich auch bei AD-Patienten. Dies könnte relevant für die Pathogenese der AD sein (Kuhn et al. 2007).

Bei der Untersuchung der Neurogenese in AD-Mausmodellen ergeben sich widersprüchliche Ergebnisse. In verschiedenen Mausmodellen zeigte sich eine abgeschwächte Neurogeneserate, wohingegen in anderen Mausmodellen ein Anstieg der Neurogeneserate beobachtet werden konnte. In einigen APP-Mausmodellen ließ sich eine Abnahme der Neurogeneserate ermitteln. Im PDAPP-Mausmodell beispielsweise, welches eine APP-Mutation aufweist (Games et al. 1995) und Plaques im Hippocampus bildet, zeigte sich in der subgranulären Zone des GD eine Abnahme der Neurogenese mit steigendem Alter. Eine Korrelation zwischen Plaques und Abnahme der Neurogeneserate bestand jedoch nicht (Donovan et al. 2006). In einem Mausmodell mit zwei Mutationen im APP ließ sich ebenfalls eine abgeschwächte Neurogenese beobachten (Haughey et al. 2002). Im Gegensatz dazu konnte in Mausmodellen, die drei oder mehr Mutationen im APP aufwiesen, ein Anstieg der Zellproliferation und neuronalen Differenzierung im Hippocampus beobachtet werden (Jin et al. 2004a; Jin et al. 2004b). 
Neben mutiertem APP führt auch eine Überexpression von nicht-mutiertem humanem APP zu einer eingeschränkten Neurogeneserate (Naumann et al. 2010). Ein Anstieg der Neurogeneserate scheint durch das bei der $\mathrm{AD}$ produzierte $\mathrm{A} \beta_{1-42}$ sowohl in vitro als auch in vivo erleichtert zu sein (Sotthibundhu et al. 2009). In einer anderen Studie in welcher der scheinbare neurogene Effekt von $A \beta_{1-42}$ ebenfalls untersucht wurde, fanden sich ähnliche Ergebnisse. Interessanterweise zeigte sich in dieser Studie auch, dass nur aggregiertes und in oligomerer Form vorkommendes $A \beta$ zu einer gesteigerten Neurogenese führte. Nicht-aggregiertes $A \beta_{1-42}$ sowie $A \beta_{1-40}$ in aggregierter und nicht-aggregierter Form und das am N- und C-Terminus verkürzte $\mathrm{A} \beta_{25-35}$ führten nicht zu einer verbesserten Neurogenese (López-Toledano und Shelanski 2004). Tiermodelle, in denen es zu intrazellulären Akkumulationen von A $\beta$ kommt, wiesen hingegen eine abgeschwächte Neurogenese auf. So zeigte das 3xTg-AD-Modell, welches Mutationen im APP, PSEN1 und Tau aufweist (Oddo et al. 2003), eine alters- und geschlechtsabhängige Reduktion der Proliferation hippocampaler Vorläuferzellen. Die Reduktion korrelierte dabei mit der Anzahl hippocampaler Neurone in der CA1-Region, die intrazelluläre Akkumulationen von $A \beta$ aufwiesen. Sechs Monate alte Tiere zeigten im Vergleich zu zwei Monate alten Tieren bereits eine Reduktion der Neurogeneserate von mindestens 60\%. Mit zunehmendem Alter kam es zu einem weiteren Anstieg A $\beta$-akkumulierender Neurone in der CA1Region und einem gleichzeitigen verstärkten Abfallen der Neurogeneserate (Rodríguez et al. 2008). Zwar bildet das 3xTg-AD-Modell auch extrazelluläre Plaques, jedoch schienen diese keinen Einfluss auf die eingeschränkte Neurogeneserate zu haben, da sie erst bei 12-Monate alten Tieren deutlich nach Beginn der signifikant eingeschränkten Neurogeneserate auftraten (Rodríguez et al. 2008). Im APP/PS1KI-Modell, welches ebenfalls intraneuronales A $\beta$ in der CA1-Region des Hippocampus aufweist (Casas et al. 2004), zeigte sich wie im 3xTg-ADModell ein Verlust neugebildeter Neurone im GD (Faure et al. 2011). Zudem zeigten die Mäuse Einschränkungen im räumlichen Lernen (Faure et al. 2011). Allerdings konnte intraneuronales A $\beta$ im APP/PS1KI-Modell bislang nur in der CA1-Region (Casas et al. 2004) und nicht im GD (Cotel et al. 2008) direkt nachgewiesen werden. In dem in dieser Arbeit untersuchten Tg4-42-Mausmodell fanden sich wie im 3xTg-AD- und im APP/PS1KI-Modell intraneuronale A $\beta$-Akkumulationen in der CA1-Region des Hippocampus, allerdings ohne begleitende Überexpression von mutantem APP. Passend zu der in den letzten beiden genannten Tiermodellen beobachteten abgeschwächten Neurogeneserate kam es ebenfalls im Tg4-42-Mausmodell zu einem signifikanten Rückgang neugebildeter Neurone mit zunehmendem Alter. So zeigte sich zwischen drei und zwei Monate alten transgenen Tieren ein Rückgang von 21,7\% und zwischen vier und zwei Monate alten transgenen Tieren ein Rückgang von 35,6\%. Bei fünf Monate alten transgenen Tieren kam es im Vergleich zu zwei Monate 
alten transgenen Tieren zu einem signifikanten Rückgang der neugebildeten Neurone von 64,9\%. Sechs Monate alte Tiere zeigten im Vergleich zu den zwei Monate alten Tieren einen Verlust von 67,1\%. Interessant ist, dass der Rückgang neugebildeter Neurone zwischen zwei und sechs Monate im Tg4-42-Mausmodell in etwa dem Rückgang entspricht, der von Rodriguez et al. (2008) zwischen denselben Altersstufen im 3xTg-AD-Modell festgestellt wurde.

Das Tg4-42-Mausmodell zeigt somit eine Abschwächung der Neurogeneserate mit zunehmenden Alter, die mit der Neurogeneserate anderer AD-Tiermodelle vergleichbar ist. Zwischen fünf und sechs Monate alten Tieren scheint es zu einem Stillstand der Neurogeneserate zu kommen. Interessant wäre zu untersuchen, ob es wie bei Rodriguez et al. (2008) in höherem Alter zu einem weiteren Rückgang der neugebildeten Neurone kommt, oder ob zwischen fünf und sechs Monaten tatsächlich die minimalste Neurogeneserate im Tg4-42-Mausmodell erreicht ist. Beim Vergleich der drei letztgenannten Tiermodelle miteinander fällt auf, dass sich bei allen mit zunehmendem Alter ein Anstieg der intraneuronalen A $\beta$-Akkumulation in der CA1-Region, jedoch nicht im GD, detektieren lässt und es damit assoziiert zu einem Abfall der Neurogeneserate kommt. Denkbar ist, dass die eingeschränkte Neurogeneserate dennoch direkt durch innerhalb der Zellen des GD akkumuliertes $A \beta$ bedingt ist, welches jedoch aufgrund des dichten Neuronenverbandes in dieser Region (Wirths 2017) nicht detektierbar ist, beziehungsweise die Nachweismethode nicht sensitiv genug ist. Wahrscheinlich kommt es jedoch zusätzlich zu möglicherweise nicht detektierbaren intrazellulären Akkumulationen im GD durch Expression des Transgens in der CA1-Region zur negativen Beeinflussung der Neurogenese im GD aufgrund sekretierter löslicher $A \beta_{4-42}$-Peptide. Zusätzlich könnten auch andere neuropathologische Effekte, wie eine vermehrte Neuroinflammation, eine wichtige Rolle für die abgeschwächte Neurogeneserate spielen. Wahrscheinlich sind sowohl für den Neuronenverlust als auch für die eingeschränkte Neurogeneserate dieselben neuropathologischen Prozesse von Bedeutung.

Vergleicht man die in dieser Arbeit ermittelte eingeschränkte Neurogenese und den verstärkten Neuronenverlust miteinander, fällt zusätzlich auf, dass beide mit steigendem Alter stärker werden. Zudem ist bemerkenswert, dass beide neuropathologischen Manifestationen ihre maximale Ausprägung zwischen fünf und sechs Monate alten transgenen Tieren erreichen. Gleichzeitig scheint die Progression der Ausprägung zu diesem Zeitpunkt zu stagnieren. Neuronenverlust und Neurogenese scheinen sich gegenseitig zu beeinflussen oder werden gleichermaßen durch einen anderen Faktor beeinflusst. Denkbar ist, dass es sich wie oben ausgeführt hierbei um intraneuronale $A \beta_{4-42}$-Ablagerungen handelt. Möglicherweise verstärkt die abgeschwächte Neurogenese den vermehrten Neuronenverlust. Als alleinige Ursache für den Neuronenverlust kann sie, wie zuvor beschrieben, jedoch nicht angesehen werden, da 
selbst eine sehr hohe Neurogeneserate den enormen Neuronenverlust nicht kompensieren könnte. Zudem kommt es selbst bei W'T-Tieren mit zunehmendem Alter, wenn auch nicht in gleicher Ausprägung wie bei transgenen Tieren, zu einem Abfall der Neurogeneserate (Kuhn et al. 1996). Für die Symptomatik der AD kann die abgeschwächte Neurogenese dennoch mitverantwortlich sein, da neugebildete Neurone im GD die neuronale Plastizität verstärken, für Lernprozesse von entscheidender Bedeutung sind und die Gedächtnisbildung unterstützen. Eine verminderte Neurogenese würde also Einschränkungen in diesen Bereichen bedeuten beziehungsweise den Verlust kompensatorischer Prozesse begünstigen. Somit liegt es nahe, dass eine eingeschränkte Neurogeneserate wahrscheinlich nicht nur eine Folge der Erkrankung ist, sondern auch eine mögliche Ursache für die kognitiven Veränderungen bei der AD darstellt.

In einigen Experimenten konnte zudem beobachtet werden, dass eine eingeschränkte Neurogenese mit Einschränkungen im räumlichen Gedächtnis korreliert (Deng et al. 2010). Diese beobachtete Korrelation steht in ergänzendem Zusammenhang zu den von Faure et al. (2011) und Bouter et al. (2013) publizierten Arbeiten sowie zu den aus dieser Arbeit erhaltenen Beobachtungen. Beide Tiermodelle wiesen eine signifikant eingeschränkte Neurogeneserate mit zunehmendem Alter auf und zeigten gleichzeitig signifikante Auffälligkeiten im Morris-Water-Maze-Test. Denkbar ist, dass zwischen diesen beiden Parametern ein kausaler Zusammenhang besteht, da in einigen Experimenten die Integration neugebildeter Neurone als entscheidend für das Erlenen neuer Informationen sowie für die räumliche Orientierung angesehen wird (Deng et al. 2010).

In späteren Studien wäre interessant zu klären, ob die verminderte Neurogeneserate im Tg4-42-Mausmodell durch eine verfrühte Degeneration der neugebildeten Neurone bedingt ist, oder ob bereits eine Schädigung neuronaler Vorläuferzellen durch gewisse toxische Einflüsse vorliegt.

\subsection{Gesteigerte Astrogliose im Gyrus Dentatus im Tg4-42-Modell}

Astrozyten gehören neben Mikrogliazellen, Oligodendrozyten und Ependymzellen zu der Gruppe der Gliazellen. Gliazellen und Neurone sind die beiden Zellgruppen, aus denen das ZNS besteht. Gliazellen kommen zehnmal häufiger als Neurone vor. Astrozyten sind die am stärksten verbreiteten Gliazellen im ZNS (Lüllmann-Rauch und Paulsen 2012). Die physiologische Funktion der Astrozyten besteht in der Regulierung und Optimierung der Umgebung der Neurone. Dazu zählt unter anderem die Kontrolle der pH-Homöostase, die Bereitstellung von Glukose und Stoffwechselprodukten für die Neurone sowie die Aufnahme von Neuro- 
transmittern (Li et al. 2011). Pathologisch spielen Astrozyten bei einigen neurodegenerativen Erkrankungen, wie der AD (Tuppo und Arias 2005), der amyotrophen Lateralsklerose (Nagai et al. 2007) oder der Chorea Huntington (Singhrao et al. 1999) eine wichtige Rolle. In den Gehirnen von AD-Patienten konnte beobachtet werden, dass A $\beta$ die Reaktivierung von Astrozyten bedingen kann und Astrozyten die größte zelluläre Komponente in der Umgebung von A $\beta$-Plaques darstellen. Teilweise kommt es durch Astrozyten zur Infiltration der Plaques (Dickson 1997; Kato et al. 1998). Reaktivierte Astrozyten werden dazu veranlasst chemische Signalstoffe, wie Wachstumsfaktoren, Zytokine und Chemokine vermehrt freizusetzen. Denkbar ist, dass diese ausgeschütteten Faktoren an den inflammatorischen Prozessen der AD beteiligt sind (Maccioni et al. 2009; Li et al. 2011). Diese ausgeschütteten Faktoren könnten neurodegenerative Schäden, wie Neuronenverlust, gesteigerte Astrogliose, Amyloid-Plaque- und NFT-Formationen unterstützen und aufrechterhalten (Griffin 2006; Lee et al. 2010; Li et al. 2011). Zudem kann es durch die ausgeschütteten Chemo- und Zytokine zur Hochregulation der APP-mRNA kommen, was wiederum zu einer gesteigerten A $\beta$-Generierung führt (Dash und Moore 1995). Im Gegensatz dazu legen einige Experimente nahe, dass Astrozyten, die sich in der Nähe von Plaques ansammeln, nicht an der Entstehung, sondern vielmehr oder zusätzlich an der Phagozytose von Amyloid- $\beta$-Plaques beteiligt sein könnten (Yamaguchi et al. 1998; Wyss-Coray et al. 2003). Defizite in der astrozytären Phagozytose könnten somit zum Teil zur Pathologie der AD beitragen (Tuppo und Arias 2005).

Korrelierend zu den Beobachtungen in den Gehirnen von AD-Patienten weisen einige Tiermodelle ebenfalls sich in der Umgebung von Plaques ansammelnde Astrozyten auf. Die Ansammlung der Astrozyten steigt gleichmäßig mit der Stärke der A $\beta$-Ablagerung bei den transgenen Mauslinien PDAPP, Tg2576 und 5xFAD an (Games et al. 1995; Hsiao et al. 1996; Oakley et al. 2006). Aber auch ohne sichtbare A $\beta$-Ablagerungen konnten in einigen transgenen Tiermodellen, wie zum Beispiel im APP [V7171]-Mausmodell, bereits inflammatorische Prozesse nachgewiesen werden. Die Neuroinflammation ging der Entstehung von A $\beta$-Plaques um einige Monate voraus (Heneka et al. 2005). Nicht nur in der Umgebung bestehender oder sich später bildender A $\beta$-Plaques lassen sich neuroinflammatorische Prozesse beobachten. Auch in Tiermodellen ohne die Generierung neuritischer Plaques konnte eine gesteigerte Aktivität und Ansammlung von Astrozyten im Vergleich zu WT-Tieren nachgewiesen werden. So zeigte sich zum Beispiel im TBA42-Mausmodell, welches das am N-Terminus verkürzte pyroglutamierte $A \beta_{\mathrm{pE} 3-42}$ vermehrt exprimiert, eine gesteigerte astrozytäre Aktivität, ohne dass neuritische Plaques gebildet wurden. Die Ansammlung der Astrozyten korrelierte bei diesem Mausmodell mit der intrazellulären Akkumulation von A $\beta$ (Wittnam 2012). In HOM-TBA2.1Mäusen kam es zur gesteigerten Gliose in Bereichen, in denen vermehrte Neuronenverluste 
sowie $A \beta / A \beta_{\mathrm{pE}^{-}}$-Ablagerungen zu beobachten waren (Alexandru et al. 2011). Im Tiermodell Tg4-42 konnte von Bouter et al. (2013) ebenfalls eine signifikant gesteigerte Astrogliose bei zwei Monate alten transgenen Tieren in Bereichen des Hippocampus beobachtet werden. Die gesteigerte Astrogliose korrelierte in diesen Bereichen mit einem vermehrten Neuronenverlust. In diesen Bereichen konnten zudem starke intraneuronale $A \beta$-Akkumulationen nachgewiesen werden, ohne dass sich extrazelluläre Plaques bildeten, sodass vermutet werden kann, dass zwischen intraneuronaler A $\beta$-Akkumulation und stattfindender Neuroinflammation eine Assoziation besteht. Ein Zusammenhang zwischen intrazellulärer A $\beta$-Ablagerung, gesteigertem Neuronenverlust und vermehrter Astrogliose fand sich auch im APP/PS1KI-Mausmodell (Casas et al. 2004). In späteren quantitativen immunhistochemischen Untersuchungen der Neuroinflammation im APP/PS1KI-Modell zeigte sich im Alter von sechs Monaten eine signifikante Zunahme der Astrozytenzahl (Wirths et al. 2010). APP/PS1KI-Mäuse diesen Alters wiesen einen starken Neuronenverlust (Casas et al. 2004) sowie Verhaltensauffälligkeiten auf (Wirths et al. 2008), sodass der Verdacht, dass zwischen intrazellulärer A $\beta$-Akkumulation, Neuroinflammation, Neuronenverlust und Verhaltensauffälligkeiten zumindest ein korrelativer Zusammenhang besteht, erhärtet werden kann. Eine Assoziation zwischen intraneuronalem $A \beta$ und gesteigerter Astrogliose konnte ebenfalls in Experimenten beobachtet werden, in denen es durch induzierte Neuroinflammation zu einem Anstieg von intrazellulärem APP gekommen war (Sheng et al. 2003). Vergleichbar zu den von Bouter et al. (2013) erhaltenen Erkenntnissen über die Neuroinflammation in der CA1-Region, konnten in der vorliegenden Arbeit bei Tg4-42-Mäusen zusätzlich im GD aktivierte Astrozyten nachgewiesen werden, die mit einem vermehrten Neuronenverlust in dieser Region assoziiert waren. Transgene Mäuse zeigten mittels immunhistochemischer Färbung eine signifikante Astrogliose im Alter von sechs Monaten im Vergleich zu WT-Tieren. Diese Beobachtung steht in Zusammenhang zu denen von Wirths et al. (2010) durchgeführten Experimenten, in denen im APP/PS1KIModell ebenfalls bei sechs Monate alten Tieren ein signifikanter Anstieg der Astrozytenzahl sowie der GFAP-Expression beobachtet wurde. Allerdings lässt sich im Gegensatz zur CA1Region intraneuronales A $\beta$ im GD nicht direkt nachweisen (Cotel et al. 2008; Bouter 2015).

Wahrscheinlich ist, dass die im GD bei sechs Monate alten Tg4-42-Mäusen beobachtete signifikante Astrogliose schon bei jüngeren Tieren beginnt, da von Bouter et al. (2013) bereits bei zwei Monate alten transgenen Tieren in der CA1-Region ein mit dem Anstieg der Astrozyten assoziierter Neuronenverlust beobachtet werden konnte. Zu einem signifikanten Abfall der Neuronenzahl im GD kam es bereits bei drei Monate alten Tieren, sodass davon ausgegangen werden kann, dass zwischen Neuronenverlust und Neuroinflammation im GD äquivalent zur CA1-Region auch bei jüngeren Mäusen ein korrelativer Zusammenhang besteht. 
Zudem wurde die in dieser Arbeit bei sechs Monate alten transgenen Tieren immunhistochemisch beobachtete signifikante Astrogliose durch die Ergebnisse der qPCR-Analyse unterstützt. In dieser zeigte sich ein Anstieg der GFAP-Expression mit zunehmendem Alter. Die GFAP-Expression der transgenen Tiere überstieg zu jedem gemessenen Zeitpunkt (zwei, vier und acht Monate) die Expression der WT-Tiere. Im Alter von vier Monaten zeigte sich ein signifikanter Unterschied. In der Gruppe der acht Monate alten Tieren verringerte sich der Unterschied in der GFAP-Expression zwischen den beiden Genotypen im Vergleich zur Gruppe der vier Monate alten Tieren. Immunhistochemisch gemessene Astrogliose und qPCR-Daten ergänzen sich somit gut und erhärten den Verdacht, dass auch bei jüngeren Tieren eine vermehrte Astrogliose zu finden sein könnte. Zwar wurde für den Zeitraum von sechs Monaten keine qPCR-Daten erhoben. Dennoch findet sich, wie eingangs erwähnt, zwischen jüngeren vier Monate alten Tieren ein signifikanter Unterschied in der GFAPExpression, der auf den immunhistochemisch beobachteten Anstieg der Astrogliose bei sechs Monate alten Tieren hindeuten könnte. Möglicherweise findet sich im Tg4-42-Modell auch bei sechs Monate alten Tieren ein signifikanter Unterschied der GFAP-Expression zu W'T-Tieren, der mit der zu diesem Zeitpunkt beobachteten Astrogliose korreliert. Dies ist sehr wahrscheinlich, da sich bei sechs Monate alten APP/PS1KI-Mäusen ebenfalls eine Korrelation zwischen detektierter Astrogliose und GFAP-Expression zeigte. In diesem Alter kam es zu einem neunfachen Anstieg der Genexpression im Vergleich zu den WT-Tieren (Wirths et al. 2010).

In Zusammenschau mit den GFAP-Expressionsdaten ist es somit wahrscheinlich, dass der Grad der Astrogliose bei vier Monate alten transgenen Tieren stärker als bei den in dieser Arbeit betrachteten sechs Monate alten Tieren im Vergleich zu gleichalten WT-Tieren ausfällt, da der Unterschied der GFAP-Expression zwischen den Genotypen von vier zu acht Monate alten Tieren abnimmt. Somit ist auch denkbar, dass sich die beiden Genotypen acht Monate alter Tiere hinsichtlich ihres immunhistochemisch messbaren Astrogliose-Grades weniger unterscheiden als die jüngeren sechs Monate alten Tieren. Der weniger stark ausgeprägte Unterschied der GFAP-Expression zwischen acht Monate alten Tg4-42- und gleichalten WTMäusen könnte durch die mit steigendem Alter zunehmende Abnahme A $\beta_{4-42}$-exprimierender Zellen im Hippocampus erklärt werden (Bouter et al. 2013). Wie eingangs erwähnt kann A $\beta$ zu reaktiven inflammatorischen Prozessen führen. Eine mit steigendem Alter zunehmende Abnahme $A \beta_{4-42}$-produzierender Zellen im Tg4-42-Modell würde somit zu geringeren toxischen Prozessen und folgend zu verminderten neuroinflammatorischen Reaktionen führen. Passend dazu zeigte sich in anderen Mausmodellen wie dem APP/PS1KI-Modell, die mit steigendem Alter vermehrt $A \beta$-Plaques bilden, eine mit A $\beta$-Plaques assoziierte Zunahme der Neuroinflammation (Casas et al. 2004). Sinnvoll wäre eine in zukünftigen Studien zu gleichen 
Alterszeitpunkten durchgeführte Untersuchung der GFAP-Expression, des Neuronenverlustes und des Astrogliose-Grades im Tg4-42-Mausmodell. In diesen zeigt sich möglicherweise, dass es proportional zum Neuronenverlust und zur GFAP-Expression zu Veränderungen der Astrogliose kommt. Zudem wäre interessant zu klären, ob die Neuroinflammation dem Neuronenverlust vorausgeht und ihn möglicherweise bedingt, oder ob der Neuronenverlust zu einer reaktiv gesteigerten Inflammation in den umliegenden Bereichen führt. 


\section{$5 \quad$ Zusammenfassung}

Die Alzheimerdemenz (AD) ist eine neurodegenerative Erkrankung und stellt die häufigste Demenzform dar. Zu den klassischen neuropathologischen Merkmalen der Erkrankung zählen aus hyperphosphoryliertem Tau bestehende neurofibrilläre Tangles und extrazelluläre Amyloid-Beta(A $\beta)$-Plaques. Neben extrazellulären gelten intrazelluläre A $\beta$-Akkumulationen als wichtige Faktoren für die Entstehung der AD-Symptomatik, da deren Auftreten mit neuropathologischen Auffälligkeiten stark assoziiert ist. Neben den klassischen neuropathologischen Merkmalen sind vor allem ein deutlich gesteigerter Neuronenverlust und eine stark eingeschränkte Neurogeneserate sowie eine enorme Neuroinflammation bei der AD zu beobachten. Die meisten AD-Mausmodelle führen über Mutationen im Amyloid-Vorläuferprotein (APP) und/oder Presenilin (PSEN) zu einer gesteigerten A $\beta$-Expression. Das in dieser Arbeit genutzte Tg4-42-Modell weist im Gegensatz dazu ohne Mutationen im APP und/oder PSEN eine Überexpression von intrazellulär akkumulierendem $A \beta_{4.42}$ auf. Dies ist von besonderer Bedeutung, da so die alleinigen neuropathologischen Eigenschaften von $A \beta_{4-42}$ untersucht werden können, ohne dass Störfaktoren, wie überexprimiertes und/oder mutiertes APP beziehungsweise PSEN, die Ergebnisse beeinflussen.

In der vorliegenden Arbeit konnte nachgewiesen werden, dass das Tg4-42-Mausmodell signifikante neuropathologische Veränderungen im Gyrus Dentatus (GD) aufweist. Allen voran ließ sich ein starker Neuronenverlust in dieser Region beobachten. Bereits bei drei Monate alten Tieren zeigte sich stereologisch ein bedeutender Abfall der Neuronenzahl im Vergleich zu jüngeren Tieren. Mit zunehmendem Alter stieg der Neuronenverlust weiter an und wies bei fünf und sechs Monate alten Tieren signifikante Verluste im Vergleich zu jüngeren Tieren auf. Neben Veränderungen in der Neuronenzahl zeigte sich ein Rückgang Doublecortin-positiver Neurone, anhand derer sich Rückschlüsse auf die Neurogenese ziehen lassen. Die Neurogeneserate sank proportional zum Neuronenverlust mit zunehmendem Alter und zeigte ebenfalls bei fünf und sechs Monate alten Tieren einen signifikanten Rückgang der Neurogeneserate im Vergleich zu jüngeren Tieren. Sowohl der Neuronenverlust als auch die eingeschränkte Neurogeneserate schienen ihre maximale Ausprägung zwischen fünf und sechs Monate alten Tieren erreicht zu haben. Veränderungen des GD-Volumens konnten interessanterweise trotz des starken Neuronenverlustes und der eingeschränkten Neurogenese nicht detektiert werden. Zusätzlich ließ sich im GD mittels immunhistochemischer GFAP-Färbung eine im Vergleich zum Wildtyptier gesteigerte Astrogliose beobachten. Diese korrelierte mit Real-Time-PCRDaten zur GFAP-Genexpression. 
Dem GD kommt in zweierlei Hinsicht eine besondere Bedeutung für die Symptomatik der $\mathrm{AD}$ zu. Zum einen ist er Teil des Hippocampus und somit einer der ersten Hirnbereiche, der bei der AD betroffen ist. Zum anderen ist der GD als eine von zwei Regionen des Gehirns dazu fähig, adulte Neurogenese zu betreiben. Aus diesem Grund ist er im adulten Gehirn integraler Bestandteil bei Prozessen der neuronalen Plastizität, der Gedächtnisbildung und des Lernens. Eine verminderte Neurogeneserate und ein starker Neuronenverlust in dieser Region führen somit zu Einschränkungen dieser Qualitäten und in der Folge zu ADtypischen Symptomen. Weiterhin lassen sich durch die in dieser Arbeit dokumentieren Pathologien die zuvor bei $\mathrm{Tg}$ 4-42-Mäusen beobachteten Verhaltensauffälligkeiten, wie räumliche Orientierungsstörungen, erklären.

Mit den Ergebnissen dieser Arbeit wurden weitere Erkenntnisse über das Tg4-42Mausmodell und die Bedeutung von intrazellulärem $A \beta_{4-42}$ für die Pathogenese der $\mathrm{AD}$ erlangt. Es konnte gezeigt werden, dass nicht nur die CA1-Region, sondern auch der GD durch den Einfluss von $A \beta_{4-42}$ signifikante neuropathologische Auffälligkeiten aufweist. Denkbar ist, dass diese wie in der CA1-Region durch intrazelluläre $A \beta_{4-42}$-Akkumulationen oder durch Expression des Transgens in der CA1-Region aufgrund sekretierter, löslicher A $\beta_{4-42}$-Peptide bedingt sein können. Ein direkter Nachweis intrazellulärer Akkumulationen ist derzeit aufgrund des dichten Neuronenverbandes im GD noch nicht möglich. 


\section{$6 \quad$ Literaturverzeichnis}

Abrous DN, Koehl M, Moal ML (2005): Adult Neurogenesis: From Precursors to Network and Physiology. Physiol Rev $\underline{85}$, 523-569

Alexandru A, Jagla W, Graubner S, Becker A, Bäuscher C, Kohlmann S, Sedlmeier R, Raber KA, Cynis H, Rönicke R, et al. (2011): Selective hippocampal neurodegeneration in transgenic mice expressing small amounts of truncated $A \beta$ is induced by pyroglutamateA $\beta$ formation. J Neurosci $\underline{31}, 12790-12801$

Alzheimer, A. (1907): "Über eine eigenartige Erkankung der Hirnrinde". Allg. Z. Psychiatr. $\underline{64}, 146-148$

Antonios G, Borgers H, Richard BC, Brauß A, Meißner J, Weggen S, Pena V, Pillot T, Davies SL, Bakrania P, et al. (2015): Alzheimer therapy with an antibody against Nterminal Abeta 4-X and pyroglutamate Abeta 3-X. Sci Rep $\underline{5}$

Areosa SA, Sherriff F, McShane R (2005): Memantine for dementia. Cochrane Database Syst Rev., CD003154; http://onlinelibrary.wiley.com/doi/10.1002/14651858.CD0 03154.pub3/epdf; Zugriff am: 03.10.2017

Arnold SE, Hyman BT, Flory J, Damasio AR, Hoesen GWV (1991): The topographical and neuroanatomical distribution of neurofibrillary tangles and neuritic plaques in the cerebral cortex of patients with Alzheimer's disease. Cereb Cortex 1, 103-116

Asai M, Hattori C, Szabó B, Sasagawa N, Maruyama K, Tanuma S, Ishiura S (2003): Putative function of ADAM9, ADAM10, and ADAM17 as APP alpha-secretase. Biochem Biophys Res Commun $\underline{301}$, 231-235

Bard F, Cannon C, Barbour R, Burke RL, Games D, Grajeda H, Guido T, Hu K, Huang J, Johnson-Wood K, et al. (2000): Peripherally administered antibodies against amyloid betapeptide enter the central nervous system and reduce pathology in a mouse model of Alzheimer disease. Nat Med $\underline{6}$, 916-919

Bayer TA, Wirths $O$ (2011): Intraneuronal $A \beta$ as a trigger for neuron loss: can this be translated into human pathology? Biochem Soc Trans $\underline{39}$, 857-861

Bayer TA, Wirths O (2014): Focusing the amyloid cascade hypothesis on N-truncated Abeta peptides as drug targets against Alzheimer's disease. Acta Neuropathol (Berl) $\underline{127}$, $787-801$

Benilova I, Karran E, De Strooper B (2012): The toxic A $\beta$ oligomer and Alzheimer's disease: an emperor in need of clothes. Nat Neurosci $\underline{15}$, 349-357

Bertram L, Lill CM, Tanzi RE (2010): The genetics of Alzheimer disease: back to the fu- 
ture. Neuron $\underline{68}, 270-281$

Bickel H. https://www.deutsche-alzheimer.de/ueber-uns/aktuelles/artikelansicht/artikel/ne ues-informationsblatt-zur-haeufigkeit-von-demenzerkrankungen-hoehere-lebenserwartungmehr-aeltere-m.html; Zugriff am 02.02.2017

Bignami A, Eng LF, Dahl D, Uyeda CT (1972): Localization of the glial fibrillary acidic protein in astrocytes by immunofluorescence. Brain Res $\underline{43}$, 429-435

Birks JS: Cholinesterase inhibitors for Alzheimer's disease; in: Cochrane Database of Systematic Reviews; John Wiley \& Sons, Ltd 2006

Blennow K (2004): Cerebrospinal fluid protein biomarkers for Alzheimer's disease. NeuroRx $\underline{1}, 213-225$

Blennow K, Hampel H (2003): CSF markers for incipient Alzheimer’s disease. Lancet Neurol 2, 605-613

Blennow K, Vanmechelen E, Hampel H (2001): CSF total tau, A $\beta 42$ and phosphorylated tau protein as biomarkers for Alzheimer's disease. Mol Neurobiol 24, 87

Blennow K, de Leon MJ, Zetterberg H (2006): Alzheimer's disease. Lancet 368, 387-403

Bobinski M, Wegiel J, Wisniewski HM, Tarnawski M, Bobinski M, Reisberg B, De Leon MJ, Miller DC (1996): Neurofibrillary pathology--correlation with hippocampal formation atrophy in Alzheimer disease. Neurobiol Aging 17, 909-919

Boekhoorn K, Joels M, Lucassen PJ (2006): Increased proliferation reflects glial and vascular-associated changes, but not neurogenesis in the presenile Alzheimer hippocampus. Neurobiol Dis $\underline{24}, 1-14$

Bottino CMC, Castro CC, Gomes RLE, Buchpiguel CA, Marchetti RL, Neto MRL (2002): Volumetric MRI measurements can differentiate Alzheimer's disease, mild cognitive impairment, and normal aging. Int Psychogeriatr $\underline{14}$, 59-72

Bouter Y (2015): The role of amyloid beta 4-42 in the etiology of Alzheimer's disease. Rer. Nat. Diss. Göttingen 2014

Bouter Y, Dietrich K, Wittnam JL, Rezaei-Ghaleh N, Pillot T, Papot-Couturier S, Lefebvre T, Sprenger F, Wirths O, Zweckstetter M, Bayer TA (2013): N-truncated amyloid $\beta$ (A $\beta$ ) 4-42 forms stable aggregates and induces acute and long-lasting behavioral deficits. Acta Neuropathol (Berl) 126, 189-205

Braak E, Griffing K, Arai K, Bohl J, Bratzke H, Braak H (1999): Neuropathology of Alzheimer's disease: what is new since A. Alzheimer? Eur Arch Psychiatry Clin Neurosci 249, S14

Brown J, Cooper-Kuhn CM, Kempermann G, Van Praag H, Winkler J, Gage FH, Kuhn HG (2003): Enriched environment and physical activity stimulate hippocampal but not 
olfactory bulb neurogenesis. Eur J Neurosci 17, 2042-2046

Bu G, Cam J, Zerbinatti C (2006): LRP in amyloid-beta production and metabolism. Ann N Y Acad Sci 1086, 35-53

Buxbaum JD, Liu KN, Luo Y, Slack JL, Stocking KL, Peschon JJ, Johnson RS, Castner BJ, Cerretti DP, Black RA (1998): Evidence that tumor necrosis factor alpha converting enzyme is involved in regulated alpha-secretase cleavage of the Alzheimer amyloid protein precursor. J Biol Chem 273, 27765-27767

Caillé I, Allinquant B, Dupont E, Bouillot C, Langer A, Müller U, Prochiantz A (2004): Soluble form of amyloid precursor protein regulates proliferation of progenitors in the adult subventricular zone. Dev Camb Engl 131, 2173-2181

Calhoun ME, Wiederhold K-H, Abramowski D, Phinney AL, Probst A, Sturchler-Pierrat C, Staufenbiel M, Sommer B, Jucker M (1998): Neuron loss in APP transgenic mice. Nature $\underline{395}, 755-756$

Cameron HA, Mckay RDG (2001): Adult neurogenesis produces a large pool of new granule cells in the dentate gyrus. J Comp Neurol 435, 406-417

Cameron HA, Woolley CS, McEwen BS, Gould E (1993): Differentiation of newly born neurons and glia in the dentate gyrus of the adult rat. Neuroscience $\underline{56}, 337-344$

Casas C, Sergeant N, Itier J-M, Blanchard V, Wirths O, van der Kolk N, Vingtdeux V, van de Steeg E, Ret G, Canton T, et al. (2004): Massive CA1/2 Neuronal loss with intraneuronal and N-Terminal truncated A $\beta 42$ accumulation in a novel Alzheimer transgenic model. Am J Pathol 165, 1289-1300

Cavanaugh SE, Pippin JJ, Barnard ND (2014): Animal models of Alzheimer disease: historical pitfalls and a path forward. ALTEX $\underline{31}$, 279-302

Chang W-P, Koelsch G, Wong S, Downs D, Da H, Weerasena V, Gordon B, Devasamudram T, Bilcer G, Ghosh AK, Tang J (2004): In vivo inhibition of A $\beta$ production by memapsin 2 ( $\beta$-secretase) inhibitors. J Neurochem $\underline{89}$, 1409-1416

Chartier-Harlin M-C, Crawford F, Houlden H, Warren A, Hughes D, Fidani L, Goate A, Rossor M, Roques P, Hardy J, Mullan M (1991): Early-onset Alzheimer's disease caused by mutations at codon 717 of the $\beta$-amyloid precursor protein gene. Nature $\underline{353}$, 844-846

Chételat G, Desgranges B, de la Sayette V, Viader F, Eustache F, Baron J-C (2003): Mild cognitive impairment: Can FDG-PET predict who is to rapidly convert to Alzheimer's disease? Neurology $\underline{60}, 1374-1377$

Chow VW, Mattson MP, Wong PC, Gleichmann M (2010): An overview of APP processing enzymes and products. Neuromolecular Med 12, 1-12

Christensen DZ, Bayer TA, Wirths O (2010): Intracellular A $\beta$ triggers neuron loss in the 
cholinergic system of the APP/PS1KI mouse model of Alzheimer's disease. Neurobiol Aging 31, 1153-1163

Chui DH, Dobo E, Makifuchi T, Akiyama H, Kawakatsu S, Petit A, Checler F, Araki W, Takahashi K, Tabira T (2001): Apoptotic neurons in Alzheimer's disease frequently show intracellular Abeta42 labeling. J Alzheimers Dis JAD $\underline{3}$, 231-239

Citron M, Oltersdorf T, Haass C, McConlogue L, Hung AY, Seubert P, Vigo-Pelfrey C, Lieberburg I, Selkoe DJ (1992): Mutation of the beta-amyloid precursor protein in familial Alzheimer's disease increases beta-protein production. Nature $\underline{360}$, 672-674

Clarfield AM (2003): The decreasing prevalence of reversible dementias: an updated metaanalysis. Arch Intern Med 163, 2219-2229

Cleary JP, Walsh DM, Hofmeister JJ, Shankar GM, Kuskowski MA, Selkoe DJ, Ashe KH (2005): Natural oligomers of the amyloid- $\beta$ protein specifically disrupt cognitive function. Nat Neurosci $\underline{8}, 79-84$

Corder EH, Saunders AM, Strittmatter WJ, Schmechel DE, Gaskell PC, Small GW, Roses AD, Haines JL, Pericak-Vance MA (1993): Gene dose of apolipoprotein E type 4 allele and the risk of Alzheimer's disease in late onset families. Science 261, 921-923

Corder EH, Saunders AM, Risch NJ, Strittmatter WJ, Schmechel DE, Gaskell PC, Rimmler JB, Locke PA, Conneally PM, Schmader KE, et al. (1994): Protective effect of apolipoprotein E type 2 allele for late onset Alzheimer disease. Nat Genet $\underline{7}, 180-184$

Cotel M-C, Bayer TA, Wirths O (2008): Age-dependent loss of dentate gyrus granule cells in APP/PS1KI mice. Brain Res $\underline{1222}$, 207-213

Cotel M-C, Jawhar S, Christensen DZ, Bayer TA, Wirths O (2012): Environmental enrichment fails to rescue working memory deficits, neuron loss, and neurogenesis in APP/PS1KI mice. Neurobiol Aging $\underline{33}$, 96-107

Couillard-Despres S, Winner B, Schaubeck S, Aigner R, Vroemen M, Weidner N, Bogdahn U, Winkler J, Kuhn H-G, Aigner L (2005): Doublecortin expression levels in adult brain reflect neurogenesis. Eur J Neurosci 21, 1-14

Cras P, Kawai M, Lowery D, Gonzalez-DeWhitt P, Greenberg B, Perry G (1991): Senile plaque neurites in Alzheimer disease accumulate amyloid precursor protein. Proc Natl Acad Sci U S A $\underline{88}, 7552-7556$

Crews L, Masliah E (2010): Molecular mechanisms of neurodegeneration in Alzheimer's disease. Hum Mol Genet 19, R12-R20

Dash PK, Moore AN (1995): Enhanced processing of APP induced by IL-1 beta can be reduced by indomethacin and nordihydroguaiaretic acid. Biochem Biophys Res Commun 208, 542-548 
De Strooper B, Vassar R, Golde T (2010): The secretases: enzymes with therapeutic potential in Alzheimer disease. Nat Rev Neurol 6, 99-107

Deng W, Aimone JB, Gage FH (2010): New neurons and new memories: how does adult hippocampal neurogenesis affect learning and memory? Nat Rev Neurosci 11, 339-350

Dickerson BC, Bakkour A, Salat DH, Feczko E, Pacheco J, Greve DN, Grodstein F, Wright CI, Blacker D, Rosas HD, et al. (2009): The cortical signature of Alzheimer's disease: regionally specific cortical thinning relates to symptom severity in very mild to mild $\mathrm{AD}$ dementia and is detectable in asymptomatic amyloid-positive individuals. Cereb Cortex N Y NY $\underline{19}$, 497-510

Dickerson BC, Stoub TR, Shah RC, Sperling RA, Killiany RJ, Albert MS, Hyman BT, Blacker D, deToledo-Morrell L (2011): Alzheimer-signature MRI biomarker predicts AD dementia in cognitively normal adults. Neurology $\underline{76}$, 1395-1402

Dickson DW (1997): The pathogenesis of senile plaques. J Neuropathol Exp Neurol $\underline{56}$, 321-339

Dickson DW, Wertkin A, Mattiace LA, Fier E, Kress Y, Davies P, Yen SH (1990): Ubiquitin immunoelectron microscopy of dystrophic neurites in cerebellar senile plaques of Alzheimer's disease. Acta Neuropathol (Berl) 79, 486-493

Donovan MH, Yazdani U, Norris RD, Games D, German DC, Eisch AJ (2006): Decreased adult hippocampal neurogenesis in the PDAPP mouse model of Alzheimer's disease. $\mathrm{J}$ Comp Neurol 495, 70-83

Duyckaerts C, Potier M-C, Delatour B (2008): Alzheimer disease models and human neuropathology: similarities and differences. Acta Neuropathol (Berl) 115, 5-38

Eriksson PS, Perfilieva E, Björk-Eriksson T, Alborn A-M, Nordborg C, Peterson DA, Gage FH (1998): Neurogenesis in the adult human hippocampus. Nat Med $\underline{4}, 1313-1317$

Evans KC, Berger EP, Cho CG, Weisgraber KH, Lansbury PT (1995): Apolipoprotein E is a kinetic but not a thermodynamic inhibitor of amyloid formation: implications for the pathogenesis and treatment of Alzheimer disease. Proc Natl Acad Sci U S A $\underline{92}, 763-767$

Farkas E, Luiten PGM (2001): Cerebral microvascular pathology in aging and Alzheimer's disease. Prog Neurobiol 64, 575-611

Farris W, Mansourian S, Chang Y, Lindsley L, Eckman EA, Frosch MP, Eckman CB, Tanzi RE, Selkoe DJ, Guénette S (2003): Insulin-degrading enzyme regulates the levels of insulin, amyloid $\beta$-protein, and the $\beta$-amyloid precursor protein intracellular domain in vivo. Proc Natl Acad Sci U S A $\underline{100,}$ 4162-4167

Faure A, Verret L, Bozon B, El Tannir El Tayara N, Ly M, Kober F, Dhenain M, Rampon C, Delatour B (2011): Impaired neurogenesis, neuronal loss, and brain functional deficits 
in the APPxPS1-Ki mouse model of Alzheimer's disease. Neurobiol Aging 32, 407-418

Fernández-Vizarra P, Fernández AP, Castro-Blanco S, Serrano J, Bentura ML, MartínezMurillo R, Martínez A, Rodrigo J (2004): Intra- and extracellular Abeta and PHF in clinically evaluated cases of Alzheimer's disease. Histol Histopathol $\underline{19}$, 823-844

Fitzpatrick AL, Kuller LH, Lopez OL, Kawas CH, Jagust W (2005): Survival following dementia onset: Alzheimer's disease and vascular dementia. J Neurol Sci 229-230, 43-49

Fleminger S, Oliver D, Lovestone S, Rabe-Hesketh S, Giora A (2003): Head injury as a risk factor for Alzheimer's disease: the evidence 10 years on; a partial replication. J Neurol Neurosurg Psychiatry $\underline{74}$, 857-862

Folstein MF, Folstein SE, McHugh PR (1975): “Mini-mental state”: A practical method for grading the cognitive state of patients for the clinician. J Psychiatr Res 12, 189-198

Frisoni GB, Laakso MP, Beltramello A, Geroldi C, Bianchetti A, Soininen H, Trabucchi M (1999): Hippocampal and entorhinal cortex atrophy in frontotemporal dementia and Alzheimer's disease. Neurology $\underline{52}, 91-91$

Gage FH, Kempermann G, Palmer TD, Peterson DA, Ray J (1998): Multipotent progenitor cells in the adult dentate gyrus. J Neurobiol $\underline{36}$, 249-266

Games D, Adams D, Alessandrini R, Barbour R, Borthelette P, Blackwell C, Carr T, Clemens J, Donaldson T, Gillespie F, et al. (1995): Alzheimer-type neuropathology in transgenic mice overexpressing V717F $\beta$-amyloid precursor protein. Nature $\underline{373}$, 523-527

Glenner GG (2012): Reprint of “Alzheimer’s disease: Initial report of the purification and characterization of a novel cerebrovascular amyloid protein”. Biochem Biophys Res Commun 425, 534-539

Glenner GG, Wong CW (1984): Alzheimer's disease and Down’s syndrome: sharing of a unique cerebrovascular amyloid fibril protein. Biochem Biophys Res Commun 122, 11311135

Goate A, Chartier-Harlin M-C, Mullan M, Brown J, Crawford F, Fidani L, Giuffra L, Haynes A, Irving N, James L, et al. (1991): Segregation of a missense mutation in the amyloid precursor protein gene with familial Alzheimer's disease. Nature 349, 704-706

Gómez-Isla T, Price JL, Jr DWM, Morris JC, Growdon JH, Hyman BT (1996): Profound L loss of layer II entorhinal cortex neurons occurs in very mild Alzheimer's disease. J Neurosci $\underline{16}$, 4491-4500

Gómez-Isla T, Hollister R, West H, Mui S, Growdon JH, Petersen RC, Parisi JE, Hyman BT (1997): Neuronal loss correlates with but exceeds neurofibrillary tangles in Alzheimer's disease. Ann Neurol 41, 17-24

Gouras GK, Tsai J, Naslund J, Vincent B, Edgar M, Checler F, Greenfield JP, Haroutunian 
V, Buxbaum JD, Xu H, et al. (2000): Intraneuronal A $\beta 42$ accumulation in human brain. Am J Pathol 156, 15-20

Griffin WST (2006): Inflammation and neurodegenerative diseases. Am J Clin Nutr $\underline{\text { 83, }}$ 470S-474S

Grundke-Iqbal I, Iqbal K, Tung YC, Quinlan M, Wisniewski HM, Binder LI (1986): Abnormal phosphorylation of the microtubule-associated protein tau (tau) in Alzheimer cytoskeletal pathology. Proc Natl Acad Sci U S A $\underline{83}$, 4913-4917

Gyure KA, Durham R, Stewart WF, Smialek JE, Troncoso JC (2001): Intraneuronal abetaamyloid precedes development of amyloid plaques in Down syndrome. Arch Pathol Lab Med 125, 489-492

Hampel H, Buerger K, Zinkowski R, Teipel SJ, Goernitz A, Andreasen N, Sjoegren M, DeBernardis J, Kerkman D, Ishiguro K, et al. (2004): Measurement of Phosphorylated Tau Epitopes in the Differential Diagnosisof Alzheimer Disease: A Comparative Cerebrospinal Fluid Study. Arch Gen Psychiatry $\underline{61}$, 95-102

Hardy J, Selkoe DJ (2002): The amyloid hypothesis of Alzheimer's disease: progress and problems on the road to therapeutics. Science 297, 353-356

Hardy JA, Higgins GA (1992): Alzheimer's disease: the amyloid cascade hypothesis. Science $\underline{256}, 184-185$

Hattiangady B, Rao MS, Shetty GA, Shetty AK (2005): Brain-derived neurotrophic factor, phosphorylated cyclic AMP response element binding protein and neuropeptide $\mathrm{Y}$ decline as early as middle age in the dentate gyrus and CA1 and CA3 subfields of the hippocampus. Exp Neurol 195, 353-371

Haughey NJ, Nath A, Chan SL, Borchard AC, Rao MS, Mattson MP (2002): Disruption of neurogenesis by amyloid $\beta$-peptide, and perturbed neural progenitor cell homeostasis, in models of Alzheimer's disease. J Neurochem 푸, 1509-1524

Haupt C, Leppert J, Rönicke R, Meinhardt J, Yadav JK, Ramachandran R, Ohlenschläger O, Reymann KG, Görlach M, Fändrich M (2012): Structural basis of $\beta$-amyloid-dependent synaptic dysfunctions. Angew Chem Int Ed ㅁ1, 1576-1579

Hejl A, Høgh P, Waldemar G (2002): Potentially reversible conditions in 1000 consecutive memory clinic patients. J Neurol Neurosurg Psychiatry 73, 390-394

Heneka MT, Sastre M, Dumitrescu-Ozimek L, Dewachter I, Walter J, Klockgether T, Van Leuven F (2005): Focal glial activation coincides with increased BACE1 activation and precedes amyloid plaque deposition in APP[V717I] transgenic mice. J Neuroinflammation 2, 22

Herholz K, Salmon E, Perani D, Baron JC, Holthoff V, Frölich L, Schönknecht P, Ito K, 
Mielke R, Kalbe E, et al. (2002): Discrimination between Alzheimer dementia and controls by automated analysis of multicenter FDG PET. NeuroImage 17, 302-316

Hesse C, Rosengren L, Vanmechelen E, Vanderstichele H, Jensen C, Davidsson P, Blennow K (2000): Cerebrospinal fluid markers for Alzheimer's disease evaluated after acute ischemic stroke. J Alzheimers Dis JAD 2, 199-206

Hesse C, Rosengren L, Andreasen N, Davidsson P, Vanderstichele H, Vanmechelen E, Blennow K (2001): Transient increase in total tau but not phospho-tau in human cerebrospinal fluid after acute stroke. Neurosci Lett 297, 187-190

Hirai K, Aliev G, Nunomura A, Fujioka H, Russell RL, Atwood CS, Johnson AB, Kress Y, Vinters HV, Tabaton M, et al. (2001): Mitochondrial abnormalities in Alzheimer's disease. J Neurosci 21, 3017-3023

Holtzman DM, John CM, Goate A (2011): Alzheimer's sisease: the challenge of the second Century. Sci Transl Med $\underline{3}, 77 \mathrm{sr} 1$

Honer WG, Dickson DW, Gleeson J, Davies P (1992): Regional synaptic pathology in Alzheimer's disease. Neurobiol Aging $\underline{13}$, 375-382

Hsiao K, Chapman P, Nilsen S, Eckman C, Harigaya Y, Younkin S, Yang F, Cole G (1996): Correlative memory deficits, $A \beta$ elevation, and amyloid plaques in transgenic mice. Science $\underline{274}$, 99-103

Hüttenrauch M, Brauß A, Kurdakova A, Borgers H, Klinker F, Liebetanz D, SalinasRiester G, Wiltfang J, Klafki HW, Wirths O (2016): Physical activity delays hippocampal neurodegeneration and rescues memory deficits in an Alzheimer disease mouse model. Transl Psychiatry $\underline{6}$, e800

Iadecola C (2004): Neurovascular regulation in the normal brain and in Alzheimer's disease. Nat Rev Neurosci $\underline{5}$, 347-360

ICD-10-GM-2017 F00.-*. http://www.icd-code.de/icd/code/F00.-*.html; Zugriff am 05.01 .2017

Ingelsson M, Fukumoto H, Newell KL, Growdon JH, Hedley-Whyte ET, Frosch MP, Albert MS, Hyman BT, Irizarry MC (2004): Early Abeta accumulation and progressive synaptic loss, gliosis, and tangle formation in AD brain. Neurology 62, 925-931

Iqbal K, del C. Alonso A, Chen S, Chohan MO, El-Akkad E, Gong C-X, Khatoon S, Li B, Liu F, Rahman A, et al. (2005): Tau pathology in Alzheimer disease and other tauopathies. Biochim Biophys Acta BBA - Mol Basis Dis 1739, 198-210

Irizarry MC, Soriano F, McNamara M, Page KJ, Schenk D, Games D, Hyman BT (1997): $\mathrm{A} \beta$ deposition is associated with neuropil changes, but not with overt neuronal loss in the human amyloid precursor protein V717F (PDAPP) transgenic mouse. J Neurosci $\underline{17}$, 
7053-7059

Itagaki S, McGeer PL, Akiyama H, Zhu S, Selkoe D (1989): Relationship of microglia and astrocytes to amyloid deposits of Alzheimer disease. J Neuroimmunol 24, 173-182

Iwatsubo T, Odaka A, Suzuki N, Mizusawa H, Nukina N, Ihara Y (1994): Visualization of A beta 42(43) and A beta 40 in senile plaques with end-specific A beta monoclonals: evidence that an initially deposited species is A beta 42(43). Neuron $\underline{13}, 45-53$

Jack CR, Shiung MM, Weigand SD, O’Brien PC, Gunter JL, Boeve BF, Knopman DS, Smith GE, Ivnik RJ, Tangalos EG, Petersen RC (2005): Brain atrophy rates predict subsequent clinical conversion in normal elderly and amnestic MCI. Neurology $\underline{65}, 1227-1231$

Jagust W (2006): Positron emission tomography and magnetic resonance imaging in the diagnosis and prediction of dementia. Alzheimers Dement 2, 36-42

Jarrett JT, Berger EP, Lansbury PT (1993): The carboxy terminus of the beta amyloid protein is critical for the seeding of amyloid formation: implications for the pathogenesis of Alzheimer's disease. Biochemistry (Mosc) 32, 4693-4697

Jawhar S, Trawicka A, Jenneckens C, Bayer TA, Wirths O (2012): Motor deficits, neuron loss, and reduced anxiety coinciding with axonal degeneration and intraneuronal $A \beta$ aggregation in the 5XFAD mouse model of Alzheimer's disease. Neurobiol Aging $\underline{33}$, 196.e29-196.e40

Jellinger KA (2006): Clinicopathological analysis of dementia disorders in the elderly--an update. J Alzheimers Dis JAD $\underline{9}, 61-70$

Jendroska K, Poewe W, Pluess J, Iwerssen-Schmidt H, Paulsen J, Barthel S, Schelosky L, Cervós-Navarro J, Daniel SE, DeArmond SJ (1995): Ischemic stress induces deposition of amyloid $\beta$ immunoreactivity in human brain. Acta Neuropathol (Berl) 90, 461-466

Jeong YH, Kim JM, Yoo J, Lee SH, Kim H-S, Suh Y-H (2011): Environmental enrichment compensates for the effects of stress on disease progression in Tg2576 mice, an Alzheimer's disease model. J Neurochem $\underline{119}, 1282-1293$

Jin K, Galvan V, Xie L, Mao XO, Gorostiza OF, Bredesen DE, Greenberg DA (2004a): Enhanced neurogenesis in Alzheimer's disease transgenic (PDGF-APPSw,Ind) mice. Proc Natl Acad Sci U S A $\underline{101}, 13363$

Jin K, Peel AL, Mao XO, Xie L, Cottrell BA, Henshall DC, Greenberg DA (2004b): Increased hippocampal neurogenesis in Alzheimer's disease. Proc Natl Acad Sci U S A $\underline{101}$, 343-347

Joachim CL, Morris JH, Selkoe DJ (1989): Diffuse senile plaques occur commonly in the cerebellum in Alzheimer's disease. Am J Pathol 135, 309-319

Kang J, Müller-Hill B (1990): Differential splicing of Alzheimer's disease amyloid A4 
precursor RNA in rat tissues: PreA4(695) mRNA is predominantly produced in rat and human brain. Biochem Biophys Res Commun 166, 1192-1200

Karran E, Mercken M, Strooper BD (2011): The amyloid cascade hypothesis for Alzheimer's disease: an appraisal for the development of therapeutics. Nat Rev Drug Dis$\operatorname{cov} \underline{10}, 698-712$

Kato S, Gondo T, Hoshii Y, Takahashi M, Yamada M, Ishihara T (1998): Confocal observation of senile plaques in Alzheimer's disease: Senile plaque morphology and relationship between senile plaques and astrocytes. Pathol Int $\underline{48}$, 332-340

Kempermann G, Kuhn HG, Gage FH (1998): Experience-Induced Neurogenesis in the Senescent Dentate Gyrus. J Neurosci 18, 3206-3212

Knowles RB, Wyart C, Buldyrev SV, Cruz L, Urbanc B, Hasselmo ME, Stanley HE, Hyman BT (1999): Plaque-induced neurite abnormalities: implications for disruption of neural networks in Alzheimer's disease. Proc Natl Acad Sci U S A 96, 5274-5279

Kuhn HG, Dickinson-Anson H, Gage FH (1996): Neurogenesis in the dentate gyrus of the adult rat: age-related decrease of neuronal progenitor proliferation. J Neurosci $\underline{16}$, 20272033

Kuhn HG, Cooper-Kuhn CM, Boekhoorn K, Lucassen PJ (2007): Changes in neurogenesis in dementia and Alzheimer mouse models: are they functionally relevant? Eur Arch Psychiatry Clin Neurosci 257, 281-289

LaFerla FM, Tinkle BT, Bieberich CJ, Haudenschild CC, Jay G (1995): The Alzheimer's A beta peptide induces neurodegeneration and apoptotic cell death in transgenic mice. Nat Genet $\underline{9}, 21-30$

LaFerla FM, Green KN, Oddo S (2007): Intracellular amyloid- $\beta$ in Alzheimer's disease. Nat Rev Neurosci $\underline{8}$, 499-509

Lammich S, Kojro E, Postina R, Gilbert S, Pfeiffer R, Jasionowski M, Haass C, Fahrenholz F (1999): Constitutive and regulated alpha-secretase cleavage of Alzheimer's amyloid precursor protein by a disintegrin metalloprotease. Proc Natl Acad Sci U S A $\underline{96}$, 39223927

Lazarov O, Marr RA (2010): Neurogenesis and Alzheimer's disease: At the crossroads. Exp Neurol 223, 267-281

Lee Y-J, Han SB, Nam S-Y, Oh K-W, Hong JT (2010): Inflammation and Alzheimer's disease. Arch Pharm Res 33, 1539-1556

Leitlinie Demenzen. http://www.dgn.org/leitlinien/3176-leitlinie-diagnose-und-therapievon-demenzen-2016; Zugriff am 06.01.2017

Lemere CA, Blusztajn JK, Yamaguchi H, Wisniewski T, Saido TC, Selkoe DJ (1996): Se- 
quence of deposition of heterogeneous amyloid beta-peptides and APO E in Down syndrome: implications for initial events in amyloid plaque formation. Neurobiol Dis $\underline{3}, 16-32$ Lesné S, Koh MT, Kotilinek L, Kayed R, Glabe CG, Yang A, Gallagher M, Ashe KH (2006): A specific amyloid- $\beta$ protein assembly in the brain impairs memory. Nature $\underline{440}$, 352-357

Lesné S, Kotilinek L, Ashe KH (2008): Plaque-bearing mice with reduced levels of oligomeric amyloid- $\beta$ assemblies have intact memory function. Neuroscience $\underline{151}$, 745-749

Lewis H, Beher D, Cookson N, Oakley A, Piggott M, Morris CM, Jaros E, Perry R, Ince P, Kenny RA, et al. (2006): Quantification of Alzheimer pathology in ageing and dementia: age-related accumulation of amyloid- $\beta(42)$ peptide in vascular dementia. Neuropathol Appl Neurobiol 32, 103-118

Li C, Zhao R, Gao K, Wei Z, Yin MY, Lau LT, Chui D, Yu ACH (2011): Astrocytes: implications for neuroinflammatory pathogenesis of Alzheimer's disease. Curr Alzheimer Res $\underline{8}, 67-80$

López-Toledano MA, Shelanski ML (2004): Neurogenic effect of $\beta$-amyloid peptide in the development of neural stem cells. J Neurosci 24, 5439-5444

Lucin KM, Wyss-Coray T (2009): Immune activation in brain aging and neurodegeneration: too much or too little? Neuron $\underline{64}, 110-122$

Lüllmann-Rauch R, Paulsen F: Taschenlehrbuch Histologie. 4. Auflage; Thieme, Stuttgart u.a. 2012

Luskin MB (1993): Restricted proliferation and migration of postnatally generated neurons derived from the forebrain subventricular zone. Neuron $\underline{11}$, 173-189

Ma J, Yee A, Brewer HB, Das S, Potter H (1994): Amyloid-associated proteins $\alpha 1$ antichymotrypsin and apolipoprotein E promote assembly of Alzheimer $\beta$-protein into filaments. Nature $\underline{372}, 92-94$

Maccioni RB, Rojo LE, Fernández JA, Kuljis RO (2009): The role of neuroimmunomodulation in Alzheimer's disease. Ann N Y Acad Sci 1153, 240-246

Mahley RW, Innerarity TL, Rall SC, Weisgraber KH (1984): Plasma lipoproteins: apolipoprotein structure and function. J Lipid Res $\underline{25}$, 1277-1294

Masters CL, Simms G, Weinman NA, Multhaup G, McDonald BL, Beyreuther K (1985a): Amyloid plaque core protein in Alzheimer disease and Down syndrome. Proc Natl Acad Sci U S A $\underline{82}, 4245-4249$

Masters CL, Multhaup G, Simms G, Pottgiesser J, Martins RN, Beyreuther K (1985b): Neuronal origin of a cerebral amyloid: neurofibrillary tangles of Alzheimer's disease contain the same protein as the amyloid of plaque cores and blood vessels. EMBO J 4 , 2757- 
2763

Masuhr KF, Masuhr F, Neumann M: Duale Reihe Neurologie. 7.; Thieme, Stuttgart 2013

Mattson MP (1997): Cellular actions of beta-amyloid precursor protein and its soluble and fibrillogenic derivatives. Physiol Rev 77, 1081-1132

Mayeux R, Stern Y (2012): Epidemiology of Alzheimer disease. Cold Spring Harb Perspect Med 2

McGeer PL, McGeer EG (1995): The inflammatory response system of brain: implications for therapy of Alzheimer and other neurodegenerative diseases. Brain Res Rev 21, 195218

McKhann GM, Knopman DS, Chertkow H, Hyman BT, Jack CR, Kawas CH, Klunk WE, Koroshetz WJ, Manly JJ, Mayeux R, et al. (2011): The diagnosis of dementia due to Alzheimer's disease: recommendations from the National Institute on Aging-Alzheimer's Association workgroups on diagnostic guidelines for Alzheimer's disease. Alzheimers Dement $\underline{7}, 263-269$

Minoshima S, Foster NL, Sima AA, Frey KA, Albin RL, Kuhl DE (2001): Alzheimer's disease versus dementia with Lewy bodies: cerebral metabolic distinction with autopsy confirmation. Ann Neurol 50, 358-365

Mitchell AJ (2009): A meta-analysis of the accuracy of the mini-mental state examination in the detection of dementia and mild cognitive impairment. J Psychiatr Res $\underline{43}$, 411-431

Mullan M, Crawford F, Axelman K, Houlden H, Lilius L, Winblad B, Lannfelt L (1992): A pathogenic mutation for probable Alzheimer's disease in the APP gene at the Nterminus of $\beta$-amyloid. Nat Genet $\underline{1}$, 345-347

Nagai M, Re DB, Nagata T, Chalazonitis A, Jessell TM, Wichterle H, Przedborski S (2007): Astrocytes expressing ALS-linked mutated SOD1 release factors selectively toxic to motor neurons. Nat Neurosci $\underline{10}, 615-622$

Nagele RG, D’Andrea MR, Anderson WJ, Wang H-Y (2002): Intracellular accumulation of beta-amyloid(1-42) in neurons is facilitated by the alpha 7 nicotinic acetylcholine receptor in Alzheimer's disease. Neuroscience 110, 199-211

Naumann N, Alpár A, Ueberham U, Arendt T, Gärtner U (2010): Transgenic expression of human wild-type amyloid precursor protein decreases neurogenesis in the adult hippocampus. Hippocampus 20, 971-979

Nestor SM, Rupsingh R, Borrie M, Smith M, Accomazzi V, Wells JL, Fogarty J, Bartha R (2008): Ventricular enlargement as a possible measure of Alzheimer's disease progression validated using the Alzheimer's disease neuroimaging initiative database. Brain $\underline{131}$, 2443-2454 
Nilsberth C, Westlind-Danielsson A, Eckman CB, Condron MM, Axelman K, Forsell C, Stenh C, Luthman J, Teplow DB, Younkin SG, et al. (2001): The „Arctic“ APP mutation (E693G) causes Alzheimer's disease by enhanced A $\beta$ protofibril formation. Nat Neurosci 4, 887-893

Oakley H, Cole SL, Logan S, Maus E, Shao P, Craft J, Guillozet-Bongaarts A, Ohno M, Disterhoft J, Eldik LV, et al. (2006): Intraneuronal $\beta$-amyloid aggregates, neurodegeneration, and neuron loss in transgenic mice with five familial Alzheimer's disease mutations: potential factors in amyloid plaque formation. J Neurosci 26, 10129-10140

Oddo S, Caccamo A, Kitazawa M, Tseng BP, LaFerla FM (2003): Amyloid deposition precedes tangle formation in a triple transgenic model of Alzheimer's disease. Neurobiol Aging 24, 1063-1070

Oddo S, Caccamo A, Tran L, Lambert MP, Glabe CG, Klein WL, LaFerla FM (2006): Temporal profile of amyloid- $\beta(A \beta)$ oligomerization in an in vivo model of Alzheimer disease a link between A $\beta$ and tau pathology. J Biol Chem 281, 1599-1604

Ohsawa I, Takamura C, Morimoto T, Ishiguro M, Kohsaka S (1999): Amino-terminal region of secreted form of amyloid precursor protein stimulates proliferation of neural stem cells. Eur J Neurosci 11, 1907-1913

Orgogozo J-M, Gilman S, Dartigues J-F, Laurent B, Puel M, Kirby LC, Jouanny P, Dubois B, Eisner L, Flitman S, et al. (2003): Subacute meningoencephalitis in a subset of patients with AD after Abeta42 immunization. Neurology $\underline{61}, 46-54$

Owen MJ, James LA, Hardy JA, Williamson R, Goate AM (1990): Physical mapping around the Alzheimer disease locus on the proximal long arm of chromosome 21. Am J Hum Genet 46, 316-322

Oyama F, Sawamura N, Kobayashi K, Morishima-Kawashima M, Kuramochi T, Ito M, Tomita T, Maruyama K, Saido TC, Iwatsubo T, et al. (1998): Mutant presenilin 2 transgenic mouse: effect on an age-dependent increase of amyloid $\beta$-protein 42 in the brain. $\mathrm{J}$ Neurochem $\underline{71}, 313-322$

Padurariu M, Ciobica A, Mavroudis I, Fotiou D, Baloyannis S (2012): Hippocampal neuronal loss in the CA1 and CA3 areas of Alzheimer's disease patients. Psychiatr Danub 24, $152-158$

Parsons CG, Stöffler A, Danysz W (2007): Memantine: a NMDA receptor antagonist that improves memory by restoration of homeostasis in the glutamatergic system - too little activation is bad, too much is even worse. Neuropharmacology $\underline{53}$, 699-723

Parsons CG, Danysz W, Dekundy A, Pulte I (2013): Memantine and cholinesterase inhibitors: complementary mechanisms in the treatment of Alzheimer's disease. Neurotox Res 24, 358-369 
Petersen RC, Smith GE, Waring SC, Ivnik RJ, Tangalos EG, Kokmen E (1999): Mild cognitive impairment: clinical characterization and outcome. Arch Neurol 56, 303-308

Pike CJ, Overman MJ, Cotman CW (1995a): Amino-terminal deletions enhance aggregation of $\beta$-amyloid peptides in Vitro. J Biol Chem $\underline{270}$, 23895-23898

Pike CJ, Cummings BJ, Cotman CW (1995b): Early association of reactive astrocytes with senile plaques in Alzheimer's disease. Exp Neurol 132, 172-179

Pimplikar SW (2009): Reassessing the amyloid cascade hypothesis of Alzheimer's disease. Int J Biochem Cell Biol 41, 1261-1268

Portelius E, Bogdanovic N, Gustavsson MK, Volkmann I, Brinkmalm G, Zetterberg H, Winblad B, Blennow K (2010): Mass spectrometric characterization of brain amyloid beta isoform signatures in familial and sporadic Alzheimer's disease. Acta Neuropathol (Berl) 120, 185-193

Portelius E, Lashley T, Westerlund A, Persson R, Fox NC, Blennow K, Revesz T, Zetterberg H (2015): Brain amyloid-beta fragment signatures in pathological ageing and Alzheimer's disease by hybrid immunoprecipitation mass spectrometry. Neurodegener Dis $\underline{15}$, 50-57

Profenno LA, Porsteinsson AP, Faraone SV (2010): Meta-analysis of Alzheimer's disease risk with obesity, diabetes, and related disorders. Biol Psychiatry 67, 505-512

Redwine JM, Kosofsky B, Jacobs RE, Games D, Reilly JF, Morrison JH, Young WG, Bloom FE (2003): Dentate gyrus volume is reduced before onset of plaque formation in PDAPP mice: A magnetic resonance microscopy and stereologic analysis. Proc Natl Acad Sci $\underline{100}, 1381-1386$

Reitz C, Mayeux R (2014): Alzheimer disease: epidemiology, diagnostic criteria, risk factors and biomarkers. Biochem Pharmacol $\underline{88}$, 640-651

Ribé EM, Pérez M, Puig B, Gich I, Lim F, Cuadrado M, Sesma T, Catena S, Sánchez B, Nieto M, et al. (2005): Accelerated amyloid deposition, neurofibrillary degeneration and neuronal loss in double mutant APP/tau transgenic mice. Neurobiol Dis 20, 814-822

Riekse RG, Leverenz JB, McCormick W, Bowen JD, Teri L, Nochlin D, Simpson K, Eugenio C, Larson EB, Tsuang D (2004): Effect of vascular lesions on cognition in Alzheimer's disease: a community-based study. J Am Geriatr Soc 52, 1442-1448

Rodríguez JJ, Verkhratsky A (2011): Neurogenesis in Alzheimer’s disease. J Anat 219, 78-89

Rodríguez JJ, Jones VC, Tabuchi M, Allan SM, Knight EM, LaFerla FM, Oddo S, Verkhratsky A (2008): Impaired adult neurogenesis in the dentate gyrus of a triple transgenic mouse model of Alzheimer's disease. PLoS ONE $\underline{3}$ 
Rogaev EI, Sherrington R, Rogaeva EA, Levesque G, Ikeda M, Liang Y, Chi H, Lin C, Holman K, Tsuda T, et al. (1995): Familial Alzheimer's disease in kindreds with missense mutations in a gene on chromosome 1 related to the Alzheimer's disease type 3 gene. Nature $\underline{376}, 775-778$

Royall DR (2002): Alzheimer disease as a vascular disorder: nosological evidence. Stroke $\underline{33}$, 2147-2148

Russo C, Violani E, Salis S, Venezia V, Dolcini V, Damonte G, Benatti U, D’Arrigo C, Patrone E, Carlo P, Schettini G (2002): Pyroglutamate-modified amyloid $\beta$-peptides A $\beta N 3(p E)$ - strongly affect cultured neuron and astrocyte survival. J Neurochem $\underline{82}$, 1480-1489

Scarmeas N, Stern Y, Mayeux R, Luchsinger JA (2006): Mediterranean diet, Alzheimer disease, and vascular mediation. Arch Neurol $\underline{63}, 1709-1717$

Scarmeas N, Luchsinger JA, Schupf N, Brickman AM, Cosentino S, Tang MX, Stern Y (2009): Physical activity, diet, and risk of Alzheimer disease. JAMA J Am Med Assoc $\underline{302}$, 627-637

Scheff SW, Price DA (1993): Synapse loss in the temporal lobe in Alzheimer's disease. Ann Neurol 33, 190-199

Schellenberg GD, Bird TD, Wijsman EM, Orr HT, Anderson L, Nemens E, White JA, Bonnycastle L, Weber JL, Alonso ME, Et A (1992): Genetic linkage evidence for a familial Alzheimer's disease locus on chromosome 14. Science 258, 668-671

Scheltens P, Blennow K, Breteler MMB, de Strooper B, Frisoni GB, Salloway S, Van der Flier WM (2016): Alzheimer's disease. Lancet $\underline{388}$, 505-517

Schmitz C, Hof PR (2005): Design-based stereology in neuroscience. Neuroscience $\underline{130}$, 813-831

Schmitz C, Rutten BPF, Pielen A, Schäfer S, Wirths O, Tremp G, Czech C, Blanchard V, Multhaup G, Rezaie P, et al. (2004): Hippocampal neuron loss exceeds amyloid plaque load in a transgenic mouse model of Alzheimer’s disease. Am J Pathol 164, 1495-1502

Schneider J, Bennett D (2010): Where vascular meets neurodegenerative disease. Stroke J Cereb Circ 41, S144-S146

Selkoe DJ (2001): Alzheimer’s disease: genes, proteins, and therapy. Physiol Rev $\underline{81}$, 741766

Selkoe DJ (2011): Alzheimer’s disease. Cold Spring Harb Perspect Biol $\underline{3}$

Serrano-Pozo A, Frosch MP, Masliah E, Hyman BT (2011a): Neuropathological alterations in Alzheimer disease. Cold Spring Harb Perspect Med $\underline{1}$

Serrano-Pozo A, Mielke ML, Gómez-Isla T, Betensky RA, Growdon JH, Frosch MP, Hy- 
man BT (2011b): Reactive glia not only associates with plaques but also parallels tangles in Alzheimer's disease. Am J Pathol $\underline{179}, 1373-1384$

Sheng JG, Bora SH, Xu G, Borchelt DR, Price DL, Koliatsos VE (2003): Lipopolysaccharide-induced-neuroinflammation increases intracellular accumulation of amyloid precursor protein and amyloid $\beta$ peptide in APPswe transgenic mice. Neurobiol Dis $\underline{14}$, 133-145

Simić G, Kostović I, Winblad B, Bogdanović N (1997): Volume and number of neurons of the human hippocampal formation in normal aging and Alzheimer's disease. J Comp Neurol $\underline{379}$, 482-494

Singhrao SK, Neal JW, Morgan BP, Gasque P (1999): Increased complement biosynthesis by microglia and complement activation on neurons in Huntington's disease. Exp Neurol $\underline{159}$, 362-376

Sisodia SS (1992): Beta-amyloid precursor protein cleavage by a membrane-bound protease. Proc Natl Acad Sci U S A $\underline{89}$, 6075-6079

Sotthibundhu A, Li Q-X, Thangnipon W, Coulson EJ (2009): Abeta(1-42) stimulates adult SVZ neurogenesis through the p75 neurotrophin receptor. Neurobiol Aging 30, 1975-1985

Strittmatter WJ, Saunders AM, Schmechel D, Pericak-Vance M, Enghild J, Salvesen GS, Roses AD (1993): Apolipoprotein E: high-avidity binding to beta-amyloid and increased frequency of type 4 allele in late-onset familial Alzheimer disease. Proc Natl Acad Sci U S A $\underline{90}, 1977-1981$

Su JH, Cummings BJ, Cotman CW (1998): Plaque biogenesis in brain aging and Alzheimer's disease. II. Progressive transformation and developmental sequence of dystrophic neurites. Acta Neuropathol (Berl) $\underline{96}$, 463-471

Sucher NJ, Awobuluyi M, Choi Y-B, Lipton SA (1996): NMDA receptors: from genes to channels. Trends Pharmacol Sci 17, 348-355

Suzuki N, Cheung TT, Cai XD, Odaka A, Otvos L, Eckman C, Golde TE, Younkin SG (1994): An increased percentage of long amyloid beta protein secreted by familial amyloid beta protein precursor (beta APP717) mutants. Science 264, 1336-1340

Tanzi RE (2012): The genetics of Alzheimer disease. Cold Spring Harb Perspect Med $\underline{2}$

Tanzi RE, Bertram L (2005): Twenty years of the Alzheimer's disease amyloid hypothesis: a genetic perspective. Cell $\underline{120}, 545-555$

Tariot PN, Farlow MR, Grossberg GT, Graham SM, McDonald S, Gergel I, Group for the MS (2004): Memantine treatment in patients with moderate to severe Alzheimer disease already receiving donepezil: a randomized controlled trial. JAMA 291, 317-324

Taupin P, Gage FH (2002): Adult neurogenesis and neural stem cells of the central nervous system in mammals. J Neurosci Res $\underline{69}, 745-749$ 
Terry AV, Buccafusco JJ (2003): The cholinergic hypothesis of age and Alzheimer's disease-related cognitive deficits: recent challenges and their implications for novel drug development. J Pharmacol Exp Ther $\underline{306}$, 821-827

Terry RD, Masliah E, Salmon DP, Butters N, DeTeresa R, Hill R, Hansen LA, Katzman R (1991): Physical basis of cognitive alterations in Alzheimer's disease: synapse loss is the major correlate of cognitive impairment. Ann Neurol 30, 572-580

Thal DR, Rüb U, Orantes M, Braak H (2002): Phases of A beta-deposition in the human brain and its relevance for the development of AD. Neurology $\underline{58}, 1791-1800$

Thompson PM, Hayashi KM, Zubicaray G de, Janke AL, Rose SE, Semple J, Herman D, Hong MS, Dittmer SS, Doddrell DM, Toga AW (2003): Dynamics of gray matter loss in Alzheimer's disease. J Neurosci 23, 994-1005

Thompson PM, Hayashi KM, Dutton RA, Chiang M-C, Leow AD, Sowell ER, de Zubicaray G, Becker JT, Lopez OL, Aizenstein HJ, Toga AW (2007): Tracking Alzheimer’s disease. Ann N Y Acad Sci 1097, 183-214

Toni N, Teng EM, Bushong EA, Aimone JB, Zhao C, Consiglio A, Praag H van, Martone ME, Ellisman MH, Gage FH (2007): Synapse formation on neurons born in the adult hippocampus. Nat Neurosci $\underline{10}$, 727-734

Tuppo EE, Arias HR (2005): The role of inflammation in Alzheimer's disease. Int J Biochem Cell Biol 37, 289-305

van Praag H, Schinder AF, Christie BR, Toni N, Palmer TD, Gage FH (2002): Functional neurogenesis in the adult hippocampus. Nature $\underline{415}, 1030-1034$

Vehmas AK, Kawas CH, Stewart WF, Troncoso JC (2003): Immune reactive cells in senile plaques and cognitive decline in Alzheimer's disease. Neurobiol Aging 24, 321-331

Walsh DM, Tseng BP, Rydel RE, Podlisny MB, Selkoe DJ (2000): The oligomerization of amyloid beta-protein begins intracellularly in cells derived from human brain. Biochemistry (Mosc) $\underline{39}$, 10831-10839

Walsh DM, Klyubin I, Fadeeva JV, Cullen WK, Anwyl R, Wolfe MS, Rowan MJ, Selkoe DJ (2002): Naturally secreted oligomers of amyloid $\beta$ protein potently inhibit hippocampal long-term potentiation in vivo. Nature $\underline{416}$, 535-539

Wang R, Dineley KT, Sweatt JD, Zheng H (2004): Presenilin 1 familial Alzheimer's disease mutation leads to defective associative learning and impaired adult neurogenesis. Neuroscience 126 , 305-312

Weiss C, Venkatasubramanian PN, Aguado AS, Power JM, Tom BC, Li L, Chen KS, Disterhoft JF, Wyrwicz AM (2002): Impaired eyeblink conditioning and decreased hippocampal volume in PDAPP V717F mice. Neurobiol Dis $\underline{11}$, 425-433 
West MJ (1993): Regionally specific loss of neurons in the aging human hippocampus. Neurobiol Aging 14, 287-293

West MJ, Slomianka L, Gundersen HJ (1991): Unbiased stereological estimation of the total number of neurons in thesubdivisions of the rat hippocampus using the optical fractionator. Anat Rec 231, 482-497

West MJ, Kawas CH, Stewart WF, Rudow GL, Troncoso JC (2004): Hippocampal neurons in pre-clinical Alzheimer’s disease. Neurobiol Aging 25, 1205-1212

Whitmer RA, Sidney S, Selby J, Johnston SC, Yaffe K (2005): Midlife cardiovascular risk factors and risk of dementia in late life. Neurology $\underline{64}, 277-281$

Whitwell JL (2008): Longitudinal imaging: change and causality. Curr Opin Neurol 21, 410-416

WHO | Dementia: a public health priority. http://www.who.int/mental_heal th/publications/dementia_report_2012/en/; Zugriff am 18.12.2016

Wilcock GK (2003): Memantine for the treatment of dementia. Lancet Neurol 2, 503-505

Williamson J, Goldman J, Marder KS (2009): Genetic aspects of Alzheimer disease. The neurologist $\underline{15}, 80-86$

Wirths O (2017): Altered neurogenesis in mouse models of Alzheimer's disease. Neurogenesis $\underline{4}$, e1327002

Wirths O, Bayer TA (2012): Intraneuronal A $\beta$ accumulation and neurodegeneration: lessons from transgenic models. Life Sci $\underline{91}, 1148-1152$

Wirths O, Multhaup G, Czech C, Blanchard V, Moussaoui S, Tremp G, Pradier L, Beyreuther K, Bayer TA (2001): Intraneuronal A $\beta$ accumulation precedes plaque formation in $\beta$ amyloid precursor protein and presenilin-1 double-transgenic mice. Neurosci Lett $\underline{306}$, $116-120$

Wirths O, Multhaup G, Bayer TA (2004): A modified $\beta$-amyloid hypothesis: intraneuronal accumulation of the $\beta$-amyloid peptide - the first step of a fatal cascade. J Neurochem $\underline{91}$, $513-520$

Wirths O, Breyhan H, Schäfer S, Roth C, Bayer TA (2008): Deficits in working memory and motor performance in the APP/PS1ki mouse model for Alzheimer's disease. Neurobiol Aging 29, 891-901

Wirths O, Breyhan H, Marcello A, Cotel M-C, Brück W, Bayer TA (2010): Inflammatory changes are tightly associated with neurodegeneration in the brain and spinal cord of the APP/PS1KI mouse model of Alzheimer’s disease. Neurobiol Aging 31, 747-757

Wittnam JL (2012): The contribution of N-terminally modified amyloid beta to the etiology of Alzheimer’s disease. Rer. Nat. Diss. Göttingen 2012 
Wolfe MS (2007): When loss is gain: reduced presenilin proteolytic function leads to increased $A \beta 42 / A \beta 40$. Talking Point on the role of presenilin mutations in Alzheimer disease. EMBO Rep $\underline{8}, 136-140$

Wolfe MS, Xia W, Ostaszewski BL, Diehl TS, Kimberly WT, Selkoe DJ (1999): Two transmembrane aspartates in presenilin-1 required for presenilin endoproteolysis and gamma-secretase activity. Nature $\underline{398}, 513-517$

World Alzheimer Report 2015. https:/www.alz.co.uk/research/world-report-2015; Zugriff am 16.12.2016

Wyss-Coray T, Loike JD, Brionne TC, Lu E, Anankov R, Yan F, Silverstein SC, Husemann J (2003): Adult mouse astrocytes degrade amyloid- $\beta$ in vitro and in situ. Nat Med $\underline{9}$, $453-457$

Yamaguchi H, Hirai S, Morimatsu M, Shoji M, Harigaya Y (1988): Diffuse type of senile plaques in the brains of Alzheimer-type dementia. Acta Neuropathol (Berl) $77,113-119$

Yamaguchi H, Sugihara S, Ogawa A, Saido TC, Ihara Y (1998): Diffuse plaques associated with astroglial amyloid $\beta$ protein, possibly showing a disappearing stage of senile plaques. Acta Neuropathol (Berl) $\underline{95}, 217-222$

Yan R, Bienkowski MJ, Shuck ME, Miao H, Tory MC, Pauley AM, Brashler JR, Stratman NC, Mathews WR, Buhl AE, et al. (1999): Membrane-anchored aspartyl protease with Alzheimer's disease $\beta$-secretase activity. Nature 402, 533-537

Yang L-B, Lindholm K, Yan R, Citron M, Xia W, Yang X-L, Beach T, Sue L, Wong P, Price D, et al. (2003): Elevated $\beta$-secretase expression and enzymatic activity detected in sporadic Alzheimer disease. Nat Med $\underline{9}$, 3-4

Zakzanis KK, Graham SJ, Campbell Z (2003): A meta-analysis of structural and functional brain imaging in dementia of the Alzheimer's type: a neuroimaging profile. Neuropsychol Rev $\underline{13}, 1-18$

Zhang H, Ma Q, Zhang Y, Xu H (2012): Proteolytic processing of Alzheimer's $\beta$-amyloid precursor protein. J Neurochem $\underline{120}$, 9-21

Zhang Y, Thompson R, Zhang H, Xu H (2011): APP processing in Alzheimer's disease. Mol Brain 4, 3

Ziabreva I, Perry E, Perry R, Minger SL, Ekonomou A, Przyborski S, Ballard C (2006): Altered neurogenesis in Alzheimer's disease. J Psychosom Res 61, 311-316 


\section{Danksagung}

An dieser Stelle möchte ich meinen besonderen Dank nachstehenden Personen entgegenbringen ohne deren Unterstützung, Mithilfe und Anregung die Erstellung dieser Promotionsschrift nicht möglich gewesen wäre. Mein herzlicher Dank gilt zunächst meinem Doktorvater, Herrn Prof. Dr. Oliver Wirths, für die Überlassung dieses interessanten Themas. Er war in jeder Phase der Arbeit eine große und außergewöhnlich geduldige Unterstützung. Durch seine mannigfaltigen Anregungen trug er sehr zum Gelingen dieser Dissertation bei. Weiterer Dank kommt Herrn Prof. Dr. Thomas Bayer für die Bereitstellung des Labors zur Durchführung der Experimente zu. Zudem bedanke ich mich bei allen Doktorandinnen und Doktoranden sowie Mitarbeitern der Arbeitsgruppe für Molekulare Psychiatrie. Besonderer Dank gilt dabei Dr. Yvonne Bouter, die mich bei der praktischen Durchführung meiner Dissertation in auBerordentlicher Weise unterstützt hat. Zudem möchte ich mich bei Dr. Melanie Hüttenrauch und Petra Tucholla dafür bedanken, dass sie mir jederzeit mit unterstützendem Rat zur Seite standen. 


\section{Lebenslauf}

Am ersten November 1990 wurde ich als erstes Kind meiner Eltern Hans-Jürgen und Birgit Schubert, geborene Spillmann, in Moers geboren. Von 1997 bis 2001 besuchte ich die AstridLindgren-Grundschule in Moers und wechselte 2001 zum Gymnasium Adolfinum. Dort schloss ich 2010 meine schulische Laufbahn mit dem Abitur ab.

Im Oktober 2010 begann ich eine Ausbildung zum Gesundheits- und Krankenpfleger im St. Bernhard-Hospital in Kamp-Lintfort, die ich im März 2011 aufgrund des erhaltenen Studienplatzes für Humanmedizin in Göttingen abbrach. Im April 2011 nahm ich mein Medizinstudium an der Georg-August-Universität Göttingen auf. Im März 2015 begann ich mit der experimentellen Arbeit zu der vorliegenden Dissertation in der Arbeitsgruppe für Molekulare Psychiatrie der Abteilung Psychiatrie und Psychotherapie unter der Leitung von Herrn Prof. Dr. rer. nat. Thomas A. Bayer. Meine wissenschaftliche Arbeit zum Thema „Analyse neurodegenerativer Prozesse im Gyrus Dentatus im Tg4-42-Mausmodell der Alzheimerdemenz“ wurde von meinem Doktorvater Herrn Prof. Dr. Oliver Wirths betreut. 